\title{
Coordination Complexes of Transition Metals ( $M=$ Mo, Fe, Rh, and Ru) with Tin(II) Phthalocyanine in Neutral, Monoanionic, and Dianionic States
}

\author{
AUTHOR(S): \\ Konarev, Dmitri V.; Kuzmin, Alexey V.; Nakano, Yoshiaki; \\ Faraonov, Maxim A.; Khasanov, Salavat S.; Otsuka, Akihiro; \\ Yamochi, Hideki; Saito, Gunzi; Lyubovskaya, Rimma N.
}

\section{CITATION:}

Konarev, Dmitri V....[et al]. Coordination Complexes of Transition Metals ( $M=$ Mo, Fe, Rh, and Ru) with Tin(II) Phthalocyanine in Neutral, Monoanionic, and Dianionic States. Inorganic Chemistry 2016, 55(4): 1390-1402

\section{ISSUE DATE:}

2016-02-02

\section{URL:}

http://hdl.handle.net/2433/219606

\section{RIGHT:}

This document is the Accepted Manuscript version of a Published Work that appeared in final form in Inorganic Chemistry, copyright (c) American Chemical Society after peer review and technical editing by the publisher. To access the final edited and published work see http://doi.org/10.1021/acs.inorgchem.5b01906; この論文は出版社版でありま せん。引用の際には出版社版をご確認ご利用ください。; This is not the published version. Please cite only the published version. 


\section{Coordination complexes of transition metals $(\mathrm{M}=\mathrm{Mo}, \mathrm{Fe}, \mathrm{Rh}$, and $\mathrm{Ru})$}

\section{with tin(II) phthalocyanine in neutral, monoanionic, and dianionic states}

Dmitri V. Konarev, ${ }^{*} †$ Alexey V. Kuzmin, $¥$ Yoshiaki Nakano,${ }^{\S}$ Maxim A. Faraonov, $†$ Salavat S.

Khasanov,¥ Akihiro Otsuka, ${ }^{\S}$ Hideki Yamochi, ${ }^{\S}$ Gunzi Saito, ${ }^{\|, ~}$ " and Rimma N. Lyubovskaya† Institute of Problems of Chemical Physics RAS, Chernogolovka, Moscow region, 142432 Russia;

fInstitute of Solid State Physics RAS, Chernogolovka, Moscow region, 142432 Russia;

${ }^{\S}$ Research Center for Low Temperature and Materials Sciences, Kyoto University, Sakyo-ku, Kyoto 606-8501, Japan;

"Faculty of Agriculture, Meijo University, 1-501 Shiogamaguchi, Tempaku-ku, Nagoya 4688502, Japan.

ๆToyota Physical and Chemical Research Institute, 41-1, Yokomichi, Nagakute, Aichi 480-1192, Japan

Abstract-The ability of tin atoms to form stable $\mathrm{Sn}-\mathrm{M}$ bonds with transition metals was used to prepare transition metal complexes with tin(II) phthalocyanine in neutral, monoanionic, and dianionic states. These complexes were obtained via the interactions of $\left[\mathrm{Sn}^{\mathrm{IV}} \mathrm{Cl}_{2} \mathrm{Pc}(3-)\right]^{\bullet-}$ or $\left[\mathrm{Sn}^{\mathrm{II}} \mathrm{Pc}(3-)\right]^{\bullet-}$ radical anions with $\left\{\mathrm{Cp} * \mathrm{Mo}(\mathrm{CO})_{2}\right\}_{2},\left\{\mathrm{CpFe}(\mathrm{CO})_{2}\right\}_{2}, \quad\left\{\mathrm{CpMo}(\mathrm{CO})_{3}\right\}_{2}, \mathrm{Fe}_{3}(\mathrm{CO})_{12}$, $\left\{\mathrm{Cp}^{*} \mathrm{RhCl}_{2}\right\}_{2}, \quad$ or $\mathrm{Ph}_{5} \mathrm{CpRu}(\mathrm{CO})_{2} \mathrm{Cl}$. The neutral coordination complexes of $\mathrm{Cp} * \mathrm{MoBr}(\mathrm{CO})_{2}\left[\mathrm{Sn}^{\mathrm{II}} \mathrm{Pc}(2-)\right] \cdot 0.5 \mathrm{C}_{6} \mathrm{H}_{4} \mathrm{Cl}_{2}$ (1) and $\mathrm{CpFe}(\mathrm{CO})_{2}\left[\mathrm{Sn}^{\mathrm{II}} \mathrm{Pc}(2-)\right] \cdot 2 \mathrm{C}_{6} \mathrm{H}_{4} \mathrm{Cl}_{2}$ (2) were obtained from $\left[\mathrm{Sn}^{\mathrm{IV}} \mathrm{Cl}_{2} \mathrm{Pc}(3-)\right]^{\bullet-}$. On the other hand, the coordination of transition metals to $\left[\mathrm{Sn}{ }^{\mathrm{II}} \mathrm{Pc}(3-)\right]^{\bullet-}$ yielded anionic coordination complexes and preserving the spin on $\left[\operatorname{Sn}^{\mathrm{II}} \mathrm{Pc}(3-)\right]^{\bullet-}$. However, in the case of $\left\{\right.$ cryptand $\left.[2,2,2]\left(\mathrm{Na}^{+}\right)\right\}\left\{\mathrm{CpFe}^{\mathrm{II}}(\mathrm{CO})_{2}\left[\mathrm{Sn}^{\mathrm{II}} \mathrm{Pc}(4-)\right]\right\}^{-} \cdot \mathrm{C}_{6} \mathrm{H}_{4} \mathrm{Cl}_{2}$ (4), charge transfer from $\mathrm{CpFe}^{\mathrm{I}}(\mathrm{CO})_{2}$ to $\left[\mathrm{Sn}^{\mathrm{II}} \mathrm{Pc}(3-)\right]^{\bullet-}$ took place to form the diamagnetic $\left[\mathrm{Sn}^{\mathrm{II}} \mathrm{Pc}(4-)\right]^{2-}$ dianion and $\left\{\mathrm{CpFe}^{\mathrm{II}}(\mathrm{CO})_{2}\right\}^{+} . \quad$ The $\quad$ complexes $\quad\left\{\right.$ cryptand $\left.[2,2,2]\left(\mathrm{Na}^{+}\right)\right\}\left\{\mathrm{Fe}(\mathrm{CO})_{4}\left[\operatorname{Sn}^{\mathrm{II}} \mathrm{Pc}(3-)\right]^{\bullet-}\right\}$ 
$\left\{\right.$ cryptand $\left.[2,2,2]\left(\mathrm{Na}^{+}\right)\right\} \quad\left\{\mathrm{CpMo}(\mathrm{CO})_{2}\left[\mathrm{Sn}^{\mathrm{II}} \mathrm{Pc}(2-) \mathrm{Sn}^{\mathrm{II}} \mathrm{Pc}(3-)^{\bullet-}\right]\right\} \quad(6), \quad$ and $\quad\left\{\operatorname{cryptand}[2,2,2]\left(\mathrm{Na}^{+}\right)\right\}$ $\left\{\mathrm{Cp}^{*} \mathrm{RhCl}_{2}\left[\mathrm{Sn}^{\mathrm{II}} \mathrm{Pc}(3-)\right]^{\bullet-}\right\}$ (7) have the magnetic moments of $1.75 \mu_{\mathrm{B}}, 2.41 \mu_{\mathrm{B}}$, and $1.75 \mu_{\mathrm{B}}$, respectively, owing to the presence of $S=1 / 2$ spins on $\left[\mathrm{Sn}^{\mathrm{II}} \mathrm{Pc}(3-)\right]^{\bullet-}$ and $\mathrm{CpMo}^{\mathrm{I}}(\mathrm{CO})_{2}$ (for 6). In addition, the strong antiferromagnetic coupling of spins with Weiss temperatures of $-27.6 \mathrm{~K}$ and $-28.6 \mathrm{~K}$ was realized between the $\mathrm{CpMo}^{\mathrm{I}}(\mathrm{CO})_{2}$ and $\left[\mathrm{Sn}^{\mathrm{II}} \mathrm{Pc}(3-)\right]^{\bullet-}$ units in 6 and the $\pi$-stacking $\left\{\mathrm{Fe}(\mathrm{CO})_{4}\left[\mathrm{Sn}^{\mathrm{II}} \mathrm{Pc}(3-)\right]^{\bullet-}\right\}_{2}$ dimers of 5, respectively. The $\left[\mathrm{Sn}^{\mathrm{II}} \mathrm{Pc}(3-)\right]^{\bullet-}$ radical anions substituted the chloride anions in $\mathrm{Ph}_{5} \mathrm{CpRu}(\mathrm{CO})_{2} \mathrm{Cl}$ to form the formally neutral compound $\left\{\mathrm{Ph}_{5} \mathrm{CpRu}^{\mathrm{II}}(\mathrm{CO})_{2}\left[\mathrm{Sn}^{\mathrm{II}} \mathrm{Pc}(3-)\right]\right\}$ (8) in which the negative charge and spin are preserved on $\left[\mathrm{Sn}{ }^{\mathrm{II}} \mathrm{Pc}(3-)\right]^{\bullet-}$. The strong antiferromagnetic coupling of spins with a magnetic exchange interaction $J / k_{\mathrm{B}}=-183 \mathrm{~K}$ in 8 is explained by the close packing of $\left[\mathrm{Sn}^{\mathrm{II}} \mathrm{Pc}(3-)\right]^{\circ}-$ in the $\pi$-stacked $\left\{\mathrm{Ph}_{5} \mathrm{CpRu}{ }^{\mathrm{II}}(\mathrm{CO})_{2}\left[\mathrm{Sn}{ }^{\mathrm{II}} \mathrm{Pc}(3-)\right]^{\bullet-}\right\}_{2}$ dimers.

*Correspondence to: Dmitri V. Konarev, e-mail: konarev@icp.ac.ru, fax: +7 49652-21852.

\section{Introduction}

Metal phthalocyanines (Pcs) and porphyrins are used for the preparation of photoactive, magnetic, and conducting compounds. ${ }^{1}$ The coordination of transition metals to metal macroheterocycles can affect their electronic structures and properties, and these complexes are thus of special interest. ${ }^{2-5}$ Transition metals coordinate via $\eta^{6}$-type bonding to the isoindole subunits of the Pc ligands as in $\left\{\mathrm{Cp} * \mathrm{Ru}\left[\eta^{6}-\mathrm{Ni}(\mathrm{PcOEt})\right]\right\} \mathrm{PF}_{6}$, which was obtained via the interaction of metal octa(ethoxy)phthalocyanine $\mathrm{M}(\mathrm{PcOEt})\left(\mathrm{M}=\mathrm{H}_{2}, \mathrm{Ni}, \mathrm{Cu}, \mathrm{VO}\right)$ with $\left[\mathrm{Cp} * \mathrm{Ru}(\mathrm{MeCN})_{3}\right] \mathrm{PF}_{6}(\mathrm{Cp} *=$ 1,2,3,4,5-pentamethylcyclopentadienyl). ${ }^{2}$ In addition, the $\eta^{5}$-type complexes of zinc and nickel octaethylporphyrin with (cymene) $\mathrm{Ru}^{2+}$ and $\mathrm{Cp}^{*} \operatorname{Ir}^{2+}$ have been obtained and structurally characterized. ${ }^{3}$ The transition metal complexes of metal macroheterocycles can also be prepared 
with metal-metal bonds, such as those observed in phthalocyanine and porphyrin dimers. ${ }^{6}$ Manganese, cobalt, molybdenum, and osmium in the form of carbonyl (CO) and cyclopentadienyl (Cp) complexes have been shown to coordinate to the central metal atoms of indium, thallium, and tin tetraphenylporphyrins. ${ }^{4}$ Two coordination compounds were obtained as powders following the reaction of tin phthalocyanine: $\mathrm{Fe}(\mathrm{CO})_{4}(\mathrm{SnPc})$ and $\left[\mathrm{Re}(\mathrm{CO})_{3}\right]_{2}(\mathrm{SnPc}) .^{5}$ Recently, we prepared $\left(\mathrm{Cp} * \mathrm{Ir}^{\mathrm{III}} \mathrm{I}_{2}\right)\left[\mathrm{Sn}{ }^{\mathrm{II}} \mathrm{Pc}(2-)\right] \cdot 2 \mathrm{C}_{6} \mathrm{H}_{4} \mathrm{Cl}_{2}$, the first crystalline neutral coordination complex in which two metal-containing fragments are bound via an Sn-Ir bond with a length of $2.58 \AA \AA^{7}$ Thus, transition metal complexes are obtained from neutral metal porphyrins and phthalocyanines. ${ }^{5-7}$ However, such complexes with radical anions of metal phthalocyanine remain unknown, and synthetic routes for their preparation have not yet been developed.

Insoluble-unsubstituted metal phthalocyanines become soluble in organic solvents under reducing conditions, ${ }^{8}$ allowing the reaction investigations of metal phthalocyanine radical anions with transition metals. The interactions of $\left(\right.$ cation $\left.^{+}\right)\left[\mathrm{Sn}^{\mathrm{IV}} \mathrm{Cl}_{2} \mathrm{Pc}(3-)\right]^{0^{-}}$(cation $=\mathrm{Bu}_{4} \mathrm{~N}^{+}$or cryptand $\left.[2,2,2]\left(\mathrm{Na}^{+}\right)\right)$and $\left\{\right.$cryptand$\left.[2,2,2]\left(\mathrm{Na}^{+}\right)\right\}\left[\mathrm{Sn}^{\mathrm{II}} \mathrm{Pc}(3-)\right]^{\bullet-}$ (henceforth, cryptand[2,2,2] is abbreviated to cryptand) with transition metal compounds result in the direct coordination of these complexes to tin(II) phthalocyanine to form neutral $(\mathbf{1}, \mathbf{2})$, monoanionic $(5-8)$, and even dianionic (4) coordination complexes, in some of which the spin on $\left[\mathrm{Sn}^{\mathrm{II}} \mathrm{Pc}(3-)\right]^{{ }^{--}}$is preserved (5-8, Table 1). Thus, $\left[\mathrm{Sn}{ }^{\mathrm{II}} \mathrm{Pc}(3-)\right]^{\bullet-}$ radical anions are new paramagnetic anionic ligands for transition metals. Herein, we describe the synthesis, molecular structures, and optical and magnetic properties of these complexes. The optical and magnetic properties of the salt $\left\{\right.$ cryptand $\left.\left(\mathrm{Na}^{+}\right)\right\}\left[\mathrm{Sn}^{\mathrm{II}} \mathrm{Pc}(3-)\right]^{\bullet-} \cdot \mathrm{C}_{6} \mathrm{H}_{4} \mathrm{Cl}_{2}(3)$ were also studied and compared with those of the transition metal complexes. The developed approach offers new possibilities for the design of magnetic and conducting assemblies based on metal phthalocyanines and transition metals. 
Table 1. Starting compounds for the syntheses of 1-8 and compositions of obtained compounds.

\begin{tabular}{|c|c|c|c|}
\hline \multirow[t]{2}{*}{ № } & \multicolumn{2}{|c|}{ Starting compounds } & \multirow{3}{*}{$\begin{array}{l}\text { Composition of the obtained complexes } \\
\mathrm{Cp}^{*} \mathrm{Mo}^{\mathrm{II}} \mathrm{Br}(\mathrm{CO})_{2}\left[\mathrm{Sn}^{\mathrm{II}} \mathrm{Pc}(2-)\right] \cdot 0.5 \mathrm{C}_{6} \mathrm{H}_{4} \mathrm{Cl}_{2}\end{array}$} \\
\hline & Phthalocyanine* & $\begin{array}{l}\text { Transition metal } \\
\text { complex }\end{array}$ & \\
\hline 1 & {$\left[\mathrm{Sn}^{\mathrm{IV}} \mathrm{Cl}_{2} \mathrm{Pc}(3-)\right]^{\bullet-}$} & $\left\{\mathrm{Cp} * \mathrm{Mo}(\mathrm{CO})_{2}\right\}_{2}$ & \\
\hline 2 & {$\left[\mathrm{Sn}^{\mathrm{IV}} \mathrm{Cl}_{2} \mathrm{Pc}(3-)\right]^{\bullet-}$} & $\left\{\mathrm{CpFe}(\mathrm{CO})_{2}\right\}_{2}$ & $\mathrm{CpFe}^{\mathrm{I}}(\mathrm{CO})_{2}\left[\mathrm{Sn}^{\mathrm{II}} \mathrm{Pc}(2-)\right] \cdot 2 \mathrm{C}_{6} \mathrm{H}_{4} \mathrm{Cl}_{2}$ \\
\hline 3 & \multicolumn{2}{|l|}{$\left[\mathrm{Sn}^{\mathrm{II}} \mathrm{Pc}(3-)\right]^{\bullet-}$} & $\left\{\operatorname{cryptand}\left(\mathrm{Na}^{+}\right)\right\}\left[\mathrm{Sn}^{\mathrm{II}} \mathrm{Pc}(3-)\right]^{\bullet-} \cdot \mathrm{C}_{6} \mathrm{H}_{4} \mathrm{Cl}_{2}$ \\
\hline 4 & {$\left[\operatorname{Sn}{ }^{\text {II }} \mathrm{Pc}(3-)\right]^{\bullet-}$} & $\left\{\mathrm{CpFe}(\mathrm{CO})_{2}\right\}_{2}$ & $\left\{\right.$ cryptand $\left.\left(\mathrm{Na}^{+}\right)\right\}\left\{\mathrm{CpFe}^{\mathrm{II}}(\mathrm{CO})_{2}\left[\mathrm{Sn}^{\mathrm{II}} \mathrm{Pc}(4-)\right]\right\}^{-} \cdot 1.5 \mathrm{C}_{6} \mathrm{H}_{4} \mathrm{Cl}_{2}$ \\
\hline 5 & {$\left[\mathrm{Sn}{ }^{\mathrm{II}} \mathrm{Pc}(3-)\right]^{\bullet-}$} & $\mathrm{Fe}_{3}(\mathrm{CO})_{12}$ & $\left\{\right.$ cryptand $\left.\left(\mathrm{Na}^{+}\right)\right\}\left\{\mathrm{Fe}^{0}(\mathrm{CO})_{4}\left[\mathrm{Sn}^{\mathrm{II}} \mathrm{Pc}(3-)\right]^{\bullet-}\right\} \cdot 1 / 3 \mathrm{C}_{6} \mathrm{H}_{4} \mathrm{Cl}_{2}$ \\
\hline 6 & {$\left[\mathrm{Sn}^{\mathrm{II}} \mathrm{Pc}(3-)\right]^{\bullet-}$} & $\left\{\mathrm{CpMo}(\mathrm{CO})_{3}\right\}_{2}$ & $\begin{array}{l}\left\{\operatorname{cryptand}\left(\mathrm{Na}^{+}\right)\right\}\left\{\mathrm{CpMo}^{\mathrm{I}}(\mathrm{CO})_{2}\left[\left(\mathrm{Sn}^{\mathrm{II}} \mathrm{Pc}(2-)\left(\mathrm{Sn}^{\mathrm{II}} \mathrm{Pc}(3-)^{\circ}\right]\right\} \cdot\right.\right. \\
3.5 \mathrm{C}_{6} \mathrm{H}_{4} \mathrm{Cl}_{2}\end{array}$ \\
\hline 7 & {$\left[\operatorname{Sn}{ }^{\text {II }} \operatorname{Pc}(3-)\right]^{\bullet-}$} & $\left(\mathrm{Cp} * \mathrm{RhCl}_{2}\right)_{2}$ & $\left\{\operatorname{cryptand}\left(\mathrm{Na}^{+}\right)\right\}\left\{\mathrm{Cp}^{*} \mathrm{Rh}^{\mathrm{III}} \mathrm{Cl}_{2}\left[\mathrm{Sn}{ }^{\mathrm{II}} \mathrm{Pc}(3-)\right]^{\bullet}\right\} \cdot \mathrm{C}_{6} \mathrm{H}_{4} \mathrm{Cl}_{2}$ \\
\hline 8 & {$\left[\mathrm{Sn}{ }^{\mathrm{II}} \mathrm{Pc}(3-)\right]^{\bullet-}$} & $\mathrm{Ph}_{5} \mathrm{CpRu}(\mathrm{CO})_{2} \mathrm{Cl}$ & $\mathrm{Ph}_{5} \mathrm{CpRu}{ }^{\mathrm{II}}(\mathrm{CO})_{2}\left[\mathrm{Sn}^{\mathrm{II}} \mathrm{Pc}(3-)\right]$ \\
\hline
\end{tabular}

Formal oxidation state of metals is shown.

*Salts with cryptand $\left(\mathrm{Na}^{+}\right)$counter cations were used for all of the syntheses, except for complex $\mathbf{1}$, which was prepared using $\left(\mathrm{Bu}_{4} \mathrm{~N}^{+}\right)\left[\mathrm{Sn}^{\mathrm{IV}} \mathrm{Cl}_{2} \mathrm{Pc}(3-)\right]^{*}$.

\section{RESULTS AND DISCUSSION}

\section{Synthesis}

$\left[\mathrm{Sn}^{\mathrm{IV}} \mathrm{Cl}_{2} \mathrm{Pc}(2-)\right]^{0}$ and $\left[\mathrm{M}^{\mathrm{II}} \mathrm{Pc}(2-)\right]^{0}$ can be reduced at reasonable redox potentials (approximately -0.52 and $-0.4--0.8 \mathrm{~V}$ vs. SCE, respectively). ${ }^{9}$ The reduction of $\left[\mathrm{Sn}^{\mathrm{IV}} \mathrm{Cl}_{2} \mathrm{Pc}(2-)\right]^{0}$ and $\left[\mathrm{Sn}{ }^{\mathrm{II}} \mathrm{Pc}(2-)\right]^{0}$ with sodium fluorenone ketyl in the presence of an excess of $\left(\mathrm{Bu}_{4} \mathrm{~N}^{+}\right)\left(\mathrm{Br}^{-}\right)$or one equivalent of cryptand yielded the soluble, deep-blue salts $\left(\right.$ cation $\left.{ }^{+}\right)\left[\mathrm{Sn}^{\mathrm{IV}} \mathrm{Cl}_{2} \mathrm{Pc}(3-)\right]^{\bullet-}$ (cation $=\mathrm{Bu}_{4} \mathrm{~N}^{+}$or cryptand $\left.\left(\mathrm{Na}^{+}\right)\right)$and $\left\{\right.$cryptand $\left.\left(\mathrm{Na}^{+}\right)\right\}\left[\mathrm{Sn}^{\mathrm{II}} \mathrm{Pc}(3-)\right]^{\bullet-}$. The salts with cryptand $\left(\mathrm{Na}^{+}\right)$counter cations were crystallized as $\left\{\operatorname{cryptand}\left(\mathrm{Na}^{+}\right)\right\}\left[\mathrm{Sn}^{\mathrm{II}} \mathrm{Pc}(3-)\right]^{\bullet-} \cdot \mathrm{C}_{6} \mathrm{H}_{4} \mathrm{Cl}_{2}(3)$ and $\left\{\operatorname{cryptand}\left(\mathrm{Na}^{+}\right)\right\}\left[\mathrm{Sn}^{\mathrm{IV}} \mathrm{Cl}_{2} \mathrm{Pc}(3-)\right]^{\bullet-}$ . $\mathrm{C}_{6} \mathrm{H}_{4} \mathrm{Cl}_{2}$, and here, we present the crystal structure and properties of 3 . When the $\left[\mathrm{Sn}^{\mathrm{IV}} \mathrm{Cl}_{2} \mathrm{Pc}(3-)\right]^{\bullet-}$ and $\left[\mathrm{Sn}^{\mathrm{II}} \mathrm{Pc}(3-)\right]^{\bullet-}$ radical anions were allowed to interact with $\left\{\mathrm{Cp} * \mathrm{Mo}(\mathrm{CO})_{2}\right\}_{2}, \quad\left\{\mathrm{CpFe}(\mathrm{CO})_{2}\right\}_{2}$, $\left\{\mathrm{CpMo}(\mathrm{CO})_{3}\right\}_{2}, \mathrm{Fe}_{3}(\mathrm{CO})_{12},\left\{\mathrm{Cp} * \mathrm{RhCl}_{2}\right\}_{2}$, or $\mathrm{Ph}_{5} \mathrm{CpRu}(\mathrm{CO})_{2} \mathrm{Cl}$, the crystals of the corresponding transition metal complexes of neutral and anionic tin(II) phthalocyanine were obtained (see Table 1 for the compositions of the complexes). 
When the $\left(\right.$ cation $\left.^{+}\right)\left[\mathrm{Sn}^{\mathrm{IV}} \mathrm{Cl}_{2} \mathrm{Pc}(3-)\right]^{\bullet-}$ salts $\left(\right.$ cation $=\mathrm{Bu}_{4} \mathrm{~N}^{+}$or cryptand $\left.\left(\mathrm{Na}^{+}\right)\right)$were reacted with $\left\{\mathrm{Cp}^{*} \mathrm{Mo}(\mathrm{CO})_{2}\right\}_{2}$ and $\left\{\mathrm{CpFe}(\mathrm{CO})_{2}\right\}_{2}$, an immediate color change from deep blue to green or greenish-blue, respectively, was observed, which is the characteristic of neutral coordination complexes of tin(II) phthalocyanine, such as $\mathrm{Cp}^{*} \mathrm{Ir}^{\mathrm{III}} \mathrm{I}_{2}\left[\mathrm{Sn}{ }^{\mathrm{II}} \mathrm{Pc}(2-)\right] \cdot 2 \mathrm{C}_{6} \mathrm{H}_{4} \mathrm{Cl}_{2}{ }^{7}$ The color changes indicated that the coordination of the transition metal was accompanied by the oxidation of the $\left[\mathrm{Sn}^{\mathrm{IV}} \mathrm{Cl}_{2} \mathrm{Pc}(3-)\right]^{\bullet-}$ radical anions. This oxidation most likely occurs via the transition of $\mathrm{Sn}^{\mathrm{IV}}$ to $\mathrm{Sn}^{\mathrm{II}}$ with the elimination of the chloride anions, followed by the coordination of the transition metal to the tin(II) atom of $\mathrm{Sn}^{\mathrm{II}} \mathrm{Pc}(2-)$. Therefore, this synthetic route through $\left[\mathrm{Sn}^{\mathrm{IV}} \mathrm{Cl}_{2} \mathrm{Pc}(3-)\right]^{\bullet-}$ is useful for the preparation of neutral coordination complexes of tin(II) phthalocyanine. Because the excesses of the transition metal compounds $\left\{\mathrm{Cp} * \mathrm{Mo}(\mathrm{CO})_{2}\right\}_{2}$ and $\left\{\mathrm{CpFe}(\mathrm{CO})_{2}\right\}_{2}$ are used in the syntheses, these complexes can also participate in redox reactions, specifically the oxidation of $\mathrm{Sn}^{\mathrm{IV}}$ to $\mathrm{Sn}^{\mathrm{II}}$ with the acceptance of a halide anion to form, for example, $\mathrm{Cp} * \mathrm{Mo}^{\mathrm{II}} \mathrm{Br}(\mathrm{CO})_{2}$ and $\mathrm{CpFe}^{\mathrm{II}} \mathrm{Cl}(\mathrm{CO})_{2}$. In the case of $\mathbf{1}, \mathrm{Cp}^{*} \mathrm{Mo}^{\mathrm{II}} \mathrm{Br}(\mathrm{CO})_{2}$ is coordinated to $\mathrm{Sn}^{\mathrm{II}} \mathrm{Pc}(2-)$ (the length of the $\mathrm{Mo}-\mathrm{Br}$ bond in $\mathbf{1}$ is the characteristic of Mo-Br bonds in other $\mathrm{Cp}\left({ }^{*}\right)$ Mo compounds $) .{ }^{11,12}$ The excess of $\left(\mathrm{Bu}_{4} \mathrm{~N}^{+}\right)\left(\mathrm{Br}^{-}\right)$in the reaction solutions leads to the substitution of $\mathrm{Cl}^{-}$by $\mathrm{Br}^{-}$to form $\left[\mathrm{Sn}^{\mathrm{IV}} \mathrm{Br}_{2} \mathrm{Pc}(3-)\right]^{\bullet-}$ and explains the presence of $\mathrm{Br}^{-}$rather than $\mathrm{Cl}^{-}$in $\mathbf{1}$. A similar substitution was observed during the formation of salts with indium(III) bromide phthalocyanine radical anions $\left(\left[\operatorname{In}{ }^{\mathrm{III}} \operatorname{BrPc}(3-)\right]^{\bullet}\right) .^{8 \mathrm{~d}}$

The reaction of $\left\{\right.$ cryptand $\left.\left(\mathrm{Na}^{+}\right)\right\}\left[\mathrm{Sn}^{\mathrm{II}} \mathrm{Pc}(3-)\right]^{\bullet-}$ with $\left\{\mathrm{CpFe}(\mathrm{CO})_{2}\right\}_{2}$ to form $\mathbf{4}$ was accompanied by a slow color change (over several hours) from deep blue to violet, indicating that the $\left[\mathrm{Sn}^{\mathrm{II}} \mathrm{Pc}(3-)\right]^{\bullet-}$ radical anions disappeared following the coordination of $\mathrm{CpFe}(\mathrm{CO})_{2}$, most likely owing to charge transfer between them (see below)

Following the addition of $\mathrm{Fe}_{3}(\mathrm{CO})_{12},\left\{\mathrm{CpMo}(\mathrm{CO})_{3}\right\}_{2},\left(\mathrm{Cp}^{*} \mathrm{RhCl}_{2}\right)_{2}$, or $\mathrm{Ph}_{5} \mathrm{CpRu}(\mathrm{CO})_{2} \mathrm{Cl}$, the solutions of $\left\{\right.$ cryptand $\left.\left(\mathrm{Na}^{+}\right)\right\}\left[\mathrm{Sn}^{\mathrm{II}} \mathrm{Pc}(3-)\right]^{\bullet-}$ remained blue, indicating that the $\left[\mathrm{Sn}^{\mathrm{II}} \mathrm{Pc}(3-)\right]^{\bullet-}$ radical 
anions were preserved in 5-8, even after the coordination of these transition metals to $\left[\mathrm{Sn}^{\mathrm{II}} \mathrm{Pc}(3-)\right]^{\bullet-}$.

In the case of compound $\mathbf{8}$, the $\left[\operatorname{Sn}{ }^{\mathrm{II}} \mathrm{Pc}(3-)\right]^{\bullet-}$ radical anion substituted the halogen at the metal center of $\mathrm{Ph}_{5} \mathrm{CpRu}(\mathrm{CO})_{2} \mathrm{Cl}$ to form the formally neutral compound $\mathrm{Ph}_{5} \mathrm{CpRu}(\mathrm{CO})_{2}\left[\mathrm{Sn}{ }^{\mathrm{II}} \mathrm{Pc}(3-)\right]$, which, however, still contained $\left[\mathrm{Sn}^{\mathrm{II}} \mathrm{Pc}(3-)\right]^{\bullet-}$ as a ligand.

\section{Spectroscopic properties}

The charged state of a $\mathrm{Sn}^{\mathrm{II}} \mathrm{Pc}$ complex can be estimated by anazlyzing its ultraviolet (UV)-visiblenear-infrared (NIR) spectrum, because the formation of $\left[\mathrm{Sn}^{\mathrm{II}} \mathrm{Pc}(3-)\right]^{\bullet-}$ is accompanied by noticeable changes in the optical properties of tin(II) phthalocyanine. The spectrum of the starting $\left[\mathrm{Sn}{ }^{\mathrm{II}} \mathrm{Pc}(2-)\right]^{0}$ unit shows absorption bands at 342 (Soret band), 558, 729, and $852 \mathrm{~nm}$ (Q-bands), and no absorption bands are observed in the NIR range above $900 \mathrm{~nm}$ (Fig. 1). The spectrum of $\left[\mathrm{Sn}{ }^{\mathrm{II}} \mathrm{Pc}(2-)\right]^{0}$ in the solution shows an essentially narrower Soret and Q-bands centered at 302, $359 \mathrm{~nm}$ and 616, $682 \mathrm{~nm}$, respectively. ${ }^{10}$ The formation of $\mathrm{Sn}^{\mathrm{II}} \mathrm{Pc}(3-)^{\bullet-}$ in previously studied $\left(\mathrm{Bu}_{4} \mathrm{~N}^{+}\right)_{2}\left[\operatorname{Sn}{ }^{\mathrm{II}} \mathrm{Pc}(3-)\right]^{\bullet-}$ $\left(\mathrm{Br}^{-}\right) \cdot 0.5 \mathrm{C}_{6} \mathrm{H}_{4} \mathrm{Cl}_{2} \cdot 0.5 \mathrm{C}_{6} \mathrm{H}_{14}$ and $\left(\mathrm{Et}_{4} \mathrm{~N}^{+}\right)\left[\mathrm{Sn}^{\mathrm{II}} \mathrm{Pc}(3-)\right]^{\bullet-} \cdot 1.5 \mathrm{C}_{6} \mathrm{H}_{4} \mathrm{Cl}_{2}{ }^{8 \mathrm{e}}$ and newly obtained 3 is

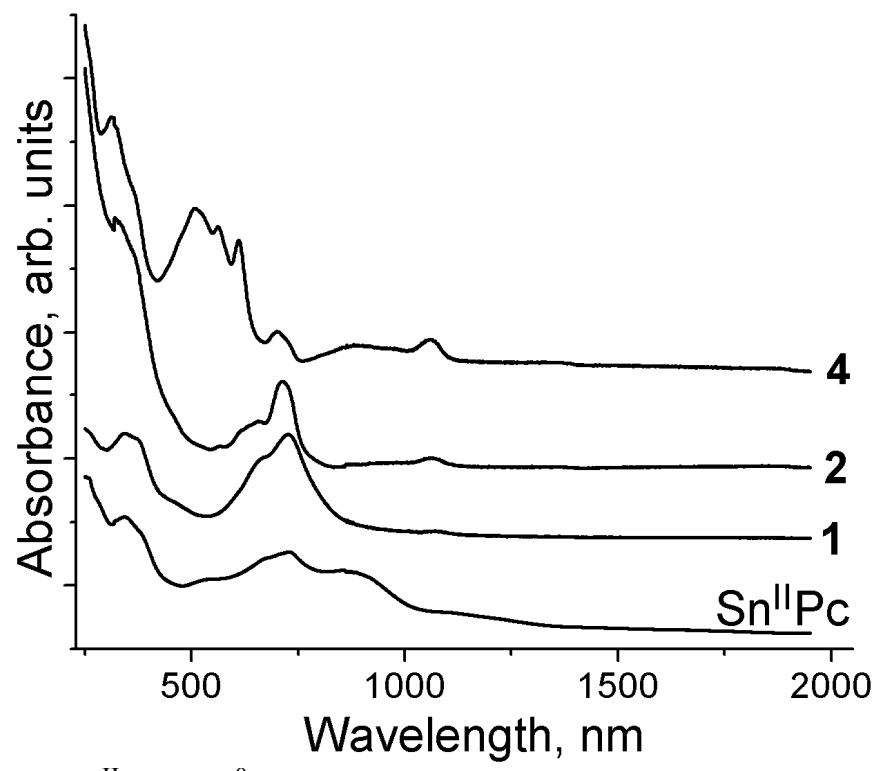

Figure 1. Spectra of $\left[\mathrm{Sn}^{\mathrm{II}} \mathrm{Pc}(2-)\right]^{0}$, neutral complexes 1 and 2 (c), and anionic complex 4 containing $\left[\mathrm{Sn}^{\mathrm{II}} \mathrm{Pc}(4-)\right]^{2-}$ dianion, obtained using $\mathrm{KBr}$ pellets prepared under anaerobic conditions. 
Table 2. Data for the UV-visible-NIR spectra of $\mathrm{Sn}^{\mathrm{II}} \mathrm{Pc}(2-)$, salt 3, and their neutral and anionic coordination complexes with transition metals (Figs. 1 and 2) obtained using KBr pellets.

\begin{tabular}{|c|c|c|c|}
\hline \multirow[t]{2}{*}{ Compound } & \multicolumn{3}{|c|}{ Position of phthalocyanine absorption bands, $\mathrm{nm}$} \\
\hline & Soret band & Q-band & $\begin{array}{l}\text { Bands attributed to the } \\
\text { radical anion }\end{array}$ \\
\hline $\begin{array}{c}\operatorname{Sn}^{\mathrm{II}} \operatorname{Pc}\left(2^{-}\right) \\
\operatorname{Sn}^{\mathrm{II}} \operatorname{Pc}(2-) \text { in } \\
\text { ethanol }^{10}\end{array}$ & $\begin{array}{l}342 \\
302,359\end{array}$ & $\begin{array}{l}558,668,726(\max ), 852 \\
616,682\end{array}$ & $\begin{array}{l}- \\
- \\
-\end{array}$ \\
\hline 1 & 340 & $665,726(\max )$ & - \\
\hline 2 & 321 & $649,714(\max )$ & 1062 (weak) \\
\hline 3 & 337 & $560,649(\max )$ & 890 (weak), 1032 \\
\hline 4 & 315 & $508(\max ), 560,610,704$ & 900 (weak), 1063 (weak) \\
\hline 5 & 334 & $613(\max ), 722$ & 1050 \\
\hline 6 & 340 & $660,714(\max )$ & 904 (weak), 1042 \\
\hline 7 & 338 & $638,726(\max )$ & 854 (weak), 1038 \\
\hline 8 & 343 & $618,730(\max )$ & 893 (weak), 1063 \\
\hline
\end{tabular}

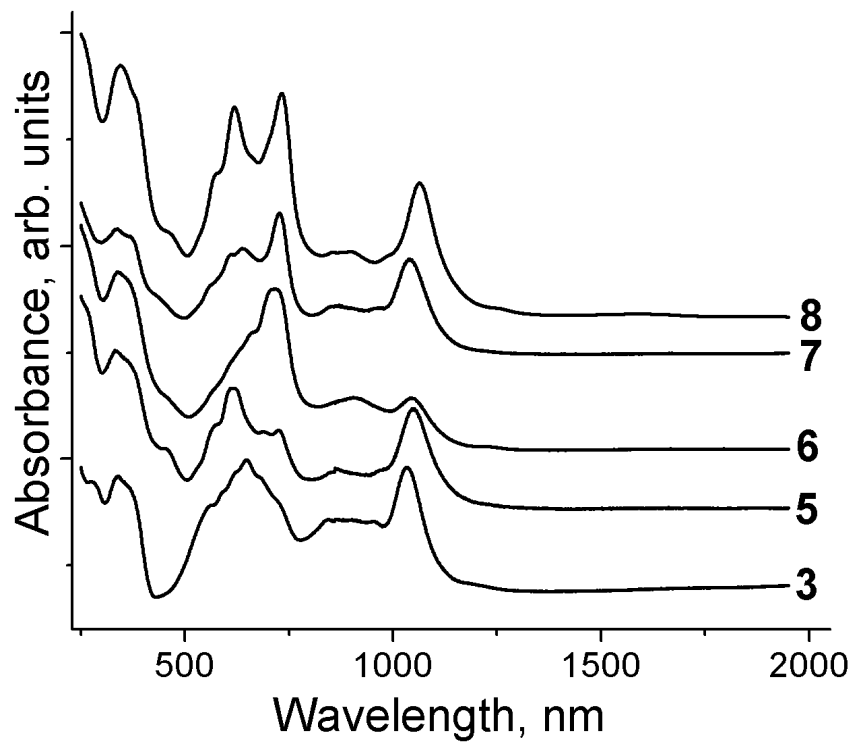

Figure 2. UV-visible-NIR spectra of salt $\mathbf{3}$ and coordination complexes 5, 6, 7, and 8 containing $\left[\mathrm{Sn}^{\mathrm{II}} \mathrm{Pc}(3-)\right]^{\bullet-}$ radical anion, obtained using $\mathrm{KBr}$ pellets prepared under anaerobic conditions. 
accompanied by the appearance of new intense bands in the NIR region at 1032-1041 nm, along with weaker absorption bands at 840-890 nm (Fig. 2). The appearance of these bands unambiguously indicates the formation of $\left[\mathrm{Sn}^{\mathrm{II}} \mathrm{Pc}(3-)\right]^{\bullet-}$.

The spectra of $\mathbf{1}$ and $\mathbf{2}$ are shown in Fig. 1. It can be seen in the figures that absorption bands in the NIR region are very weak or absent from these spectra, indicating the existence of the neutral state $\left[\mathrm{Sn}^{\mathrm{II}} \mathrm{Pc}(2-)\right]^{0}$ in these complexes. The shapes and positions of the Q-bands in the spectra of 1 and 2 (Table 1, Fig. 1) are also very close to those in the spectrum of $\left(\mathrm{Cp}^{*} \mathrm{Ir}^{\mathrm{III}} \mathrm{I}_{2}\right)\left[\operatorname{Sn}{ }^{\mathrm{II}} \mathrm{Pc}(2-)\right]$. $2 \mathrm{C}_{6} \mathrm{H}_{4} \mathrm{Cl}_{2}$, which contains neutral $\left[\mathrm{Sn}^{\mathrm{II}} \mathrm{Pc}(2-)\right]^{0} .{ }^{7}$

Complex 4, which contains a negatively charged $\left\{\mathrm{CpFe}(\mathrm{CO})_{2}\left[\mathrm{Sn}^{\mathrm{II}} \mathrm{Pc}\right]\right\}^{-}$anion, yielded an unusual spectrum, with rather weak absorption bands at 900 and $1063 \mathrm{~nm}$ (Fig. 1), indicating the absence of the $\left[\mathrm{Sn}^{\mathrm{II}} \mathrm{Pc}(3-)\right]^{\bullet-}$ radical anion. The violet color of $\mathbf{4}$ in the solid state also supports this assumption, because all of the salts with $\left[\mathrm{Sn}^{\mathrm{II}} \mathrm{Pc}(3-)\right]^{\bullet-}$ ligands are deep blue in color. ${ }^{8 \mathrm{e}}$ Most likely, the charge transfer between the initial $\left[\mathrm{Sn}^{\mathrm{II}} \mathrm{Pc}(3-)\right]^{\bullet-}$ and $\mathrm{CpFe}^{\mathrm{I}}(\mathrm{CO})_{2}$ reagents occurred in 4 to form either (A) neutral $\left[\mathrm{Sn}^{\mathrm{II}} \mathrm{Pc}(2-)\right]^{0}$ and $\left\{\mathrm{CpFe}^{0}(\mathrm{CO})_{2}\right\}^{-}$anions or $(\mathrm{B})\left[\mathrm{Sn}^{\mathrm{II}} \mathrm{Pc}(4-)\right]^{2-}$ dianions and $\left\{\mathrm{CpFe}{ }^{\mathrm{II}}(\mathrm{CO})_{2}\right\}^{+}$ cations. In both cases, $\left\{\mathrm{CpFe}(\mathrm{CO})_{2}\left[\mathrm{Sn}^{\mathrm{II}} \mathrm{Pc}\right]\right\}^{-}$anions result. Charge transfer is accompanied by large blue shifts of the Q-bands of phthalocyanine to $508 \mathrm{~nm}(\max ), 560 \mathrm{~nm}$, and $610 \mathrm{~nm}$, whereas the intensity of the band at $704 \mathrm{~nm}$ decreases (Fig. 1). The Soret band is also blue-shifted in the spectrum of 4 from $342 \mathrm{~nm}$ to $315 \mathrm{~nm}$. These results suggest that pathway (B) occurred, because the positions of the absorption bands for $\mathrm{Sn}^{\mathrm{II}} \mathrm{Pc}$ in the spectrum of $\mathbf{4}$ are not coincident with those characteristic of the neutral $\left[\operatorname{Sn}{ }^{\mathrm{II}} \mathrm{Pc}(2-)\right]^{0}$ ligands in the spectra of $\mathbf{1}$ and $\mathbf{2}$. Previously, we found that the formation of negatively charged metal phthalocyanines is accompanied by the noticeable blue shifts of the Soret and Q-bands. ${ }^{8 e}$ Blue shifts are also observed for the $\left[\operatorname{Sn}{ }^{\mathrm{II}} \mathrm{Pc}(4-)\right]^{2-}$ dianions.

The spectra of 5-7 presented in Fig. 2 show intense bands in the NIR region with maxima at $1038-1048 \mathrm{~nm}$ and weaker bands at $854-908 \mathrm{~nm}$, indicating the presence of $\left[\operatorname{Snn}^{\mathrm{II}} \mathrm{Pc}(3-)\right]^{\bullet-}$. The 
intensities of these NIR bands in the spectra of $\mathbf{5}$ and $\mathbf{7}$ are comparable to those of the Q-bands in the spectrum of 3 (Fig. 2), while the band at $1048 \mathrm{~nm}$ in the spectrum of 6 is almost two times less intense than those of the Q-bands (Fig. 2). These results can be explained by the presence of two $\mathrm{Sn}^{\mathrm{II}} \mathrm{Pc}$ units per one cryptand $\left(\mathrm{Na}^{+}\right)$cation in 6; only one of two $\mathrm{Sn}^{\mathrm{II}} \mathrm{Pc}$ units has a charge of -1 (the other is neutral), and thus, the charge disproportionation is observed, or -1 charge, is delocalized over two $\mathrm{Sn}^{\mathrm{II}} \mathrm{Pc}$ moieties. The spectrum of $\mathbf{6}$ in the visible-NIR and IR regions is more consistent with the charge disproportionation.

In the spectrum of the neutral coordination complex 8, an intense NIR band at $1063 \mathrm{~nm}$ and a weaker band at $893 \mathrm{~nm}$ were observed, indicating the retention of $\left[\mathrm{Sn}^{\mathrm{II}} \mathrm{Pc}(3-)\right]^{\bullet-}$ after its coordination with $\mathrm{Ph}_{5} \mathrm{CpRu}(\mathrm{CO})_{2}$.

The formation of the $\left[\mathrm{Sn}^{\mathrm{II}} \mathrm{Pc}(3-)\right]^{\bullet-}$ salts was also accompanied by the blue shifts of the Q- and Soret bands compared with the locations of these peaks in the spectrum of neutral $\left[\mathrm{Sn}{ }^{\mathrm{II}} \mathrm{Pc}(2-)\right]^{0.8 e}$ However, no such effect was observed for the coordination complexes with $\left[\operatorname{Sn}^{\mathrm{II}} \mathrm{Pc}(3-)\right]^{\bullet-}$. All of the spectra of these complexes exhibited two Q-bands with maxima at 617-658 nm and 714-736 nm. Only in the spectrum of 6 band at $617-658 \mathrm{~nm}$ is weak (Fig. 2). In addition, no measurable differences in the positions of the Soret bands (315-340 nm and 332-343 nm) were detected in the
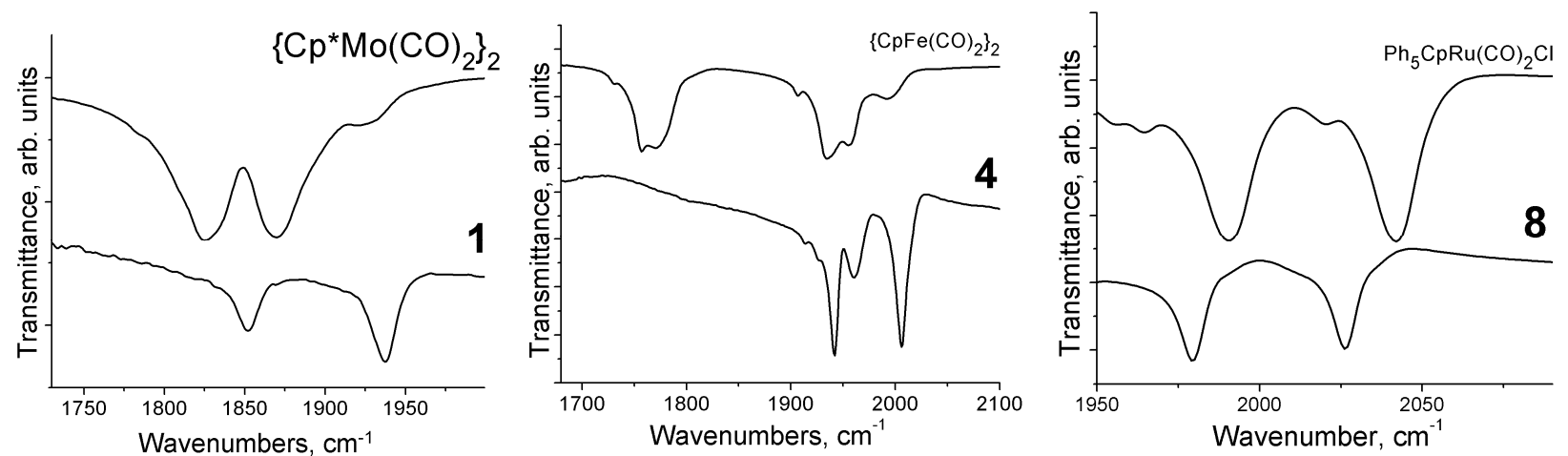

Figure 3. IR spectra of starting compounds and complexes 1, 4, and $\mathbf{8}$ in the range of the $\mathrm{CO}$ stretching vibrations. 
spectra of the coordination complexes with $\left[\operatorname{Sn}^{\mathrm{II}} \mathrm{Pc}(2-)\right]^{0}$ and $\left[\operatorname{Sn}{ }^{\mathrm{II}} \mathrm{Pc}(3-)\right]^{\bullet-}$.

The key bands in the IR spectra of the starting compounds, salt $\mathbf{3}$, and coordination complexes $\mathbf{1}$, 2, and 4-8 are listed in Tables S1-S3 and presented in Figs. S1-S8. Most of the transition metal complexes used in the present study contained carbonyl ligands. The positions of the CO stretching modes in the IR spectra of metal carbonyls are very sensitive to the charged states of the metal centers, with shifts to lower or higher frequencies upon reduction or oxidation, respectively. Indeed, the $\mathrm{CO}$ stretching modes for the $\left\{\mathrm{Cp} * \mathrm{Mo}(\mathrm{CO})_{2}\right\}_{2}$ dimers at 1825 and $1870 \mathrm{~cm}^{-1}$ are shifted to 1852 and $1937 \mathrm{~cm}^{-1}$, respectively, in the spectrum of $\mathbf{1}$ (Fig. 3, left panel), which is in agreement with the change in the oxidation state of Mo from $\mathrm{Mo}^{\mathrm{I}}$ to $\mathrm{Mo}^{\mathrm{II}}$ upon the formation of $\mathbf{1}$. The IR spectrum of the starting complex $\left\{\mathrm{CpFe}(\mathrm{CO})_{2}\right\}_{2}$ exhibits two split bands at $1756,1771 \mathrm{~cm}^{-1}$ and 1936,1956 $\mathrm{cm}^{-1} \cdot{ }^{13}$ After the formation of 4, these bands are shifted to higher frequencies (1942, 1961, and 2006 $\mathrm{cm}^{-1}$ ), as shown in the central panel of Fig. 3. This result can be explained by a change in the oxidation state of iron from $\mathrm{Fe}^{\mathrm{I}}$ to $\mathrm{Fe}^{\mathrm{II}}$. On the other hand, the $\mathrm{CO}$ stretching modes for $\mathrm{Ph}_{5} \mathrm{CpRu}(\mathrm{CO})_{2} \mathrm{Cl}$, the dimer $\left\{\mathrm{CpMo}(\mathrm{CO})_{3}\right\}_{2}$, and $\mathrm{Fe}_{3}(\mathrm{CO})_{12}$ are shifted to lower frequencies upon the coordination of donor $\left[\mathrm{Sn}^{\mathrm{II}} \mathrm{Pc}\left(3^{-}\right)\right]^{\bullet-}$ units (Fig. 3, right panel), indicating the partial reduction of the metal centers (Tables S1-S3).

\section{Crystal structures}

The geometries and key structural parameters for $\left[\operatorname{Sn}{ }^{\mathrm{II}} \mathrm{Pc}(2-)\right]^{0}$ and coordination complexes and salts 1 and 3-8 are listed in Table 3, and the molecular structures of these units are shown in Fig. 4. Owing to their large sizes, the tin(II) atoms are displaced out of the 24 -atom Pc plane by $1.22-1.27$ $\AA$ for both the neutral $\left[\mathrm{Sn}^{\mathrm{II}} \mathrm{Pc}(2-)\right]^{0}$ and $\left[\mathrm{Sn}^{\mathrm{II}} \mathrm{Pc}(3-)\right]^{\bullet-}$ radical anions. As a result, the equatorial $\mathrm{Sn}-$ $\mathrm{N}(\mathrm{Pc})$ bonds noticeably elongate up to $2.26 \AA$ (Table 3 ). The coordination of transition metals to the tin(II) atoms stabilizes the $\mathrm{Sn}-\mathrm{N}(\mathrm{Pc})$ bonds, which is reflected in the reductions of both their lengths 
and displacements of the tin atoms from the 24-atom Pc plane in all of the coordination complexes.

The smallest displacement of $0.90 \AA$ was observed in 4, whereas the displacements of 1.01-1.13

were observed for other complexes. The shortest $\mathrm{Sn}-\mathrm{M}$ bond lengths of 2.49-2.51 $\AA$ correspond to the coordination complexes with iron atoms (4 and 5), and the Sn-M bond lengths for the other metals are 2.55-2.56 $\AA$ for $7(\mathrm{Rh}), 2.64 \AA$ for $\mathbf{8}(\mathrm{Ru})$, and 2.68-2.76 $\AA$ for $\mathbf{1}$ and $\mathbf{6}$ (Mo).

Table 3. Geometric parameters for $\mathrm{Sn}^{\mathrm{II}} \mathrm{Pc}(2-)$, coordination complexes, and salts $\mathbf{1}$ and 3-8.

\begin{tabular}{|c|c|c|c|c|c|c|c|c|c|}
\hline \multirow{2}{*}{$\begin{array}{l}\text { Compound and number of } \\
\text { crystallographically } \\
\text { independent units; } \\
\text { Characteristic features } \\
\left.\mathrm{Sn}^{\mathrm{II}} \mathrm{Pc}(2-)\right]^{14}\end{array}$} & $\mathrm{Sn}-\mathrm{N}(\mathrm{Pc})$ & $\begin{array}{c}\mathrm{N}_{\mathrm{im}}-\mathrm{C} \\
\text { short/long }\end{array}$ & d lengths, & Sn-M & \multicolumn{2}{|c|}{$\begin{array}{l}\text { Displacement of atoms } \\
\text { from the } 24 \text {-atom Pc } \\
\text { plane, } \AA\end{array}$} & \multicolumn{3}{|c|}{$\begin{array}{l}\text { Geometry of the coordination unit } \\
\text { with the transition metal } \\
\mathrm{M}-\mathrm{C}(\mathrm{CO}) \mathrm{C} \equiv \mathrm{O} \text { group } \mathrm{M}-\mathrm{C}\left(\mathrm{Cp}^{(*)}\right)\end{array}$} \\
\hline & $2.266(3)$ & - & - & - & 1.275 & $0.107-0.200$ & - & - & - \\
\hline $\begin{array}{l}\left\{\mathrm{Cp}^{*} \mathrm{MoBr}(\mathrm{CO})_{2}\right. \\
\left.\left[\mathrm{Sn}^{\mathrm{II}} \mathrm{Pc}(2-)\right]\right\} \\
\cdot 0.5 \mathrm{C}_{6} \mathrm{H}_{4} \mathrm{Cl}_{2}(\mathbf{1}), 1 \text { unit; } \\
\text { infinite chains of dimeric } \mathrm{Pc}\end{array}$ & $2.214(2)$ & $1.340(3)$ & $1.393(3)$ & $2.7593(3)$ & 1.131 & $0.077-0.183$ & $\begin{array}{l}1.982(4) \\
\mathrm{Mo}-\mathrm{Br} \\
2.697(8)\end{array}$ & $1.162(2)$ & $2.366(4)$ \\
\hline $\begin{array}{l}\left\{\text { cryptand }\left(\mathrm{Na}^{+}\right)\right\} \\
{\left[\mathrm{Sn}^{\mathrm{II}} \mathrm{Pc}\left(3^{-}\right)\right]^{\bullet-}} \\
\cdot \mathrm{C}_{6} \mathrm{H}_{4} \mathrm{Cl}_{2} \quad(3), 2 \text { units; } \\
\text { channel structure, isolated } \\
\mathrm{Pc}\end{array}$ & $\begin{array}{l}2.253(6) \\
2.258(6)\end{array}$ & $\begin{array}{l}1.326(9) / \\
1.334(9) \\
1.326(10) / \\
1.327(10)\end{array}$ & $\begin{array}{l}1.387(10) \\
1.381(10)\end{array}$ & - & $\begin{array}{l}1.225 \\
1.268\end{array}$ & $\begin{array}{l}0.093-0.185 \\
0.123-0.197\end{array}$ & - & - & - \\
\hline $\begin{array}{l}\left\{\text { cryptand }\left(\mathrm{Na}^{+}\right)\right\} \\
\left\{\mathrm{CpFe}(\mathrm{CO})_{2}\left[\mathrm{Sn}^{\mathrm{II}} \mathrm{Pc}(4-)\right]\right\}^{-} \\
\cdot 1.5 \mathrm{C}_{6} \mathrm{H}_{4} \mathrm{Cl}_{2}(4), 1 \text { unit; } \\
\text { channel structure }\end{array}$ & $2.132(3)$ & $\begin{array}{l}1.294(4) / \\
1.368(4)\end{array}$ & $1.396(4)$ & $2.5087(5)$ & 0.905 & $0.066-0.143$ & $1.764(4)$ & $1.146(4)$ & $2.102(4)$ \\
\hline $\begin{array}{l}\left\{\text { cryptand }\left(\mathrm{Na}^{+}\right)\right\} \\
\left\{\mathrm{Fe}(\mathrm{CO})_{4}\left[\mathrm{Sn}^{\mathrm{II}} \mathrm{Pc}\left(3^{-}\right)\right]^{--}\right\} \\
\cdot 1 / 3 \mathrm{C}_{6} \mathrm{H}_{4} \mathrm{Cl}_{2}(5), 2 \text { units; } \\
\text { stacks of shifted Pc dimers }\end{array}$ & $\begin{array}{l}2.154(3) \\
2.164(3)\end{array}$ & $\begin{array}{l}1.324(5) / \\
1.336(5) \\
1.308(5) / \\
1.347(5) \\
\end{array}$ & $\begin{array}{l}1.386(5) \\
1.386(5)\end{array}$ & $\begin{array}{l}2.4947(6) \\
2.4947(9)\end{array}$ & $\begin{array}{l}1.015 \\
1.084\end{array}$ & $\begin{array}{l}0.140-0.194 \\
0.158-0.274\end{array}$ & $\begin{array}{l}1.781(7) \\
1.772(8)\end{array}$ & $\begin{array}{l}1.151(8) \\
1.144(8)\end{array}$ & $\begin{array}{l}- \\
-\end{array}$ \\
\hline $\begin{array}{l}\left\{\text { cryptand }\left(\mathrm{Na}^{+}\right)\right\} \\
\left\{\mathrm{CpMo}(\mathrm{CO})_{2}\left[\left(\mathrm{Sn}^{\mathrm{II}} \mathrm{Pc}(2-)\right.\right.\right. \\
\left.\left.\mathrm{Sn}^{\mathrm{II}} \mathrm{Pc}(3-)^{\circ-}\right]\right\} \\
\cdot 3.5 \mathrm{C}_{6} \mathrm{H}_{4} \mathrm{Cl}_{2}(\mathbf{6}), 2 \text { units }\end{array}$ & $\begin{array}{l}2.161(5) \\
2.159(5)\end{array}$ & $\begin{array}{l}1.318(6) / \\
1.334(7) \\
1.320(6) / \\
1.343(7)\end{array}$ & $\begin{array}{l}1.393(7) \\
1.386(8)\end{array}$ & $\begin{array}{l}2.6876(6) \\
2.6855(6)\end{array}$ & $\begin{array}{l}1.026 \\
1.020\end{array}$ & $\begin{array}{l}0.075-0.157 \\
0.109-0.123\end{array}$ & $1.986(6)$ & $1.158(5)$ & $2.331(5)$ \\
\hline $\begin{array}{l}\left\{\text { cryptand }\left(\mathrm{Na}^{+}\right)\right\} \\
\left\{\mathrm{Cp}^{*} \mathrm{RhCl}_{2}\left[\mathrm{Sn}^{\mathrm{II}} \mathrm{Pc}\left(3^{-}\right)\right]^{--}\right\} \\
\cdot \mathrm{C}_{6} \mathrm{H}_{4} \mathrm{Cl}_{2}(7), 2 \text { units; } \\
\text { chains through Cp* } \mathrm{RhCl}_{2}\end{array}$ & $\begin{array}{l}2.182(6) \\
2.183(6)\end{array}$ & $\begin{array}{l}1.319(7) / \\
1.338(7) \\
1.312(7) / \\
1.339(7)\end{array}$ & $\begin{array}{l}1.385(7) \\
1.388(.7)\end{array}$ & $\begin{array}{l}2.5584(7) \\
2.5677(7)\end{array}$ & $\begin{array}{l}1.090 \\
1.093\end{array}$ & $\begin{array}{l}0.102-0.174 \\
0.104-0.204\end{array}$ & $\begin{array}{c}\mathrm{Rh}-\mathrm{Cl} \\
2.400(2) \\
2.408(2)\end{array}$ & - & $\begin{array}{l}2.178(7) \\
2.170(7)\end{array}$ \\
\hline $\begin{array}{l}\left\{\mathrm{Ph}_{5} \mathrm{CpRu}{ }^{\mathrm{II}}(\mathrm{CO})_{2}\right. \\
\left.\left[\mathrm{Sn}{ }^{\mathrm{II}} \mathrm{Pc}(3-)\right]\right\}(\mathbf{8}), 1 \text { unit; } \\
\text { isolated } \mathrm{Pc} \text { dimers }\end{array}$ & $2.148(2)$ & $\begin{array}{l}1.316(3) / \\
1.341(3)\end{array}$ & $1.389(3)$ & $2.6486(3)$ & 1.028 & $0.064-0.257$ & $1.887(3)$ & $1.139(3)$ & $2.271(2)$ \\
\hline
\end{tabular}

In neutral $\left[\mathrm{Sn}{ }^{\mathrm{II}} \mathrm{Pc}(2-)\right]^{0}$, each of the eight pyrrolo-nitrogen to carbon $\left(\mathrm{N}_{\mathrm{pyr}} \mathrm{C}\right)$ and imino-nitrogen to carbon $\left(\mathrm{N}_{\mathrm{im}}-\mathrm{C}\right)$ bonds in the Pc macrocycle has a different length (Table 3 ), and no alternation of these bonds was observed. The alternation of the $\mathrm{N}_{\mathrm{im}}-\mathrm{C}$ bonds did appear, however, after the reduction of the Pc macrocycle, because four of the bonds belonging to two oppositely located 
isoindole units were elongated, and four other bonds were shortened. Bond alternation has also been observed for other complexes including metal phthalocyanine radical anions, [MPc] ${ }^{\bullet-}\left(\mathrm{M}=\mathrm{Cu}^{\mathrm{II}}, \mathrm{Ni}^{\mathrm{II}}\right.$, $\mathrm{Sn}^{\mathrm{II}}, \mathrm{Pb}^{\mathrm{II}}, \mathrm{Sn}^{\mathrm{IV}} \mathrm{Cl}_{2}, \mathrm{Ti}^{\mathrm{iV}} \mathrm{O}$, and $\mathrm{V}^{\mathrm{IV}} \mathrm{O}$ ) in which the Pc macrocycle is reduced and explained by the partial disruption of the aromaticity of the Pc ligand. ${ }^{8 \mathrm{e}} \mathrm{A}$ similar tendency was observed for the coordination complexes discussed in this study. The starting compound $\left[\mathrm{Sn}^{\mathrm{II}} \mathrm{Pc}(2-)\right]^{0}$ and complex 1 with the neutral $\left[\mathrm{Sn}{ }^{\mathrm{II}} \mathrm{Pc}(2-)\right]^{0}$ ligand did not exhibit the alternation of the $\mathrm{N}_{\mathrm{im}}-\mathrm{C}$ bonds, but such an alternation was observed for complexes 4-8 with negatively charged $\mathrm{Sn}^{\mathrm{II}} \mathrm{Pc}$ ligands. The greatest difference between the short and long $\mathrm{N}_{\mathrm{im}}-\mathrm{C}$ bonds was observed in 4, indicating that the partial
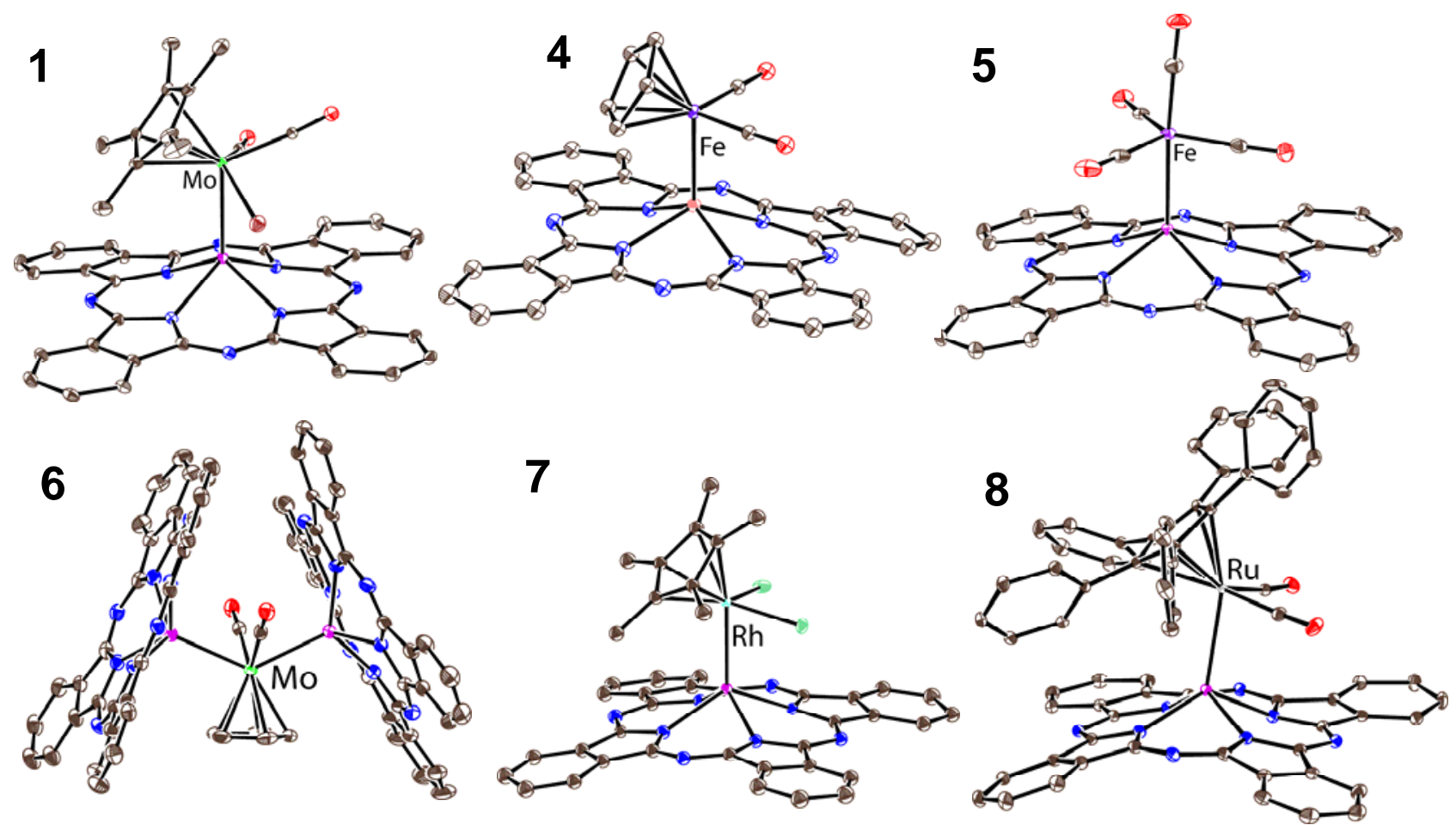

Figure 4. Molecular structures of coordination units (numbers are in accordance with Table 1: (1) Neutral $\mathrm{Cp} * \mathrm{MoBr}(\mathrm{CO})_{2}\left[\mathrm{Sn}{ }^{\mathrm{II}} \mathrm{Pc}(2-)\right]$ species (carbonyl groups and $\mathrm{Br}$ anions are shown in one orientation), (4) $\left\{\mathrm{CpFe}^{\mathrm{II}}(\mathrm{CO})_{2}\left[\mathrm{Sn}^{\mathrm{II}} \mathrm{Pc}(4-)\right]\right\}^{-}$anions, (5) $\left\{\mathrm{Fe}(\mathrm{CO})_{4}\left[\mathrm{Sn}^{\mathrm{II}} \mathrm{Pc}(3-)\right]^{\bullet-}\right\} \quad$ anions, (6) $\left\{\mathrm{CpMo}(\mathrm{CO})_{2}\left[\left(\mathrm{Sn}^{\mathrm{II}} \mathrm{Pc}(2-)\left(\mathrm{Sn}^{\mathrm{II}} \mathrm{Pc}\left(3^{-}\right)^{\bullet-}\right]\right\}\right.\right.$ anions, (7) $\left\{\mathrm{Cp}^{*} \mathrm{RhCl}_{2}\left[\mathrm{Sn}^{\mathrm{II}} \mathrm{Pc}(3-)\right]^{\bullet-}\right\}$ anions, and (8) neutral $\mathrm{Ph}_{5} \mathrm{CpRu}(\mathrm{CO})_{2}\left[\mathrm{Sn}^{\mathrm{II}} \mathrm{Pc}(3-)\right]$ units. 
disruption of aromaticity is also a characteristic of the $\left[\mathrm{Sn}^{\mathrm{II}} \mathrm{Pc}(4-)\right]^{2-}$ dianion (Table 3$)$. The Pc macrocycles in $\mathbf{1}$ and 3-8 (Fig. 4) adopted concave conformations owing to the displacement of the tin(II) atoms from the 24-atom Pc plane. In some cases, a greater deviation of one of the four isoindole units from planarity was observed, which can be explained by the coordination of the bulky metal fragments, such as $\mathrm{Cp}^{*} \mathrm{RhCl}_{2}$ or $\mathrm{Ph}_{5} \mathrm{CpRu}(\mathrm{CO})_{2}$.
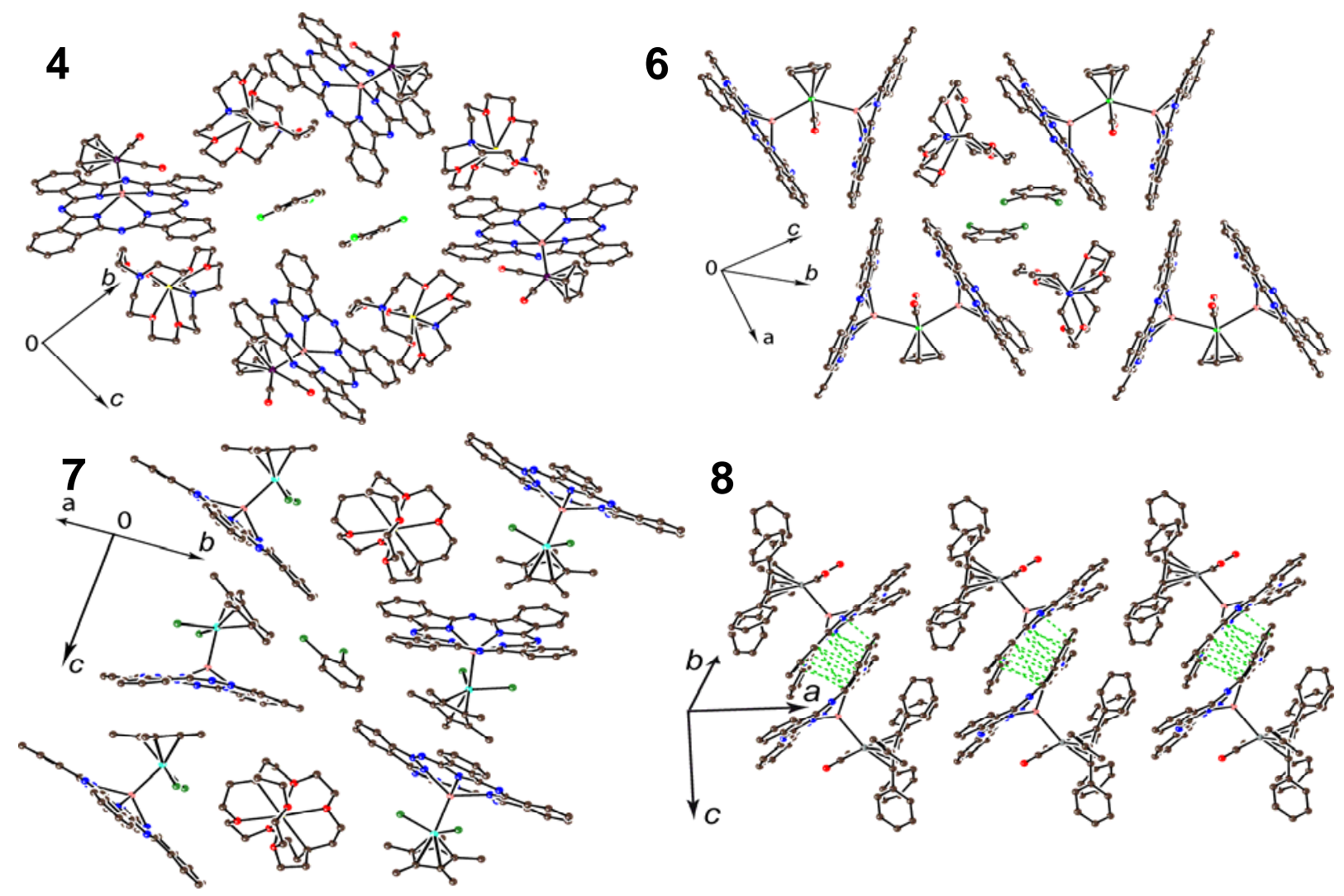

Figure 5. Crystal structures of compounds 4 and 6-8 (numbers are in accordance with Table 1): (4) channels formed by $\left\{\mathrm{CpFe}(\mathrm{CO})_{2}\left[\mathrm{Sn}^{\mathrm{II}} \mathrm{Pc}(4-)\right]\right\}^{-}$anions and cryptand $\left(\mathrm{Na}^{+}\right)$cations, (6) channels formed by four $\left\{\mathrm{CpMo}(\mathrm{CO})_{2}\left[\left(\mathrm{Sn}^{\mathrm{II}} \mathrm{Pc}(2-)\left[\left(\mathrm{Sn}^{\mathrm{II}} \mathrm{Pc}\left(3^{-}\right)^{\bullet-}\right]\right\}\right.\right.\right.$ species, (7) chains of $\left\{\mathrm{Cp}^{*} \mathrm{RhCl}_{2}\left[\mathrm{Sn}^{\mathrm{II}} \mathrm{Pc}(3-\right.\right.$ )$\left.]^{\bullet-}\right\}$, and (8) $\pi$-stacking dimers formed by $\mathrm{Ph}_{5} \mathrm{CpRu}(\mathrm{CO})_{2}\left[\mathrm{Sn}^{\mathrm{II}} \mathrm{Pc}(3-)\right]$. Disordered parts are shown in their major orientations. Shortened van der Waals C, N...C, N contacts are shown by green dashed lines. 
The crystal structures of $\mathbf{1}$ and 3-8 are shown in Figs. 5-6 and S9-S10 in the Supporting information. Salt 3 contains two types of channels formed by four $\left[\mathrm{Sn}^{\mathrm{II}} \mathrm{Pc}(3-)\right]^{\bullet-}$ planes (Fig. S9). These channels are occupied by the cryptand $\left(\mathrm{Na}^{+}\right)$cations or alternating cryptand $\left(\mathrm{Na}^{+}\right)$and $\mathrm{C}_{6} \mathrm{H}_{4} \mathrm{Cl}_{2}$ molecules. No $\pi-\pi$ interactions between the $\left[\operatorname{Sn}^{\mathrm{II}} \operatorname{Pc}(3-)\right]^{\bullet-}$ ligands are present in 3 owing to their perpendicular arrangement.

The structure of 4 contains channels formed by four $\left\{\operatorname{cryptand}\left(\mathrm{Na}^{+}\right)\right\}\left\{\mathrm{CpFe}^{\mathrm{II}}(\mathrm{CO})_{2}\left[\mathrm{Sn}^{\mathrm{II}} \mathrm{Pc}(4-)\right]^{-}\right\}$ units, and the cryptand $\left(\mathrm{Na}^{+}\right)$cations are positioned in the vacancies formed by the concave Pc macrocycles. The channels are occupied by $\mathrm{C}_{6} \mathrm{H}_{4} \mathrm{Cl}_{2}$ molecules (Fig. 5).

The large channels formed by four $\left\{\mathrm{CpMo}(\mathrm{CO})_{2}\left[\mathrm{Sn}^{\mathrm{II}} \mathrm{Pc}(2-) \mathrm{Sn}^{\mathrm{II}} \mathrm{Pc}\left(3^{-}\right)^{\bullet-}\right]\right\}$ units in 6 are occupied by cryptand $\left(\mathrm{Na}^{+}\right)$cations and $\mathrm{C}_{6} \mathrm{H}_{4} \mathrm{Cl}_{2}$ (Fig. 5). As a result, these units are completely isolated.

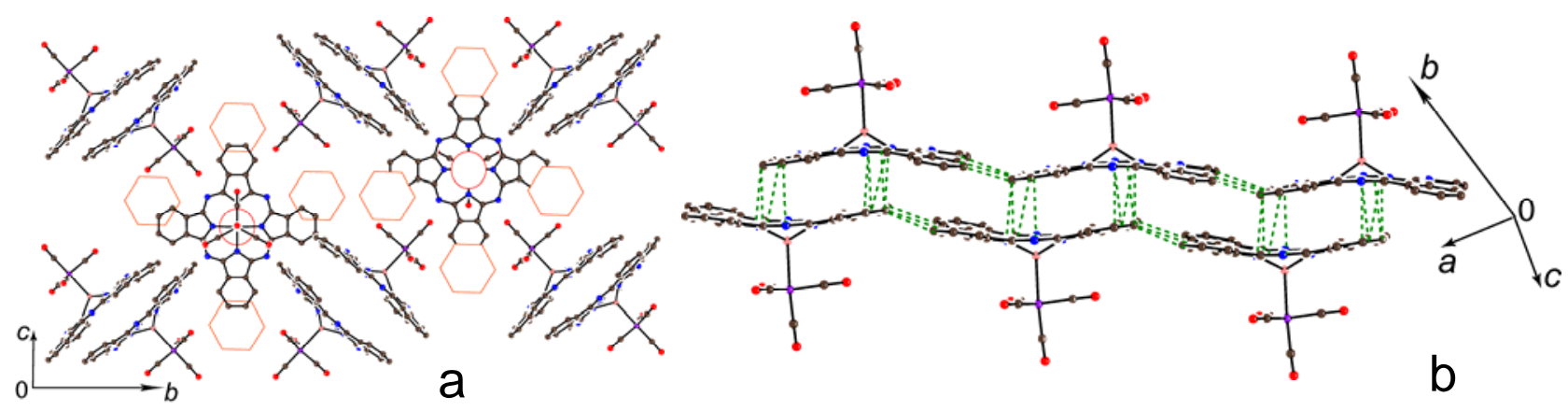

Figure 6. Crystal structure of $\left\{\operatorname{cryptand}\left(\mathrm{Na}^{+}\right)\right\}\left\{\mathrm{Fe}(\mathrm{CO})_{4}\left[\mathrm{Sn}^{\mathrm{II}} \mathrm{Pc}(3-)\right]^{\bullet-}\right\} \cdot(1 / 3) \mathrm{C}_{6} \mathrm{H}_{4} \mathrm{Cl}_{2}$ (5): (a) view along $a$ axis. Cryptand $\left(\mathrm{Na}^{+}\right)$cations and $\mathrm{C}_{6} \mathrm{H}_{4} \mathrm{Cl}_{2}$ molecules are indicated by red hexagons and circles, respectively; (b) view of chain formed of $\pi$-stacking dimers; shortened vdW C,N..C,N contacts are indicated by green dashed lines.

Chains in which the $\mathrm{Cp}^{*}$ ligand of one $\left\{\mathrm{Cp}^{*} \mathrm{RhCl}_{2}\left[\mathrm{Sn}^{\mathrm{II}} \mathrm{Pc}(3-)\right]^{\bullet-}\right\}$ is involved in $\pi-\pi$ stacking interactions with the Pc ligand of an adjacent $\left\{\mathrm{Cp}^{*} \mathrm{RhCl}_{2}\left[\mathrm{Sn}^{\mathrm{II}} \mathrm{Pc}\left(3_{-}\right)\right]^{\bullet-}\right\}$ are formed in 7 (Fig. 5). The angles between the planes of the $\mathrm{Cp}^{*}$ ligands and the isoindole units are just $5.3^{\circ}$ and $7.1^{\circ}$, indicating a nearly parallel arrangement, and the van der Waals (vdW) contacts between these 
planes are on the boundary of vdW interactions (3.40-3.55 $\AA$ ). The zigzag arrangement of the $\left\{\mathrm{Cp}^{*} \mathrm{RhCl}_{2}\left[\mathrm{Sn}^{\mathrm{II}} \mathrm{Pc}(3-)\right]^{\bullet-}\right\}$ chains provides separate channels for cryptand $\left(\mathrm{Na}^{+}\right)$and $\mathrm{C}_{6} \mathrm{H}_{4} \mathrm{Cl}_{2}$ (Fig. 5) .

The structure of $\mathbf{1}$ (Fig. S10a) contains the infinite chains of $\pi-\pi$ stacking $\left\{\mathrm{Cp} * \mathrm{Mo}(\mathrm{Br})_{0.82}(\mathrm{CO})_{1.78}\left[\mathrm{Sn}^{\mathrm{II}} \mathrm{Pc}(2-)\right]\right\}_{2}$ dimers. The interplanar distance in the dimers is $3.39 \AA$ and allows the formation of several $\mathrm{vdW} C, \mathrm{~N} \cdots \mathrm{C}, \mathrm{N}$ contacts between the phthalocyanines that range from $3.18 \AA$ to $3.38 \AA$.

Complex 5 has an unusual structure. It contains phthalocyanine chains formed by $\pi$-stacking dimers with shifted Pc planes (Fig. 6b). The interplanar distance in the dimers is $3.28 \AA$, and the

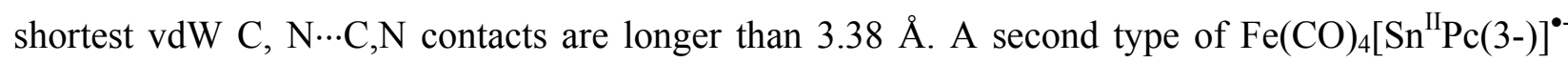
unit alternates with the cryptand $\left(\mathrm{Na}^{+}\right)$cations and solvent $\mathrm{C}_{6} \mathrm{H}_{4} \mathrm{Cl}_{2}$ molecules (indicated by red circles and hexagons, respectively, in Fig. 6a). As a result, the Pc planes of these coordination units are separated by a distance of $12.94 \AA$.

Isolated $\pi-\pi$ stacking dimers are formed in 8 (Fig. 5). These dimers have the shortest interplanar distance among the dimers in all of the studied complexes (3.25 $\AA$ ) and 17 short vdW C,N N..., N contacts ranging from 3.17 to $3.27 \AA$ in length (indicated by the green dashed lines in Fig. 5).

\section{Magnetic properties}

Magnetic property data (superconducting quantum interference device (SQUID) and electron paramagnetic resonance (EPR)) for compounds 1-8 are listed in Table 4 and Figs. S11-S24 in the Supporting information. The main contributions to the magnetic susceptibilities of these complexes are made by the transition metals, which in some cases have spin and negatively charged $\mathrm{Pc}^{\bullet 3-}$ radical trianions that (according to previous studies) have $S=1 / 2$ spin states. ${ }^{8 \mathrm{~d}-\mathrm{f},}{ }^{15}$ The crystal structures of the obtained complexes can be separated into two categories: complexes with channels 
Table 4. SQUID and EPR data for 1-8.

\begin{tabular}{|c|c|c|c|c|}
\hline \multirow[t]{2}{*}{ Compound } & \multirow{2}{*}{$\begin{array}{l}\text { Magnetic } \\
\text { moment at } \\
300 \mathrm{~K}\left(\mu_{\mathrm{B}}\right)\end{array}$} & \multirow{2}{*}{$\begin{array}{c}\text { Weiss } \\
\text { temperature } \\
\text { (temp. interval) }\end{array}$} & \multicolumn{2}{|c|}{ EPR spectra } \\
\hline & & & $\begin{array}{l}\text { Low temperature } \\
g \text {-factor } \\
\text { (linewidth, } \mathrm{mT})\end{array}$ & $\begin{array}{l}\text { RT } \\
\text { g-factor } \\
\text { linewidth, } \mathrm{mT} \text { ) }\end{array}$ \\
\hline 1 & - & - & \multicolumn{2}{|c|}{$\begin{array}{l}250 \mathrm{~K} \text { (very weak signal }) \\
1.9979(8.85 \mathrm{mT}) \\
1.9991(0.225 \mathrm{mT})(0.3 \% \text { of broad signal })\end{array}$} \\
\hline 2 & - & - & \multicolumn{2}{|c|}{$\begin{array}{l}100 \mathrm{~K} \text { Signal from } \mathrm{Fe}^{\mathrm{I}} \\
1.9878(51 \mathrm{mT}), \mathrm{HFS}, 6 \text { lines with } 8.156 \\
\text { mT splitting }\end{array}$} \\
\hline 3 & 1.63 & $-7(30-300 \mathrm{~K})$ & $\begin{array}{l}60.3 \mathrm{~K} \\
2.0039(0.555) \\
2.0013(0.770) \\
1.9954(1.706)\end{array}$ & \begin{tabular}{|ll} 
RT & \\
2.0047 & $(0.543)$ \\
2.0026 & $(0.619)$ \\
1.9959 & $(1.750)$
\end{tabular} \\
\hline 4 & 0.72 & $-3.4(20-300 \mathrm{~K})$ & $\begin{array}{l}\text { Weak signals } \\
9.3 \mathrm{~K} \\
4.154(16.45) \\
4.294(5.37) \mathrm{Fe} \\
2.0034(0.615) \\
1.9960(1.56) \mathrm{Pc}^{\bullet 3-}\end{array}$ & $\begin{array}{l}\text { Weak signals } \\
\text { RT } \\
4.280(8.07) \mathrm{Fe} \\
2.0039(0.406) \mathrm{Pc}^{\bullet 3-}\end{array}$ \\
\hline 5 & 1.75 & $-28.6(70-300 \mathrm{~K})$ & $\begin{array}{l}6 \mathrm{~K} \\
1.9952(5.95) \\
1.9788(8.58)\end{array}$ & $\begin{array}{l}275.6 \mathrm{~K} \\
1.9986(1.51) \\
1.9818(61)\end{array}$ \\
\hline 6 & 2.51 & $-27.6(45-300 \mathrm{~K})$ & $\begin{array}{ll}29 \mathrm{~K} & \\
1.9990(1.48) \\
1.9744(11.63) \\
1.9247(50.98)\end{array}$ & $\begin{array}{l}245 \mathrm{~K} \\
2.0014(0.80)<0.1 \%\end{array}$ \\
\hline 7 & 1.75 & $-7.7(40-300 \mathrm{~K})$ & $\begin{array}{l}60 \mathrm{~K} \\
1.9895(13.40) \\
1.9516(12.73) \\
1.9197(20.27)\end{array}$ & $\begin{array}{l}160.5 \mathrm{~K} \\
1.6629(141.04) \\
1.9874(67.47)\end{array}$ \\
\hline 8 & 1.66 & $\begin{array}{l}\text { Curie impurity } \\
(3 \%), \\
J / k_{\mathrm{B}}=-183 \mathrm{~K}\end{array}$ & $\begin{array}{l}28.7 \mathrm{~K} \\
2.0035(0.604) \\
1.9995(0.904) \\
1.9992(1.864)\end{array}$ & $\begin{array}{l}\text { RT } \\
\text { absent }\end{array}$ \\
\hline
\end{tabular}

occupied by the cryptand $\left(\mathrm{Na}^{+}\right)$cations and/or solvent $\mathrm{C}_{6} \mathrm{H}_{4} \mathrm{Cl}_{2}$ molecules have no $\pi-\pi$ interactions between the Pc macrocycles, and as a result no essential magnetic coupling is possible. Complexes in which the Pc macrocycles form $\pi$-stacking dimers have $\pi-\pi$ interactions between the Pc macrocycles and sufficiently strong antiferromagnetic spin coupling can be realized. Complex $\mathbf{1}$ consists of diamagnetic $\left[\mathrm{Sn}^{\mathrm{II}} \mathrm{Pc}(2-)\right]^{0}$ and $\mathrm{Mo}$ atoms. Mo atoms with formal +1 charges are 
paramagnetic. ${ }^{16}$ However, the coordination of $\left\{\mathrm{Cp}^{*} \mathrm{Mo}^{\mathrm{I}}(\mathrm{CO})_{2}\right\}_{2}$ to $\left[\mathrm{Sn}^{\mathrm{IV}} \mathrm{Br}_{2} \mathrm{Pc}(3-)\right]^{\bullet-}$ is accompanied by oxidation of $\mathrm{Mo}^{\mathrm{I}}$ to $\mathrm{Mo}^{\mathrm{II}}$ and the formation of $\mathrm{Cp}^{*} \mathrm{Mo}^{\mathrm{II}} \mathrm{Br}(\mathrm{CO})_{2}$, which should be EPR-silent. Indeed, no EPR signal from $\mathrm{Mo}^{\mathrm{I}}$ was observed in the spectrum of 1 (EPR active $\mathrm{CpMo}^{\mathrm{I}}(\mathrm{CO})_{2}$ species coordinated to fullerenes or carbon nanotubes have $g$-factors ranging from 1.975 to $2.029^{16 b}$ ). A weak EPR signal with $g=1.9979$ and a linewidth $(\Delta H)$ of $8.85 \mathrm{mT}$ (Fig. S13) with an intensity less than $2 \%$ of the spins based on the total quantity of $\mathrm{Sn}^{\mathrm{II}} \mathrm{Pc}(2-)$ was most likely due to an $\left[\mathrm{Sn}^{\mathrm{II}} \mathrm{Pc}(3-)\right]^{0-}$ impurity.

Complex 2 contains diamagnetic $\left[\mathrm{Sn}^{\mathrm{II}} \mathrm{Pc}(2-)\right]^{0}$ and paramagnetic $\mathrm{Fe}^{\mathrm{I}}$ with a $\mathrm{d}^{7}$ electron configuration. Not surprisingly, 2 manifested a very broad intense EPR signal with $g=1.9878$ and $\Delta H=51 \mathrm{mT}$ at $100 \mathrm{~K}$ (Fig. 7a). Because the hyperfine structure of this signal consisted of 6 lines with an average splitting of $8.156 \mathrm{mT}$ (Fig. 7a), the signal was attributed to $\mathrm{Fe}^{\mathrm{I}}$ with an $S=1 / 2$ spin state. The $\mathrm{Fe}^{\mathrm{I}}$ in $\left[\mathrm{Fe}^{\mathrm{I}} \mathrm{Pc}(2-)\right]^{-}$anions has a similar electronic configuration. ${ }^{8 \mathrm{a}, \mathrm{b}}$
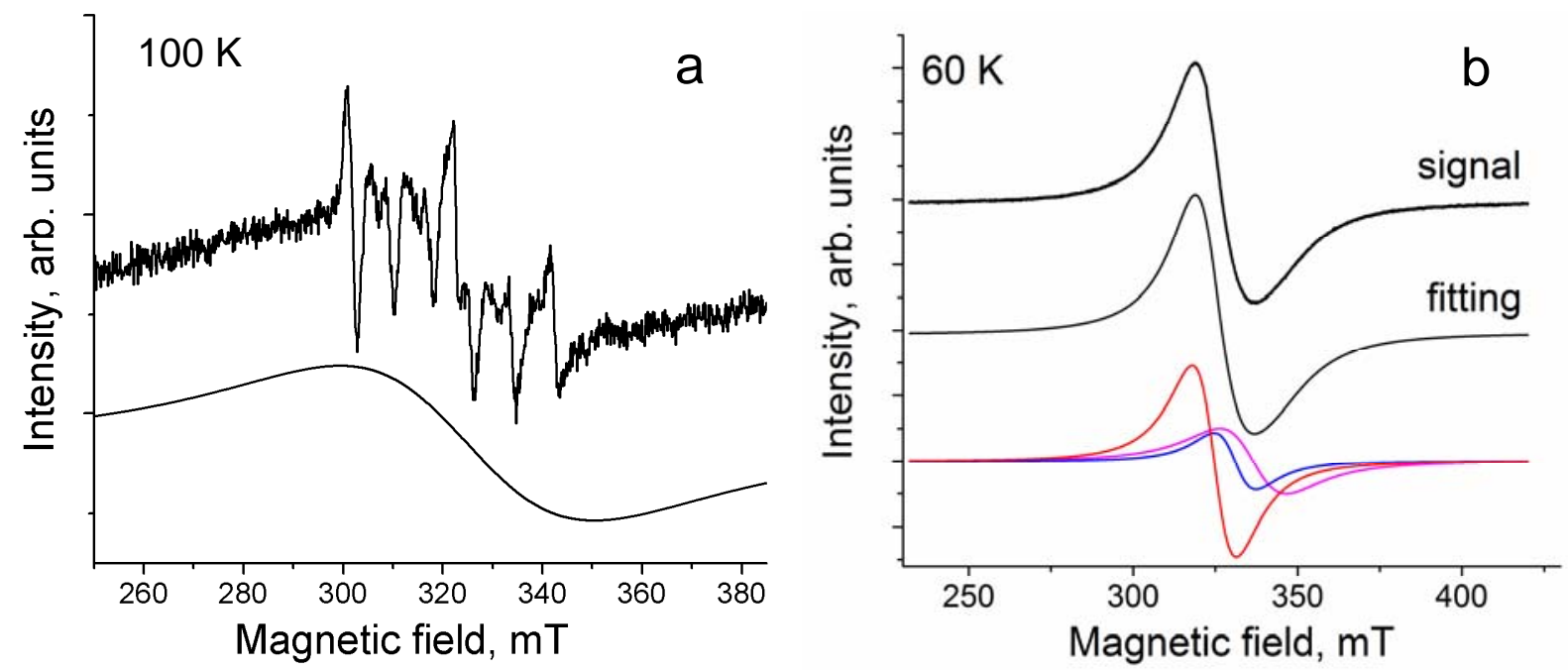

Figure 7. (a) EPR signal for polycrystalline 2 at $100 \mathrm{~K}$. Fitting of broad signal by one Lorentzian line is also shown; (b) EPR signal for polycrystalline 7 at $60 \mathrm{~K}$. Fitting of signal by three Lorentzian lines is also shown. 
The magnetic properties of an individual $\left[\mathrm{Sn}^{\mathrm{II}} \mathrm{Pc}(3-)\right]^{\bullet-}$ ligand were studied in 3 . Its magnetic moment was found to be $1.63 \mu_{\mathrm{B}}$ at $300 \mathrm{~K}$ (Fig. S11a). This value is close to that calculated for a system with one non-interacting $S=1 / 2$ spin per formula unit $\left(\mu_{\text {eff }}=1.73 \mu_{\mathrm{B}}\right)$. The temperature dependence of the reciprocal magnetic susceptibility of 3 was linear from $30 \mathrm{~K}$ to $300 \mathrm{~K}$, and the Weiss temperature was calculated to be $-7 \mathrm{~K}$ (Fig. S11b). This value indicates rather weak antiferromagnetic spin coupling in 3 due to the absence of $\pi-\pi$ interactions between the Pc macrocycles. The salt also exhibited an asymmetric EPR signal at room temperature (RT) that was fitted by three Lorentzian lines with $g_{1}=2.0047(\Delta H=0.543 \mathrm{mT}), g_{2}=2.0026(\Delta H=0.619 \mathrm{mT})$, and $g_{3}=1.9959(\Delta H=1.750 \mathrm{mT})$ (Fig. S12b). In fact, this three-component signal was observed down to $4 \mathrm{~K}$ with close $g$-factor values and only slight changes in the linewidths (Figs. S12b and S12c). Previously studied salts containing $\left[\mathrm{Sn}^{\mathrm{II}} \mathrm{Pc}(3-)\right]^{\bullet-}$ also exhibited very asymmetric signals, but most of the components were essentially broader at low temperatures ${ }^{8 \mathrm{e}}$.

It is thought that charge transfer from $\mathrm{CpFe}^{\mathrm{I}}(\mathrm{CO})_{2}$ to $\left[\mathrm{Sn}^{\mathrm{II}} \mathrm{Pc}(3-)\right]^{\bullet-}$ takes place in 4 , producing diamagnetic $\left[\mathrm{Sn}^{\mathrm{II}} \mathrm{Pc}(4-)\right]^{2-}$ dianions and, correspondingly, $\left[\mathrm{CpFe}^{\mathrm{II}}(\mathrm{CO})_{2}\right]^{+}$cations. Indeed, without such charge transfer, the complex would have contributions from two $S=1 / 2$ spins per formula unit from $\mathrm{CpFe}^{\mathrm{I}}(\mathrm{CO})_{2}$ and $\left[\mathrm{Sn}^{\mathrm{II}} \mathrm{Pc}(3-)\right]^{\bullet-}$, with an expected magnetic moment of $\sim 2.45 \mu_{\mathrm{B}}$. The lower magnetic moment of $0.72 \mu_{\mathrm{B}}$ at $300 \mathrm{~K}$ (Fig. S14a) supports the occurrence of charge transfer. The estimated Weiss temperature of $-3.4 \mathrm{~K}$ (Fig. S14b) also indicates the absence of magnetic spin coupling in 4. The complex exhibited two sets of weak EPR signals (Fig. S15) that may originate from $\mathrm{Pc}^{\bullet 3-}$ and iron-containing impurities (Table 4).

Complex 5 with paramagnetic $\left[\mathrm{Sn}^{\mathrm{II}} \mathrm{Pc}(3-)\right]^{\bullet-}$ and diamagnetic $\mathrm{Fe}^{0}(\mathrm{CO})_{4}$ groups was found to have a magnetic moment of $1.75 \mu_{\mathrm{B}}$ at $300 \mathrm{~K}$ (a contribution of one $S=1 / 2$ spin per formula unit) (Fig. S16a); its Weiss temperature of $-28.6 \mathrm{~K}$ (Fig. S16b) indicates sufficiently strong antiferromagnetic 
spin coupling. Because $2 / 3$ of the paramagnetic $\left[\operatorname{Sn}^{\mathrm{II}} \mathrm{Pc}(3-)\right]^{--}$species in 5 are packed in $\pi-\pi$ stacking dimers, magnetic coupling can be realized in these dimers. The complex manifested an asymmetric EPR signal at $270 \mathrm{~K}$ that was fitted by two lines: a narrow line with $g_{1}=1.9986(\Delta H=$ $1.51 \mathrm{mT})$ and a very broad line with $g_{2}=1.9818(\Delta H=61 \mathrm{mT})$. Narrowing of the broad line was observed only below $50 \mathrm{~K}$ (Figs. S17 and S18). These lines are attributed to $\left[\mathrm{Sn}^{\mathrm{II}} \mathrm{Pc}(3-)\right]^{\bullet-}$.

Isolated $\mathrm{CpMo}^{\mathrm{I}}(\mathrm{CO})_{2}\left[\mathrm{Sn}{ }^{\mathrm{II}} \mathrm{Pc}(2-) \mathrm{Sn}^{\mathrm{II}} \mathrm{Pc}\left(3^{-)^{\bullet-}}\right]\right.$ units are formed in 6. One of the two $\mathrm{Sn}^{\mathrm{II}} \mathrm{Pc}$ ligands is negatively charged and has an $S=1 / 2$ spin state. The $\mathrm{CpMo}^{\mathrm{I}}(\mathrm{CO})_{2}$ units are also paramagnetic, because $\mathrm{Mo}^{\mathrm{I}}$ has a $\mathrm{d}^{5}$ electron configuration. This behavior differs from that of anionic $\left(\mathrm{PPN}^{+}\right)\left\{\mathrm{CpMo}(\mathrm{CO})_{2}\left(\eta^{2}-\mathrm{C}_{60(70)}\right)\right\}^{-} \quad\left(\mathrm{PPN}^{+}=\right.$bis(triphenylphosphoranylidene)ammonium cation $)$ complexes, in which the fullerene ${ }^{\bullet-}$ radical anions reduce $\mathrm{CpMo}^{\mathrm{I}}(\mathrm{CO})_{2}$ to form diamagnetic $\mathrm{C}_{60(70)}{ }^{0}$ and $\mathrm{CpMo}^{0}(\mathrm{CO})_{2}{ }^{17}$ The magnetic moment of 6 was determined to be $2.51 \mu_{\mathrm{B}}$ at $300 \mathrm{~K}$ (Fig. S19a), which corresponds to a contribution of two $S=1 / 2$ spins per formula unit. Therefore, both the $\left[\mathrm{Sn}^{\mathrm{II}} \mathrm{Pc}(3-)\right]^{\bullet-}$ and $\mathrm{CpMo}(\mathrm{CO})_{2}$ species with $S=1 / 2$ spin states contribute to the magnetic moment. The calculated value for a system of two non-interacting $S=1 / 2$ spins is $2.45 \mu_{\mathrm{B}}$. The Weiss temperature of $-27.6 \mathrm{~K}$ for 6 was estimated in the range from $45 \mathrm{~K}$ to $300 \mathrm{~K}$ (Fig. S19b) and indicates sufficiently strong antiferromagnetic spin coupling in $\mathrm{CpMo}^{\mathrm{I}}(\mathrm{CO})_{2}\left[\mathrm{Sn}^{\mathrm{II}} \mathrm{Pc}(2-) \mathrm{Sn}^{\mathrm{II}} \mathrm{Pc}(3-)^{\bullet-}\right]$, likely because two paramagnetic species are separated by only one diamagnetic tin(II) atom. The EPR signal for 6 was observed only below $100 \mathrm{~K}$ and was approximated well by three Lorentzian lines with $g_{1}=1.9990(\Delta H=1.48 \mathrm{mT}), g_{2}=1.9744(\Delta H=11.63 \mathrm{mT})$, and $g_{3}=1.9247(\Delta H=50.98$ $\mathrm{mT}$ ) at $29 \mathrm{~K}$ (Fig. S20 shows the EPR signal at $19 \mathrm{~K}$ ). A narrow component that was less than $0.2 \%$ of the two broader components was attributed to impurities, while the two broad components were assigned to $\left[\mathrm{Sn}^{\mathrm{II}} \mathrm{Pc}(3-)\right]^{\bullet-}$, but a contribution by $\mathrm{CpMo}^{\mathrm{I}}(\mathrm{CO})_{2}$ to this signal is also possible, given that EPR active $\mathrm{CpMo}(\mathrm{CO})_{2}$ species coordinated to fullerenes or carbon nanotubes have $g$-factors 
ranging from 1.975 to $2.029 .{ }^{14 \mathrm{~b}}$ Both broad signals broadened even further as the temperature increased and could not be observed above $100 \mathrm{~K}$, whereas the narrower component was detected even at RT (Fig. S21).

Complex 7 with $\left[\mathrm{Sn}^{\mathrm{II}} \mathrm{Pc}(3-)\right]^{\bullet-}$ and diamagnetic $\mathrm{Cp}^{*} \mathrm{Rh}^{\mathrm{III}} \mathrm{Cl}_{2}$ exhibited behaviors very similar to those of 5. The magnetic moment of 7 was found to be $1.75 \mu_{\mathrm{B}}$ at $300 \mathrm{~K}$ (Fig. S22a) and corresponds to the contribution of one $S=1 / 2$ spin. The Weiss temperature was estimated to be -7.7 $\mathrm{K}$ (Fig. S22b). The $\mathrm{Cp}^{*} \mathrm{Rh}^{\mathrm{III}} \mathrm{Cl}_{2}\left[\mathrm{Sn}^{\mathrm{II}} \mathrm{Pc}\left(3^{-)^{\circ-}}\right]\right.$ anions form chains via $\pi-\pi$ interactions of the $\mathrm{Cp}^{*}$ ligands with one of four isoindole units of Pc. Nevertheless, any magnetic coupling between $\left[\mathrm{Sn}^{\mathrm{II}} \mathrm{Pc}(3-)\right]^{\bullet-}$ is ineffectively transferred in these chains due to the diamagnetism of $\mathrm{Cp}^{*} \mathrm{Rh}^{\mathrm{III}} \mathrm{Cl}_{2}$. The EPR signal was approximated by three broad lines below $60 \mathrm{~K}$ with $g_{1}=1.9895(\Delta H=13.40), g_{2}=$
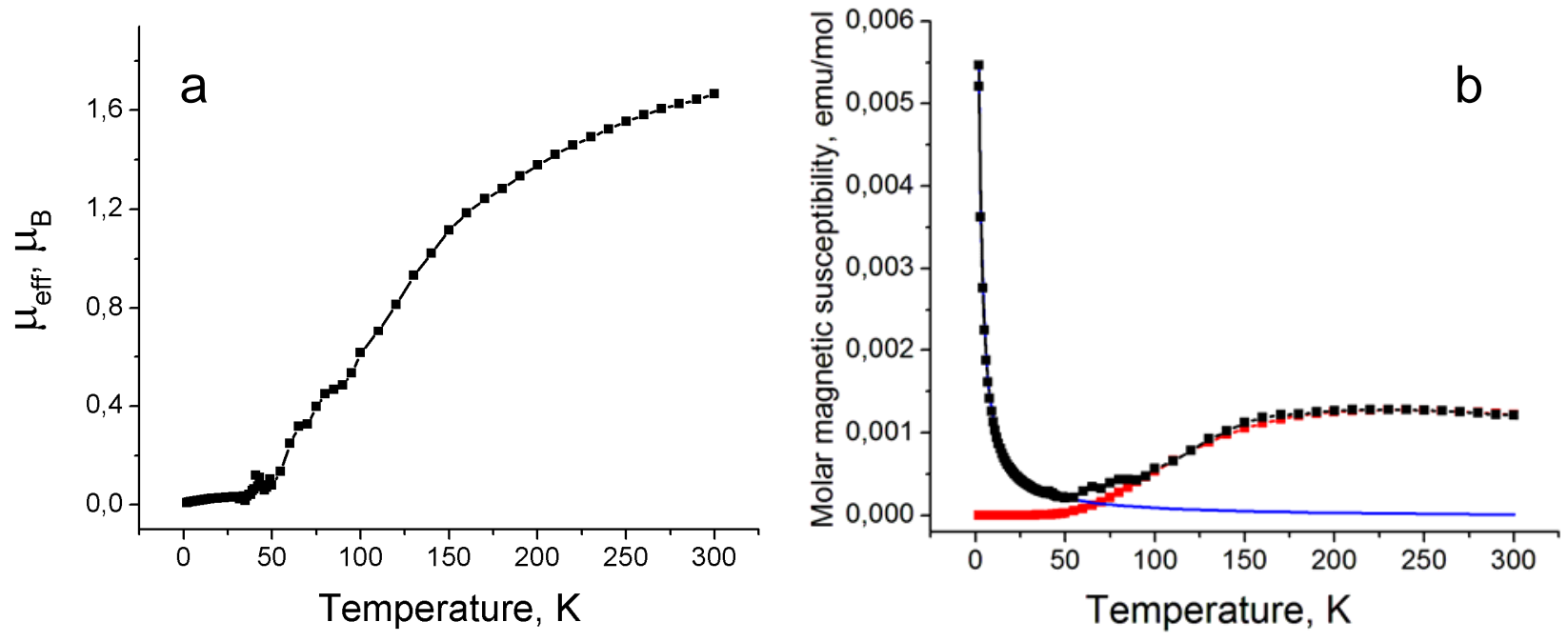

Figure 8. Temperature dependences of (a) effective magnetic moment and (b) molar magnetic susceptibility for polycrystalline 8. Dependence in right panel was approximated by two contributions: (blue curve) Curie impurities (approximately 3\% of spins based on the total quantity of $\left[\mathrm{Sn}^{\mathrm{II}} \mathrm{Pc}(3-)\right]^{\bullet-}$ ) and (red curve) isolated pairs of antiferromagnetically interacting spins ${ }^{16}$ with $J / k_{\mathrm{B}}$ $=-183 \mathrm{~K}$ (approximated by Heisenberg model). 
$1.9516(\Delta H=12.73 \mathrm{mT})$, and $g_{3}=1.9197(\Delta H=20.27 \mathrm{mT})$ at $60 \mathrm{~K}($ Fig. $7 \mathrm{~b})$. These lines are significantly broadened above $100 \mathrm{~K}$, and no signals were detected above $200 \mathrm{~K}$ (Fig. S23, Table 4).

Compound 8 is formally neutral. However, it contains negatively charged $\left[\operatorname{Sn}^{\mathrm{II}} \mathrm{Pc}(3-)\right]^{\bullet-}$ and $\mathrm{Ph}_{5} \mathrm{Cp}^{-}$ligands for $\mathrm{Ru}$. Therefore, $\mathrm{Ru}$ has a +2 oxidation state with a $\mathrm{d}^{6}$ electron configuration and can potentially be diamagnetic $(S=0)$ or in an intermediate $(S=1)$ or high-spin states $(S=2)$. The magnetic moment for 8 was found to be $1.66 \mu_{\mathrm{B}}$ at $300 \mathrm{~K}$ (Fig. 8a) and is close to the value (1.73 $\left.\mu_{\mathrm{B}}\right)$ calculated for a system with one non-interacting $S=1 / 2$ spin. It can thus be concluded that $\mathrm{Ru}$ adopts a diamagnetic $S=0$ spin state in this compound. The molar magnetic susceptibility of 8 reached a maximum at approximately $200 \mathrm{~K}$ and then decreased at lower temperatures. The magnetic moment also decreased, even below $300 \mathrm{~K}$, and never reached $1.73 \mu_{\mathrm{B}}$, even at $300 \mathrm{~K}$ (Fig. 8). These results are attributed to very strong antiferromagnetic spin coupling in $\mathbf{8}$. The molar magnetic susceptibility increased below $50 \mathrm{~K}$ due to manifestation of the Curie tail. The observed temperature dependence of the molar magnetic susceptibility can be presented as the sum of two contributions. One contribution is described by the Heisenberg model for the isolated pairs of antiferromagnetically interacting spins ${ }^{18}$ with a magnetic exchange interaction of $J / k_{\mathrm{B}}=-183 \mathrm{~K}$ (red curve in Fig. 8b). The other originates from paramagnetic impurities (approximately $3 \%$ of the spins from the total amount of $\left.\left[\mathrm{Sn}^{\mathrm{II}} \mathrm{Pc}(3-)\right]^{\bullet}\right)$. This behavior was approximated well using the Curie-Weiss law with a Weiss temperature close to $-1 \mathrm{~K}$ (blue curve in Fig. 8b). Complex 8 manifested a weak asymmetric EPR signal below $100 \mathrm{~K}$ (Figs. S24, Table 4) that most likely is due to the Curie impurities. It is assumed that strong magnetic coupling observed in $\mathbf{8}$ is realized within magnetically isolated $\pi-\pi$ stacking dimers with short interplanar distances and multiple vdW $\mathrm{C}, \mathrm{N} \cdots \mathrm{C}, \mathrm{N}$ contacts. Previously, we found that the antiferromagnetic coupling in $\pi-\pi$ stacking 
$\left\{\left[\mathrm{Ti}^{\mathrm{IV}} \mathrm{OPc}(3-)\right]^{\bullet-}\right\}_{2}$ dimers is sufficiently strong to cause the compound to fall into the diamagnetic state below $150 \mathrm{~K}^{8 \mathrm{e}}$

\section{Calculations}

To examine the electronic structures of the $\left\{\mathrm{CpFe}(\mathrm{CO})_{2}(\mathrm{SnPc})\right\}^{-}$anion, $\mathrm{Ph}_{5} \mathrm{CpRu}(\mathrm{CO})_{2}(\mathrm{SnPc})$ monomer, and $\left[\mathrm{Ph}_{5} \mathrm{CpRu}(\mathrm{CO})_{2}(\mathrm{SnPc})\right]_{2}$ dimer, theoretical analyses using density functional theory (DFT) were performed at the M11/cc-pVTZ(-PP)/cc-pVDZ level of theory. ${ }^{19}$ For the singlet, triplet, and quintet states in the $\left\{\mathrm{CpFe}(\mathrm{CO})_{2}(\mathrm{SnPc})\right\}^{-}$anion, the doublet and quartet states in the

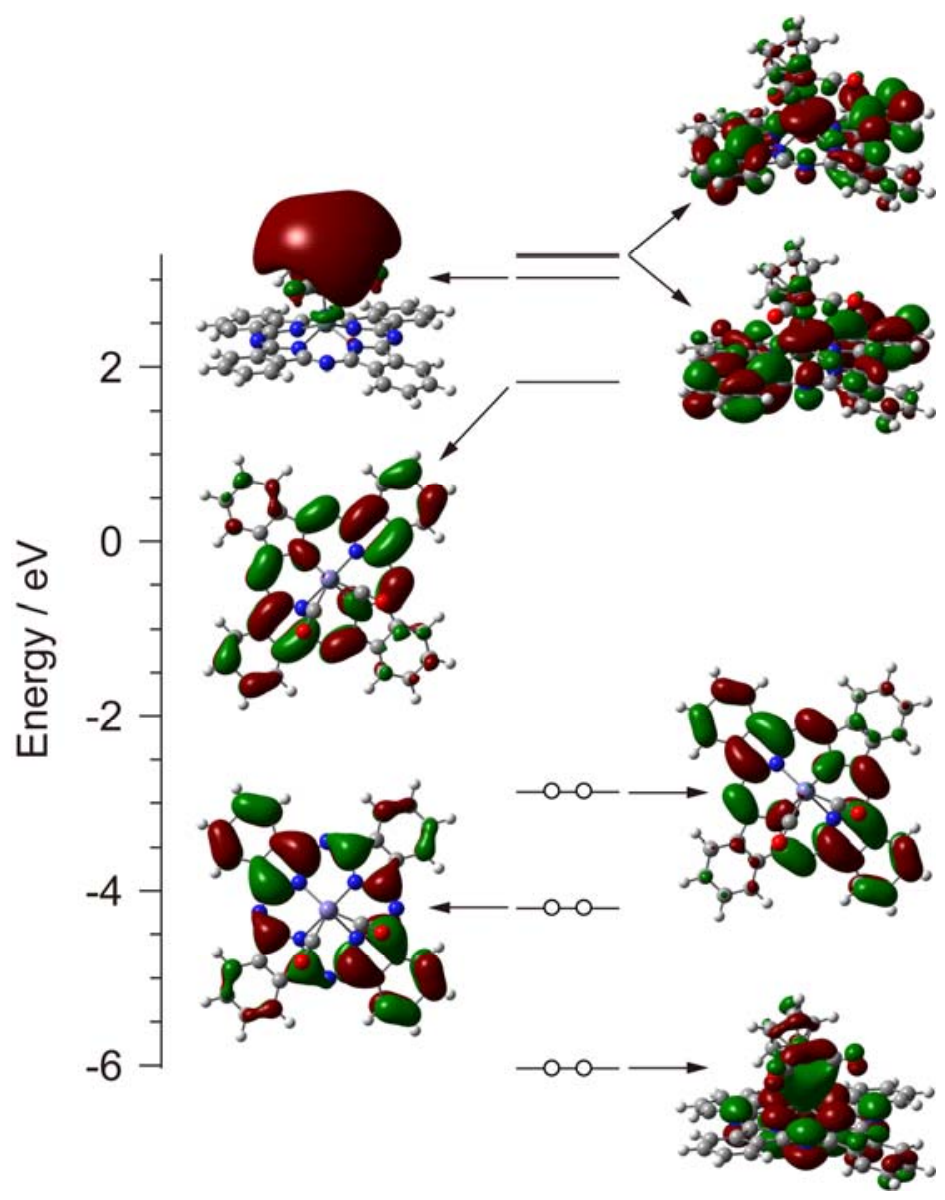

Figure 9. Energy diagram for the frontier Kohn-Sham orbitals of ${ }^{1} A$ state in $\left[\mathrm{CpFe}(\mathrm{CO})_{2}(\mathrm{SnPc})\right]^{-}$ anion calculated at the RM11/cc-pVTZ(-PP)/cc-pVDZ level of theory. For clarity, cyclopentadienyl ligand is omitted in $\mathrm{HO}-1, \mathrm{HO}$, and LU orbitals. 
$\mathrm{Ph}_{5} \mathrm{CpRu}(\mathrm{CO})_{2}(\mathrm{SnPc})$ monomer, and the singlet and triplet states in the $\left[\mathrm{Ph}_{5} \mathrm{CpRu}(\mathrm{CO})_{2}(\mathrm{SnPc})\right]_{2}$ dimer, partial optimizations only for hydrogen atoms were completed using the X-ray structural data as the initial structures. The total and relative energies and $\left\langle S^{2}\right\rangle$ values, the Mulliken and natural charges, and the Wiberg bond indices are summarized in Table S6, S7, and S8, respectively.

The closed-shell singlet state in the $\left\{\mathrm{CpFe}(\mathrm{CO})_{2}(\mathrm{SnPc})\right\}^{-}$anion is more stable in energy by 10630 $\mathrm{K}$ and $36899 \mathrm{~K}$, respectively, than the corresponding triplet and quintet states, supporting the diamagnetic nature of $\mathbf{4}$. Therefore, the observed magnetic moment and weak EPR signals of 4 appear to originate from paramagnetic impurities. The energy diagram for the frontier Kohn-Sham orbitals of the singlet state in the $\left\{\mathrm{CpFe}(\mathrm{CO})_{2}(\mathrm{SnPc})\right\}^{-}$anion is shown in Fig. 9. The highest occupied and lowest unoccupied molecular orbitals (HOMO and LUMO) stem from the doubly degenerated LUMO of the $D_{4 \mathrm{~h}}$ symmetric phthalocyaninate dianion $\left(\mathrm{Pc}^{2-}\right)$ (where the Pc ligand in 4 can be regarded as a closed shell $\mathrm{Pc}^{4-}$ tetraanion) and the (HO-1)MO from the HOMO of $\mathrm{Pc}^{2-}$, respectively. From the electrostatic potential map shown in Fig. S25, it can be seen that the isoindole moieties over which the LUMO spreads are more negatively charged than those that are not affected. The (HO-2)MO and nearly degenerate (LU+2) and (LU+3)MOs are the bonding and antibonding orbitals between the $\mathrm{Fe}$ and $\mathrm{Sn}$ atoms, respectively. The Wiberg bond index for $\mathrm{Fe}-\mathrm{Sn}$ bond was determined to be 0.641 (Table S8), and the Pc ligand had the largest negative natural charge of -2.822 (Table S7). In order to confirm the bond alternation of phthalocyanine moiety observed by X-ray structural analysis of $\mathbf{4}$, full geometry optimization on the $\left[\mathrm{CpFe}(\mathrm{CO})_{2}(\mathrm{SnPc})\right]^{-}$anion was carried out at the RM11/cc-pVTZ(-PP)/cc-pVDZ level of theory. The calculated bond lengths and electrostatic potential map are shown in Table S9 and Figs. S25 and S26. The calculated bond lengths agree rather well with the experiment ones, indicating the high reliability of present DFT calculation. Although the phthalocyanine moiety in $[\operatorname{SnPc}(2-)]^{0}$ is a $18 \pi$-electronic system with aromaticity, the two-electron-reduction makes the phthalocyanine moiety a $20 \pi$-electronic system to 


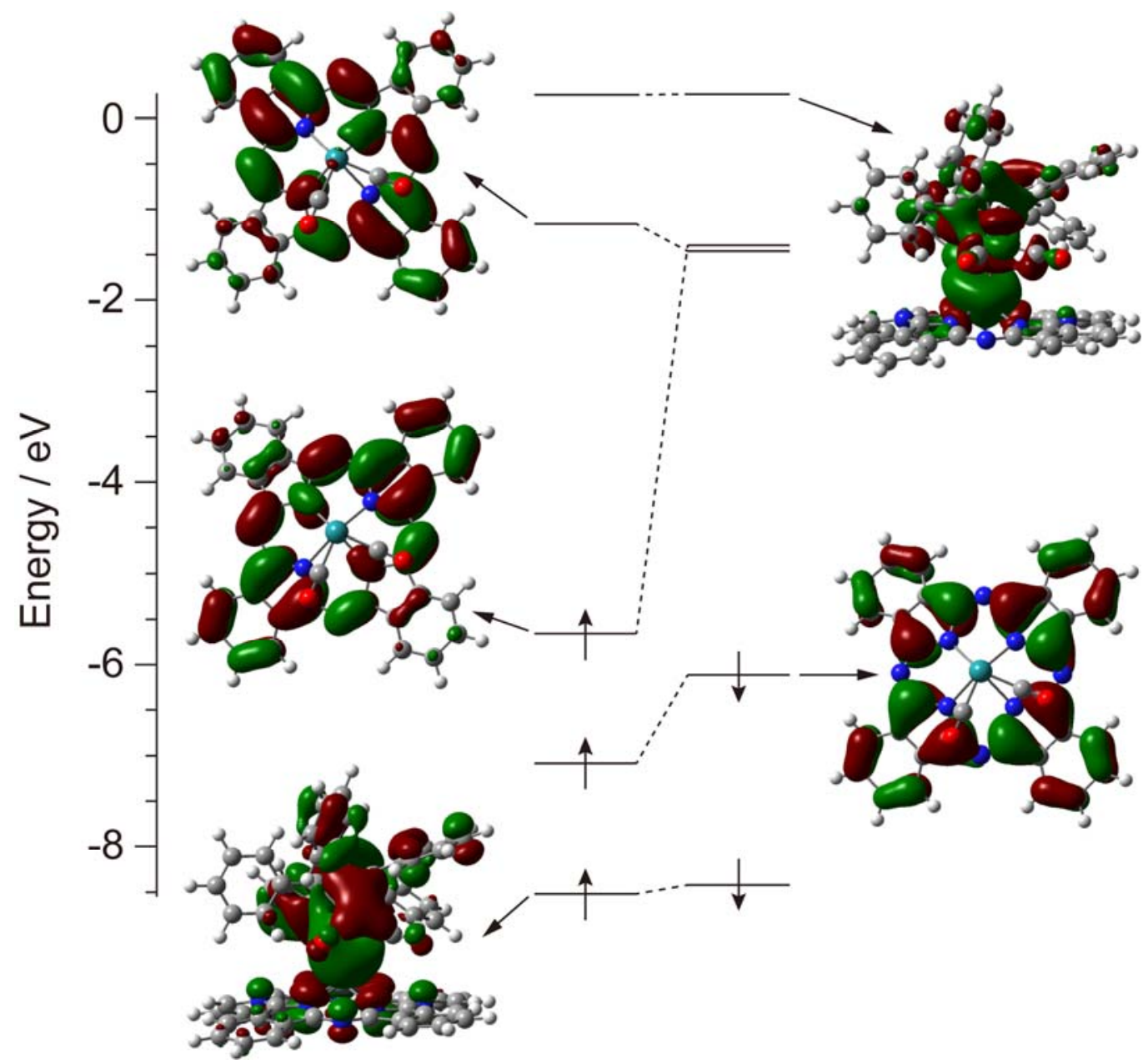

Figure 10. Energy diagram for frontier Kohn-Sham orbitals of ${ }^{2} A$ state in $\mathrm{Ph}_{5} \mathrm{CpRu}(\mathrm{CO})_{2}(\mathrm{SnPc})$ monomer calculated at the UM11/cc-pVTZ-PP/cc-pVDZ level of theory. For clarity, the pentaphenylcyclopentadienyl ligand is omitted in $\alpha-\mathrm{LU}, \alpha-\mathrm{HO}$, and $\beta$-HO orbitals.

induce anti-aromaticity (Figure S27). The $\mathrm{Pc}$ moiety in the $\left[\mathrm{CpFe}(\mathrm{CO})_{2}(\mathrm{SnPc})\right]^{-}$anion may be deformed to the boat shape to get away from anti-aromatic character, which implies that antiaromaticity would potentially come back when the Pc moiety gets the planarity by external stimuli such as pressure, light, and temperature.

The doublet state in the $\mathrm{Ph}_{5} \mathrm{CpRu}(\mathrm{CO})_{2}(\mathrm{SnPc})$ monomer and open-shell broken-symmetry singlet state in the $\left[\mathrm{Ph}_{5} \mathrm{CpRu}(\mathrm{CO})_{2}(\mathrm{SnPc})\right]_{2}$ dimer are more stable in energy than the corresponding quartet and triplet states, respectively. For the $\left[\mathrm{Ph}_{5} \mathrm{CpRu}(\mathrm{CO})_{2}(\mathrm{SnPc})\right]_{2}$ dimer, the estimated intermolecular 
antiferromagnetic interaction was calculated to be $J=-292 \mathrm{~K}$, supporting the observed antiferromagnetic behavior with a value for $J=-183 \mathrm{~K}$ between the $S=1 / 2$ spins in 8 . The energy diagrams for the frontier Kohn-Sham orbitals of the doublet state in the $\mathrm{Ph}_{5} \mathrm{CpRu}(\mathrm{CO})_{2}(\mathrm{SnPc})$ monomer and the broken-symmetry singlet state in the $\left[\mathrm{Ph}_{5} \mathrm{CpRu}(\mathrm{CO})_{2}(\mathrm{SnPc})\right]_{2}$ dimer are shown in Figs. 10 and $\mathrm{S} 28$, respectively. The electronic structure of $\mathrm{Ph}_{5} \mathrm{CpRu}(\mathrm{CO})_{2}(\mathrm{SnPc})$ resembles that of the $\left\{\mathrm{CpFe}(\mathrm{CO})_{2}(\mathrm{SnPc})\right\}^{-}$anion. The singly occupied molecular orbital (SOMO) and LUMO stem from the doubly degenerate LUMO of the $D_{4 \mathrm{~h}}$ symmetric $\mathrm{Pc}^{2-}$, where the Pc ligand in 8 can be regarded as an open-shell $\mathrm{Pc}^{\bullet 3-}$ radical trianion, and the HOMO from the HOMO of $\mathrm{Pc}^{2-}$. The $(\mathrm{HO}-1)$ and $(\mathrm{LU}+1) \mathrm{MOs}$ are the bonding and antibonding orbitals between the $\mathrm{Ru}$ and $\mathrm{Sn}$ atoms, respectively. The electrostatic potential map shown in Fig. S29 is similar to that for the $\left\{\mathrm{CpFe}(\mathrm{CO})_{2}(\mathrm{SnPc})\right\}^{-}$anion.

The electronic structure of the broken-symmetry singlet state in the $\left[\mathrm{Ph}_{5} \mathrm{CpRu}(\mathrm{CO})_{2}(\mathrm{SnPc})\right]_{2}$ dimer inherits that of the doublet state in the $\mathrm{Ph}_{5} \mathrm{CpRu}(\mathrm{CO})_{2}(\mathrm{SnPc})$ monomer, and the two SOMOs ( $\alpha$ - and $\beta$-HOMOs) providing the magnetic properties originate from the SOMO of the $\mathrm{Ph}_{5} \mathrm{CpRu}(\mathrm{CO})_{2}(\mathrm{SnPc})$ monomer (Fig. S28). The spin density distribution of the doublet state in the $\mathrm{Ph}_{5} \mathrm{CpRu}(\mathrm{CO})_{2}(\mathrm{SnPc})$ monomer and broken-symmetry singlet state in the $\left[\mathrm{Ph}_{5} \mathrm{CpRu}(\mathrm{CO})_{2}(\mathrm{SnPc})\right]_{2}$ dimer are shown in Figs. S30 and S31, respectively. It can be seen that they spread over the Pc ligand. This result was also confirmed by evaluating the Mulliken and natural spin densities of nearly one spin on a Pc ligand (Table S7). The present DFT calculations reveal that the magnetic properties of 8 derive from the $\pi$-radical spins on the Pc ligand. The Wiberg bond indices for the $\mathrm{Ru}-\mathrm{Sn}$ bond in the $\mathrm{Ph}_{5} \mathrm{CpRu}(\mathrm{CO})_{2}(\mathrm{SnPc})$ monomer and $\left[\mathrm{Ph}_{5} \mathrm{CpRu}(\mathrm{CO})_{2}(\mathrm{SnPc})\right]_{2}$ dimer were found to be 0.724 and 0.716 , respectively (Table S8), and the $\mathrm{Pc}$ ligands in the $\mathrm{Ph}_{5} \mathrm{CpRu}(\mathrm{CO})_{2}(\mathrm{SnPc})$ monomer and $\left[\mathrm{Ph}_{5} \mathrm{CpRu}(\mathrm{CO})_{2}(\mathrm{SnPc})\right]_{2}$ dimer had largest negative natural charges of -1.897 and -1.952 (Table S7). 
Since the differences in the calculated charge and spin densities and Wiberg bond indices for the $\mathrm{Ph}_{5} \mathrm{CpRu}(\mathrm{CO})_{2}(\mathrm{SnPc})$ monomer and $\left[\mathrm{Ph}_{5} \mathrm{CpRu}(\mathrm{CO})_{2}(\mathrm{SnPc})\right]_{2}$ dimer were small, the results for the $\mathrm{Ph}_{5} \mathrm{CpRu}(\mathrm{CO})_{2}(\mathrm{SnPc})$ monomer were further investigated. Specifically, the natural charges of the $\left[\mathrm{CpFe}(\mathrm{CO})_{2}(\mathrm{SnPc})\right]^{-}$anion and $\mathrm{Ph}_{5} \mathrm{CpRu}(\mathrm{CO})_{2}(\mathrm{SnPc})$ monomer were compared (Table S7). Except for the $\mathrm{Pc}$ ligands in the $\left[\mathrm{CpFe}(\mathrm{CO})_{2}(\mathrm{SnPc})\right]^{-}$anion and $\mathrm{Ph}_{5} \mathrm{CpRu}(\mathrm{CO})_{2}(\mathrm{SnPc})$ monomer, the natural charges on the corresponding moieties resembled one another, indicating that the Fe and $\mathrm{Ru}$ atoms, $\mathrm{Cp}$ and $\mathrm{Ph}_{5} \mathrm{Cp}$ ligands, $\mathrm{CO}$ ligands, and $\mathrm{Sn}$ atoms in $\mathbf{4}$ and $\mathbf{8}$ have nearly the same charges. Therefore, on a formal charge basis, if the $\mathrm{Ph}_{5} \mathrm{Cp}$ ligand has a charge of -1 , the $\mathrm{Cp}$ ligand should also have a charge of -1 , and if the $\mathrm{Ru}$ atom has a charge of +2 , the Fe ligand should also have a charge of +2 . Note that the absolute values of the natural charges do not exactly match those of the formal charges. However, the similar charges (except for the Pc ligands) and similar Wiberg bond indices for the $\mathrm{Fe}-\mathrm{Sn}$ and $\mathrm{Ru}-\mathrm{Sn}$ bonds in Tables $\mathrm{S} 7$ and $\mathrm{S} 8$ indicate that the electronic structures of the $\left[\mathrm{CpFe}(\mathrm{CO})_{2}(\mathrm{SnPc})\right]^{-}$anion and $\mathrm{Ph}_{5} \mathrm{CpRu}(\mathrm{CO})_{2}(\mathrm{SnPc})$ monomer are roughly the same, except for the Pc ligand. On the other hand, the Pc ligand in the $\left[\mathrm{CpFe}(\mathrm{CO})_{2}(\mathrm{SnPc})\right]^{-}$anion has a larger negative charge by approximately one electron than that in the $\mathrm{Ph}_{5} \mathrm{CpRu}(\mathrm{CO})_{2}(\mathrm{SnPc})$ monomer $(-2.822$ vs. -1.897 in Table S7). It can therefore be concluded that the Pc ligand is in a tetraanionic state, such as $\left\{\mathrm{CpFe}^{\mathrm{II}}(\mathrm{CO})_{2}\left[\mathrm{Sn}^{\mathrm{II}} \mathrm{Pc}(4-)\right]^{2-}\right\}^{-}$, because the optical and magnetic properties and frontier orbital picture indicate an electronic structure of $\mathrm{Ph}_{5} \mathrm{CpRu}{ }^{\mathrm{II}}(\mathrm{CO})_{2}\left[\mathrm{Sn}^{\mathrm{II}} \mathrm{Pc}(3-)\right]^{\bullet-}$ on a formal charge basis. In other words, complex 4 is generated as the result of charge transfer from $\mathrm{CpFe}^{\mathrm{I}}(\mathrm{CO})_{2}$ to $\left[\mathrm{Sn}^{\mathrm{II}} \mathrm{Pc}(3-\right.$ )$]^{\bullet-}$ to form $\left\{\mathrm{CpFe}^{\mathrm{II}}(\mathrm{CO})_{2}\left[\mathrm{Sn}^{\mathrm{II}} \mathrm{Pc}(4-)\right]^{2-}\right\}^{-}$dianions.

\section{CONCLUSION}

New approaches for obtaining crystalline transition metal complexes with neutral tin(II) phthalocyanine and tin(II) phthalocyanine radical anions and dianions were described. The ability of tin(II) atoms to form stable $\mathrm{Sn}-\mathrm{M}$ bonds with transition metals (Mo, $\mathrm{Fe}, \mathrm{Rh}$, and $\mathrm{Ru}$ ) was utilized. 
Other metals can also form such bonds (In, Ga, Bi, and others), and we plan to study these complexes in the future. In all cases except $\mathrm{CpFe}(\mathrm{CO})_{2}$, the negative charge and spin on the coordinated $\left[\mathrm{Sn}^{\mathrm{II}} \mathrm{Pc}(3-)\right]^{\bullet-}$ radical anions were preserved, and the anions acted as anionic paramagnetic ligands for the transition metals. In the coordination complex of $\mathrm{CpFe}^{\mathrm{I}}(\mathrm{CO})_{2}$ with $\left[\mathrm{Sn}^{\mathrm{II}} \mathrm{Pc}(3-)\right]^{\bullet}$, unusual charge transfer was observed, along with the formation of $\left\{\mathrm{CpFe} \mathrm{II}^{\mathrm{II}}(\mathrm{CO})_{2}\right\}^{+}$ cations and $\left[\mathrm{Sn}^{\mathrm{II}} \mathrm{Pc}(4-)\right]^{2-}$ dianions. This new approach thus provides a potential method for developing magnetic and conducting assemblies based on metal phthalocyanines and transition metals with significant variability: neutral, monoanionic, and even dianionic tin(II) phthalocyanines can be obtained. It was also found that the formally neutral $\mathrm{Ph}_{5} \mathrm{CpRu}{ }^{\mathrm{II}}(\mathrm{CO})_{2}\left[\mathrm{Sn}^{\mathrm{II}} \mathrm{Pc}\right]$ molecule contains $\left[\mathrm{Sn}^{\mathrm{II}} \mathrm{Pc}(3-)\right]^{\bullet-}$ radical anions. This compound is of a special interest because these molecules manifest strong magnetic spin coupling.

\section{EXPERIMENTAL}

\section{Materials}

Tin(II) phthalocyanine $\left(\mathrm{Sn}^{\mathrm{II}} \mathrm{Pc}\right), \quad$ tin(IV) phthalocyanine dichloride $\left(\mathrm{Sn}^{\mathrm{IV}} \mathrm{Cl}_{2} \mathrm{Pc}\right)$, and (cyclopentadienyl iron(I) dicarbonyl $\left\{\mathrm{CpFe}(\mathrm{CO})_{2}\right\}_{2}$ dimer were purchased from TCI. Molybdenum(I) cyclopentadienyl tricarbonyl $\left\{\mathrm{CpMo}(\mathrm{CO})_{3}\right\}_{2}$ dimer, pentamethylcyclopentadienyl rhodium(III) dichloride $\left\{\mathrm{Cp}^{*} \mathrm{RhCl}_{2}\right\}_{2}$ dimer, pentaphenylcyclopentadienyl ruthenium(II) dicarbonyl chloride $\mathrm{Ph}_{5} \mathrm{CpRu}(\mathrm{CO})_{2} \mathrm{Cl}$, and tetrabutylammonium bromide $\left(\mathrm{Bu}_{4} \mathrm{NBr}, 99 \%\right)$ were purchased from Aldrich. Cryptand[2,2,2] and triiron dodecacarbonyl $\mathrm{Fe}_{3}(\mathrm{CO})_{12}(99 \%)$ were purchased from Acros. Pentamethylcyclopentadienyl molybdenum(I) dicarbonyl $\left\{\mathrm{Cp} * \mathrm{Mo}(\mathrm{CO})_{2}\right\}_{2}$ dimer was purchased from Strem. Sodium fluorenone ketyl was obtained as described. ${ }^{20}$ Solvents were purified under an Ar atmosphere. Ortho-dichlorobenzene $\left(\mathrm{C}_{6} \mathrm{H}_{4} \mathrm{Cl}_{2}\right)$ was distilled over $\mathrm{CaH}_{2}$ under reduced pressure, and hexane was distilled over $\mathrm{Na} /$ benzophenone. Compounds 1-8 were synthesized and stored in an MBraun 150B-G glove box with a controlled atmosphere containing less than $1 \mathrm{ppm}$ each of water 
and oxygen. Solvents were degassed and stored in the glove box, and the KBr pellets used for the IR and UV-visible-NIR analyses were prepared in the glove box. EPR and SQUID measurements were performed on polycrystalline samples of $\mathbf{1 - 8}$ sealed in $2 \mathrm{~mm}$ quarz tubes at ambient pressure.

\section{Synthesis}

Crystals of 1-8 were obtained using a diffusion technique. A reaction mixture in $o$-dichlorobenzene was filtered into a 1.8 -cm-diameter, $50 \mathrm{~mL}$ glass tube with a ground glass plug, and then $30 \mathrm{~mL}$ of hexane was layered over the solution. Slow mixing of the $o$-dichlorobenzene solution with hexane resulted in precipitation of crystals over 1-2 months. The solvent was then decanted from the crystals, and they were washed with hexane. The compositions of the obtained compounds were determined via X-ray diffraction analysis of a single crystal of each (see Supporting information for X-ray diffraction data). For each compound, several crystals from one synthesis were found to consist of a single crystalline phase. The compositions of the neutral coordination complexes were confirmed using elemental analysis. Due to the high air sensitivity of compound 3-8, elemental analysis could not be used to determine the composition, because the complexes reacted with oxygen in the air before the quantitative oxidation procedure could be performed.

$\mathrm{Cp} * \mathrm{MoBr}(\mathrm{CO})_{2}\left[\mathrm{Sn}^{\mathrm{II}} \mathrm{Pc}(2-)\right] \cdot 0.5 \mathrm{C}_{6} \mathrm{H}_{4} \mathrm{Cl}_{2}$ (1) was obtained via the reduction of $\mathrm{Sn}^{\mathrm{IV}} \mathrm{Cl}_{2} \mathrm{Pc}(29.3 \mathrm{mg}$, $0.042 \mathrm{mmol})$ using a slight excess of sodium fluorenone ketyl $(11 \mathrm{mg}, 0.054 \mathrm{mmol})$ in the presence of excess $\mathrm{Bu}_{4} \mathrm{NBr}(30 \mathrm{mg}, 0.092 \mathrm{mmol})$ in $o$-dichlorobenzene $(16 \mathrm{ml})$. The reaction was performed for $2 \mathrm{~h}$ at $100{ }^{\circ} \mathrm{C}$. The resulting deep blue solution containing the $\mathrm{TBA}^{+}$salt of $\left[\mathrm{Sn}^{\mathrm{IV}} \mathrm{Br}{ }_{2} \mathrm{Pc}(3-)\right]^{\bullet-}$ was filtered into a flask containing one equivalent of $\left\{\mathrm{Cp} * \mathrm{Mo}(\mathrm{CO})_{2}\right\}_{2}$ dimer $(24 \mathrm{mg}, 0.042 \mathrm{mmol})$, and the solution was stirred for $1 \mathrm{~d}$ at $80{ }^{\circ} \mathrm{C}$ to produce a green solution. The solution was cooled to room temperature and then filtered into a tube for diffusion. Black prisms were obtained in $32 \%$ yield. The composition of $\mathbf{1}$ was confirmed via elemental analysis: Anal. Calcd for $\mathrm{C}_{47} \mathrm{H}_{33} \mathrm{BrClMoN}_{8} \mathrm{O}_{2} \mathrm{Sn}, \mathrm{M}_{\mathrm{r}}=1072$ : C 52.66, H 3.08, N 10.45; Found: C 53.02, H 2.96, N 10.38. The 
introduction of $\mathrm{Br}$ anions linked to Mo atoms was justified by the length of the Mo-Br bond of 2.697(8) $\AA$ in 1 , which is characteristic of the length of the Mo- $\mathrm{Br}$ bonds in the $\mathrm{CpMo}(\mathrm{CO})_{2^{-}}$ containing compounds $(\sim 2.63-2.67 \AA) .{ }^{11} \mathrm{Mo}-\mathrm{Cl}$ bonds are noticeably shorter $(\sim 2.47-2.54 \AA) .{ }^{11 \mathrm{c},} 12$

$\mathrm{CpFe}(\mathrm{CO})_{2}\left[\mathrm{Sn}{ }^{\mathrm{II}} \mathrm{Pc}(2-)\right] \cdot 2 \mathrm{C}_{6} \mathrm{H}_{4} \mathrm{Cl}_{2}$ (2) was obtained via the reduction of $\mathrm{Sn}^{\mathrm{IV}} \mathrm{Cl}_{2} \mathrm{Pc}$ (29.3 mg, $0.042 \mathrm{mmol})$ using a slight excess of sodium fluorenone ketyl $(11 \mathrm{mg}, 0.054 \mathrm{mmol})$ in the presence of one equivalent of cryptand $(16 \mathrm{mg}, 0.042 \mathrm{mmol})$ in $o$-dichlorobenzene $(16 \mathrm{ml})$. The reaction was performed for $2 \mathrm{~h}$ at $100{ }^{\circ} \mathrm{C}$. The resulting deep blue solution containing $\left\{\operatorname{cryptand}\left(\mathrm{Na}^{+}\right)\right\}\left[\mathrm{Sn}^{\mathrm{IV}} \mathrm{Cl}_{2} \mathrm{Pc}(3-)\right]^{\bullet-}$ was filtered into a flask containing excess $\left\{\mathrm{CpFe}(\mathrm{CO})_{2}\right\}_{2}$ dimer (24 mg, $0.068 \mathrm{mmol}$ ), and the resultant solution was stirred for $1 \mathrm{~d}$ at $80{ }^{\circ} \mathrm{C}$ to produce a greenishblue solution. This solution was subsequently cooled to RT and then filtered into a tube for diffusion. Black rhombs with a characteristic copper luster were obtained in 58\% yield. The composition of 2 was determined via elemental analysis: Anal. Calcd for $\mathrm{C}_{51} \mathrm{H}_{24} \mathrm{Cl}_{4} \mathrm{FeN}_{8} \mathrm{O}_{2} \mathrm{Sn}, \mathrm{M}_{\mathrm{r}}=1097$ : C 55.80, $\mathrm{H}$ 2.19, N 10.21, Cl 12.94; Found: C 55.96, H 2.34, N 10.14, Cl 12.32. All measurements were performed on freshly isolated crystals.

$\left\{\right.$ Cryptand $\left.\left(\mathrm{Na}^{+}\right)\right\}\left[\mathrm{Sn}{ }^{\mathrm{II}} \mathrm{Pc}(3-)\right]^{\bullet \cdot} \cdot \mathrm{C}_{6} \mathrm{H}_{4} \mathrm{Cl}_{2}$ (3) was obtained via the reduction of $\mathrm{Sn}^{\mathrm{II}} \mathrm{Pc}(26.4 \mathrm{mg}$, $0.042 \mathrm{mmol})$ with a slight excess of sodium fluorenone ketyl $(11 \mathrm{mg}, 0.054 \mathrm{mmol})$ in the presence of one equivalent of cryptand $(16 \mathrm{mg}, 0.042 \mathrm{mmol})$ in $o$-dichlorobenzene $(16 \mathrm{ml})$ for $2 \mathrm{~h}$ at $100{ }^{\circ} \mathrm{C}$. The resulting deep blue solution was cooled to RT and then filtered into a tube for diffusion. Black parallelepipeds of 3 with a characteristic copper luster were obtained in $74 \%$ yield.

$\left\{\right.$ Cryptand $\left.\left(\mathrm{Na}^{+}\right)\right\}\left\{\mathrm{CpFe}(\mathrm{CO})_{2}\left[\mathrm{Sn}^{\mathrm{II}} \mathrm{Pc}(4-)\right]\right\}^{-} \cdot \mathrm{C}_{6} \mathrm{H}_{4} \mathrm{Cl}_{2}$ (4) was obtained via the reduction of $\mathrm{Sn}^{\mathrm{II}} \mathrm{Pc}$ (26.4 $\mathrm{mg}, 0.042 \mathrm{mmol}$ ) with a slight excess of sodium fluorenone ketyl $(11 \mathrm{mg}, 0.054 \mathrm{mmol})$ in the presence of one equivalent of cryptand $(16 \mathrm{mg}, 0.042 \mathrm{mmol})$ in $o$-dichlorobenzene $(16 \mathrm{ml})$. The resulting deep blue solution was filtered into a flask with containing excess $\left\{\mathrm{CpFe}(\mathrm{CO})_{2}\right\}_{2}$ dimer $(24$ $\mathrm{mg}, 0.068 \mathrm{mmol}$ ), and the resultant solution was stirred for $1 \mathrm{~d}$ at $80{ }^{\circ} \mathrm{C}$ to produce a deep violet 
solution. This solution was subsequently cooled to RT and then filtered into a tube for diffusion. Black prisms with a characteristic copper luster were obtained in $72 \%$ yield.

To prepare the crystalline $\left\{\right.$ cryptand $\left.\left(\mathrm{Na}^{+}\right)\right\}\left\{\mathrm{Fe}(\mathrm{CO})_{4}\left[\mathrm{Sn}^{\mathrm{II}} \mathrm{Pc}(3-)\right]^{\bullet-}\right\} \cdot(1 / 3) \mathrm{C}_{6} \mathrm{H}_{4} \mathrm{Cl}_{2} \quad$ (5), $\left\{\right.$ cryptand $\left.\left(\mathrm{Na}^{+}\right)\right\}\left\{\mathrm{CpMo}(\mathrm{CO})_{2}\left[\left(\mathrm{Sn}^{\mathrm{II}} \mathrm{Pc}\right)_{2}\right]^{\bullet-}\right\} \cdot 3.5 \mathrm{C}_{6} \mathrm{H}_{4} \mathrm{Cl}_{2} \quad$ (6), $\quad$ cryptand $\left.\left(\mathrm{Na}^{+}\right)\right\}\left\{\mathrm{Cp}^{*} \mathrm{RhCl}_{2}\left[\mathrm{Sn}^{\mathrm{II}} \mathrm{Pc}(3-\right.\right.$ ]$\left.^{\bullet-}\right\} \cdot \mathrm{C}_{6} \mathrm{H}_{4} \mathrm{Cl}_{2}$ (7), and $\mathrm{Ph}_{5} \mathrm{CpRu}^{\mathrm{II}}(\mathrm{CO})_{2}\left[\mathrm{Sn}^{\mathrm{II}} \mathrm{Pc}(3-)\right]$ (8), the obtained deep blue solution of $\left\{\right.$ cryptand $\left.\left(\mathrm{Na}^{+}\right)\right\}\left[\mathrm{Sn}^{\mathrm{II}} \mathrm{Pc}(3-)\right]^{\bullet-}$ was filtered into a flask containing $\mathrm{Fe}_{3}(\mathrm{CO})_{12}(21 \mathrm{mg}, 0.042 \mathrm{mmol})$, $\left\{\mathrm{CpMo}(\mathrm{CO})_{3}\right\}_{2}(12 \mathrm{mg}, 0.024 \mathrm{mmol}),\left\{\mathrm{Cp}^{*} \mathrm{RhCl}_{2}\right\}_{2}(14 \mathrm{mg}, 0.022 \mathrm{mmol})$, and $\mathrm{Ph}_{5} \mathrm{CpRu}(\mathrm{CO})_{2} \mathrm{Cl}$ (28 mg, $0.044 \mathrm{mmol}$ ), respectively. Each solution was stirred for $1 \mathrm{~d}$ at $80{ }^{\circ} \mathrm{C}$, and their deep blue color remained unchanged. Each solution was then cooled to RT and filtered into a tube for diffusion. Black plates for 7, and blocks for 5, 6, and 8, all with a characteristic copper luster, were obtained in $61 \%, 58 \%, 52 \%$, and $69 \%$ yields, respectively.

\section{Computational details}

DFT calculations based on the M11 functional ${ }^{21}$ were performed using the cc-pVDZ $(\mathrm{C}, \mathrm{H}, \mathrm{N}$, and $\mathrm{O}),{ }^{22}$ cc-pVTZ $(\mathrm{Fe}),{ }^{23}$ and cc-pVTZ-PP $(\mathrm{Ru} \text { and } \mathrm{Sn})^{24}$ basis sets. For the geometries of the $\left[\mathrm{CpFe}(\mathrm{CO})_{2}(\mathrm{SnPc})\right]^{-}$anion, $\mathrm{Ph}_{5} \mathrm{CpRu}(\mathrm{CO})_{2}(\mathrm{SnPc})$, and the $\left[\mathrm{Ph}_{5} \mathrm{CpRu}(\mathrm{CO})_{2}(\mathrm{SnPc})\right]_{2}$ dimer, only the coordinates of the hydrogen atoms were optimized from the X-ray structures with "Opt = Tight." For the ${ }^{1} A$ state of $\left[\mathrm{CpFe}(\mathrm{CO})_{2}(\mathrm{SnPc})\right]^{-}$anion, full geometry optimization was also performed at the same level of theory. In the present DFT calculations, "Int = SuperFineGrid" was specified, and the stabilities of the wave functions were confirmed by specifying the "Stable=Opt" keyword. The subsequent natural bond orbital (NBO) analysis was performed using the NBO program. ${ }^{25}$ All of the computations were performed with the Gaussian 09 program package. ${ }^{19}$

Supporting information: Equipment used, crystallographic data, and IR spectra of 1-8; structural views for 1, 2, and 3; details of DFT calculations for $\mathbf{4}$ and $\mathbf{8}$; and data for magnetic measurement 
data for $\mathbf{1}$ and 3-8 using SQUID and EPR are available free of charge via the Internet at http://pubs.acs.org.

\section{Author information}

\section{Corresponding author}

*E-mail for D.V.K.: konarev@icp.ac.ru.

\section{Notes}

The authors declare no competing financial interest.

\section{Acknowledgments}

The work was supported by RFBR grant № 13-03-00769 and JSPS KAKENHI Grant Numbers 15K17901, 23225005, and 26288035. Y.N. receives a research grant from the JGC-S Scholarship Foundation. Theoretical calculations were performed at the Research Center for Computational Science, Okazaki, Japan.

\section{References}

1. (a) Nyokong, T. Coord. Chem. Rev., 2007, 251, 1707-1722; (a) Placencia, D.; Wang, W.; Gantz, J.; Jenkins, J. L.; Armstrong, N. R. J. Phys. Chem. C, 2011, 115, 18873-18884; (c) Inabe T., Tajima, H. Chem. Rev. 2004, 104, 5503-5534; (d) Rittenberg, D. K.; Baars-Hibbe, L.; Böhm, A. B.; Miller, J. S. J. Mater. Chem. 2000, 10, 241-244; (e) Konarev, D.V.; Zorina, L.V.; Khasanov, S.S.; Hakimova, E.U.; Lyubovskaya, R.N. New J. Chem., 2012, 36, 48-51.

2. Contakes, S. M.; Beatty, S. T.; Dailey, K. K.; Rauchfuss, T. B.; Fenske, D. Organomet. 2000, 19, 4767-4774.

3. (a) Dailey, K. K.; Rauchfuss, T. B., Yap, G.P.A.; Rheingold, A.L. Angew. Chem., Intl. Ed. Engl. 1996, 35, 1833-1835; (b) Dailey, K. K.; Rauchfuss, T. B. Polyhedron 1997, 16, 3129-3136.

4. (a) Onaka, S.; Kondo, Y.; Yamashita, M.; Tatematsu, Y.; Kato, Y.; Goto, M.; Ito, T. Inorg. Chem. 1985, 24, 1070-1076; (b) Zhong, X.; Feng, Y.; Ong, S.-L.; Hu, J.; Ng, W.-J.; Wang, 
Z. Chem. Commun. 2003, 1882-1883; (c) Richard, P.; Zrineh, A.; Guilard, R.; Habbou, A.; Leconte, C. Acta Cryst. Sec. C 1989, 45, 1224-1226.

5. (a) Frampton, S.C., Silver J. Inorg. Chem. Acta, 1986, 112, 203-204; (b) Kato, S.; Noda, I.; Mizuta, M.; Itoh Y., Angew. Chem. Int. Ed. Engl. 1979, 18, 82-83.

6. (a) Goldner, M.; Huckstadt, H.; Murray, K. S.; Moubaraki, B.; Homborg, H. Z. Anorg. Allg. Chem. 1998, 624, 288-294; (b) Barbe, J. -M.; Morata, G.; Espinosa, E.; Guilard, R. J. Porph. Phth. 2003, 7, 120-124; (c) Yang, C. -H.; Dzugan, S. J.; Goedken, V. L. Chem. Commun. 1986, 24, 1313-1315; (d) Guilard, R.; Kadish, K. M. Comments Inorg. Chem. 1988, 7, 287-305.

7. Konarev, D. V.; Troyanov, S. I.; Kuzmin, A.V.; Nakano, Y.; Khasanov, S. S.; Otsuka, A.; Yamochi, H.; Saito, G.; Lyubovskaya, R. N. Organometallics, 2015, 34, 879-889.

8. (a) Konarev, D. V.; Khasanov, S. S.; Ishikawa, M.; Otsuka, A.; Yamochi, H.; Saito, G.; Lyubovskaya, R.N. Inorg. Chem., 2013, 52, 3851-3859; (b) Konarev, D. V.; Kuzmin, A. V.; Khasanov, S. S.; Lyubovskaya, R. N. Dalton Trans., 2013, 42, 9870 - 9876; (c) Konarev, D. V.; Kuzmin, A. V.; Ishikawa, M.; Nakano, Y.; Faraonov, M. A.; Khasanov, S. S.; Otsuka, A.; Yamochi, H.; Saito, G.; Lyubovskaya, R. N. Eur. J. Inorg. Chem., 2014, 3863-3870; (d) Konarev, D.V.; Kuzmin, A. V.; Khasanov, S. S.; Otsuka, A.; Yamochi, H.; Saito, G.; Lyubovskaya, R. N. Dalton Trans., 2014, 43, 13061-13069; (e) Konarev, D. V.; Kuzmin, A. V.; Faraonov, M. A.; Ishikawa, M.; Nakano, Y.; Khasanov, S. S.; Otsuka, A.; Yamochi, H.; Saito, G.; Lyubovskaya R. N. Chem. Eur. J., 2015, 21, 1014-1028; (f) Konarev, D. V. ; Troyanov, S. I. ; Ishikawa, M. ; Otsuka, A.; Yamochi, H. ; Saito, G. ; Lyubovskaya, R. N. J. Porph. Phth., 2014, 18, 1157-1163; (g) Konarev, D.V. ; Zorina, L.V. ; Ishikawa, M. ; Khasanov, S.S.; Otsuka, A. ; Yamochi, H. ; Saito, G. ; Lyubovskaya, R. N. Cryst. Groth Des., 2013, 13, 4930-4939; (h) Konarev, D. V.; Khasanov, S. S.; Lyubovskaya, R. N. Coord. Chem. Rev., 2014, 
$262,16-36$.

9. (a) Nyokong, T. Polyhedron, 1994, 13, 2067-2071; (b) Lever, A. B. P.; Milaeva, E. R.; Speier, G. In Phthalocyanines: Properties and Applications. Eds. Leznoff, C. C.; Lever, A. B. P.; 1993, Vol. 3, VCH Publishing, Weinheim. P. 1-70.

10. Lever, A.B.P. Adv. Inorg. Chem. Radiochem., 1965, 7, 27-114.

11. (a) Alonso, M.; Alvarez, M. A.; García, M. E.; Ruiz, M. A.; Hamidov, H.; Jeffery, J. C. J. Am. Chem. Soc., 2005, 127, 15012-15013; (b) Boyle, T. J.; Takusagawa, F.; J. A. Heppert Acta Crystallogr., Sect. C: Cryst. Struct. Commun., 1990, 46, 892-893; (c) Drew, M. G. B.; Félix, V.; Romão, C. C.; Royo B. J. Chem. Soc., Dalton Trans., 2002, 584-590.

12. (a) Yasuda, R.; Iwasa, K.; Niikura, F.; Seino, H.; Mizobe, Y. Dalton Trans., 2014, 43, 93449355; (b) Schaper, L.-A.; Wei, X.; Altmann, P. J.; Öfele, K.; Pöthig, A.; Drees, M.; Mink, J.; Herdtweck, E.; Bechlars, B.; Herrmann, W. A.; Kühn, F. E. Inorg. Chem. 2013, 52, 7031-7044; (c) Davidson, J. L.; Wilson, W. F.; Manojlović-Muir, L.; Muir K. W. J. Organomet. Chem., 1983, 254, C6-C10.

13. Yang, F.; Yu, P.; Zhao, J.; Shi, J.; Wang, J. Phys. Chem. Chem. Phys., 2015,17, 1454214550.

14. Kubiak, R.; Janczak, J. J. Alloys Compd. 1992, 189, 107-111.

15. Konarev, D.V.; Zorina, L.V.; Khasanov, S. S.; Litvinov, A. L.; Otsuka, A.; Yamochi, H.; Saito, G.; Lyubovskaya, R.N. Dalton Trans., 2013, 42, 6810-6816.

16. (a) van der Eide, E. F.; Hou, G.-L.; Deng, S. H. M.; Wen, H.; Yang, P.; Bullock, R. M.; Wang, X.-B. Organometallics, 2013, 32, 2084-2091; (b) Gasanov, R. G.; Lobach, A. S.; Sokolov, V. I.; Demenjev, A. P.; Maslakov K. I.; Obraztsova, E. D. J. Nanosci. Nanotechno., 2007, 7, 1-5. 17. (a) Thompson, D. M.; Jones, M.; Baird, M. C. Eur. J. Inorg. Chem. 2003, 175-180; (b) 
Konarev, D. V.; Kuzmin, A. V.; Troyanov, S. I.; Nakano, Y.; Khasanov, S. S.; Otsuka, A.;

Yamochi, H.; Saito, G.; Lyubovskaya, R. N. Dalton Trans., 2015, 44, 9672-9681.

18. Smart, J. S. “Magnetism III”, eds by Rado, G.T.; Suhl, H. Academic Press, NY, 1963, p. 63.

19. Gaussian 09, Revision D.01, Frisch, M. J.; Trucks, G. W.; Schlegel, H. B.; Scuseria, G. E.;

Robb, M. A.; Cheeseman, J. R.; Scalmani, G.; Barone, V.; Mennucci, B.; Petersson, G. A.;

Nakatsuji, H.; Caricato, M.; Li, X.; Hratchian, H. P.; Izmaylov, A. F.; Bloino, J.; Zheng, G.;

Sonnenberg, J. L.; Hada, M.; Ehara, M.; Toyota, K.; Fukuda, R.; Hasegawa, J.; Ishida, M.;

Nakajima, T.; Honda, Y.; Kitao, O.; Nakai, H.; Vreven, T.; Montgomery, Jr. J. A.; Peralta, J. E.;

Ogliaro, F.; Bearpark, M.; Heyd, J.; Brothers, J. E.; Kudin, K. N.; Staroverov, V. N.; Keith, T.;

Kobayashi, R.; Normand, J.; Raghavachari, K.; Rendell, A.; Burant, J. C.; Iyengar, S. S.; Tomasi, J.; Cossi, M.; Rega, N.; Millam, J. M.; Klene, M.; Knox, J. E.; Cross, J. B.; Bakken, V.; Adamo, C.; Jaramillo, J.; Gomperts, R.; Stratmann, R.; Yazyev, E. O.; Austin, A. J.; Cammi, R.; Pomelli, C.; Ochterski, J. W.; Martin, R. L.; Morokuma, K.; Zakrzewski, V. G.; Voth, G. A.; Salvador, P.; Dannenberg, J. J.; Dapprich, S.; Daniels, A. D.; Farkas, O.; Foresman, J. B.; Ortiz, J. V.;

Cioslowski, J.; Fox, D. J. Gaussian, Inc., Wallingford CT, 2013.

20. Konarev, D.V.; Khasanov, S.S.; Yudanova, E. I.; Lyubovskaya, R.N. Eur. J. Inorg. Chem., 2011, 816-820.

21. Peverati, R.; Truhlar, D. G. J. Phys. Chem. Lett. 2011, 2, 2810-2817.

22. Dunning Jr., T. H. J. Chem. Phys. 1989, 90, 1007-1023.

23. Balabanov, N. B.; Peterson, K. A. J. Chem. Phys. 2005, 123, 064107/1-15.

24. a) Peterson, K. A.; Figgen, D.; Dolg, M.; Stoll, H. J. Chem. Phys. 2007, 126, 124101/1-12; b) Peterson, K. A. J. Chem. Phys. 2003, 119, 11099-11112; c) Feller, D. J. Comp. Chem. 1996, 17, 1571-1586; d) Schuchardt, K. L.; Didier, B. T.; Elsethagen, T.; Sun, L.; Gurumoorthi, V.; 
Chase, J.; Li, J.; Windus, T. L. J. Chem. Inf. Model. 2007, 47, 1045-1052.

25. NBO Version 3.1, Glendening, E. D.; Reed, A. E.; Carpenter, J. E.; Weinhold, F. 


\section{SYNOPSIS}

The ability of $\mathrm{Sn}$ atoms to form stable $\mathrm{Sn}-\mathrm{M}$ bonds with transition metals was used to prepare transition metal $(\mathrm{M}=\mathrm{Mo}, \mathrm{Fe}, \mathrm{Rh}$, and $\mathrm{Ru})$ complexes with tin(II) phthalocyanine in neutral, radical anionic, and dianionic states. The crystal structures and optical and magnetic properties of the complexes were investigated. It was found that $\left[\mathrm{Sn}^{\mathrm{II}} \mathrm{Pc}(3-)\right]^{\bullet-}$ radical anions are potential anionic paramagnetic ligands for transition metals that may enable the preparation of magnetic assemblies.

For Table of Contents Only

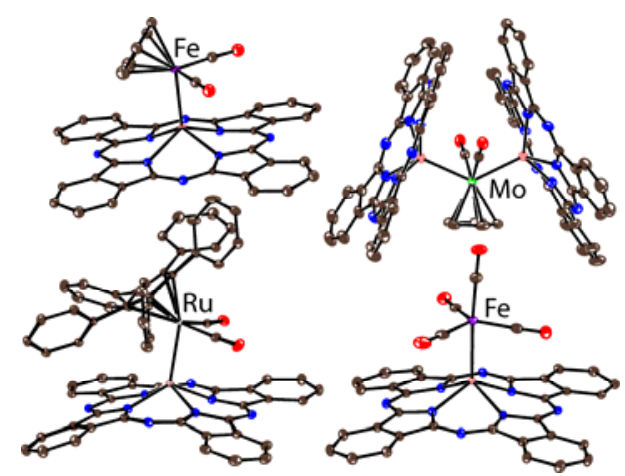




\section{Coordination complexes of transition metals $(\mathrm{M}=\mathrm{Mo}, \mathrm{Fe}, \mathrm{Rh}$ and $\mathrm{Ru})$ with} tin(II) phthalocyanine in neutral, radical anion and dianionic states

Dmitri V. Konarev, ${ }^{*}+$ Alexey V. Kuzmin, $¥$ Yoshiaki Nakano,${ }^{\S}$ Maxim A. Faraonov, $†$ Salavat S. Khasanov $¥$ Akihiro Otsuka, ${ }^{\S}$ Hideki Yamochi, ${ }^{\S}$ Gunzi Saito,,$" \rrbracket$ and Rimma N. Lyubovskaya $†$ Institute of Problems of Chemical Physics RAS, Chernogolovka, Moscow region, 142432 Russia;

‡Institute of Solid State Physics RAS, Chernogolovka, Moscow region, 142432 Russia;

${ }^{\S}$ Research Center for Low Temperature and Materials Sciences, Kyoto University, Sakyo-ku, Kyoto 606-8501, Japan;

"Faculty of Agriculture, Meijo University, 1-501 Shiogamaguchi, Tempaku-ku, Nagoya 4688502, Japan.

"Toyota Physical and Chemical Research Institute, 41-1, Yokomichi, Nagakute, Aichi 480-1192, Japan 


\section{SUPPORTING INFORMATION}

\section{General}

UV-visible-NIR spectra were obtained using $\mathrm{KBr}$ pellets on a Perkin Elmer Lambda 1050 spectrometer in the $250 \mathrm{~nm}$ to $2500 \mathrm{~nm}$ range. FT-IR spectra were obtained using $\mathrm{KBr}$ pellets with a Perkin-Elmer Spectrum 400 spectrometer $\left(400-7800 \mathrm{~cm}^{-1}\right)$. EPR spectra were recorded for sealed polycrystalline samples of $\mathbf{1 - 8}$ in the temperature range from $4 \mathrm{~K}$ to $295 \mathrm{~K}$ using a JEOL JES-TE 200 X-band ESR spectrometer equipped with a JEOL ES-CT470 cryostat. A Quantum Design MPMS-XL SQUID magnetometer was used to measure the static magnetic susceptibilities of 3-8 at a magnetic field of $100 \mathrm{mT}$ under cooling and heating conditions in the range from $300 \mathrm{~K}$ to $1.9 \mathrm{~K}$. The sample holder contribution and core temperature independent diamagnetic susceptibility $\left(\chi_{\mathrm{d}}\right)$ were subtracted from the experimental values. The $\chi_{\mathrm{d}}$ values were estimated by extrapolating the data in the high-temperature range (from $20-70 \mathrm{~K}$ up to $300 \mathrm{~K}$ ) using the following expression: $\chi_{\mathrm{M}}$ $=C /(T-\Theta)+\chi_{\mathrm{d}}$, where $C$ is the Curie constant and $\Theta$ is the Weiss temperature. Effective magnetic moments $\left(\mu_{\mathrm{eff}}\right)$ were calculated using the formula $\mu_{\mathrm{eff}}=\left(8 \cdot \chi_{\mathrm{M}} \cdot T\right)^{1 / 2}$.

\section{X-ray crystal structure determinations}

X-ray diffraction data for 1, 3-8 are listed in Tables S1 and S2. X-ray diffraction data for $\mathbf{1}$ were collected on a Bruker Smart Apex II CCD diffractometer with graphite monochromated $\mathrm{MoK}_{\alpha}$ radiation using a Japan Thermal Engineering Co. cooling system DX-CS190LD. Raw data reduction to $F^{2}$ was performed using Bruker SAINT. ${ }^{1}$ X-ray diffraction data for $\mathbf{3 - 8}$ were collected on an Oxford diffraction "Gemini-R" CCD diffractometer with graphite monochromated MoK $\mathrm{K}_{\alpha}$ radiation using an Oxford Instrument Cryojet system. Raw data reduction to $F^{2}$ was performed using CrysAlisPro, Oxford Diffraction Ltd. The structures were solved using a direct method and refined using the full-matrix least-squares method against $F^{2}$ using SHELX-2013. ${ }^{2}$ Non-hydrogen atoms 
were anisotropically refined. The positions of hydrogen atoms were included in the refinement in a riding model.

\section{Disorder}

Complex 1 contains both $\mathrm{Br}^{-}$anions and carbonyl ligands disordered between two positions. The occupancy of both positions is approximately 0.5 , which provides a composition for $\mathbf{1}$ of $\left\{\mathrm{Cp} * \mathrm{MoBr}(\mathrm{CO})_{2}\left[\mathrm{Sn}{ }^{\mathrm{II}} \mathrm{Pc}(2-)\right]\right\} \cdot 0.5 \mathrm{C}_{6} \mathrm{H}_{4} \mathrm{Cl}_{2}$. We used the following restraints: 8 DFIX to fix the length of bonds in the disordered $\mathrm{Cp}^{*} \mathrm{MoBr}(\mathrm{CO})_{2}$ groups; 4 DELU, $48 \mathrm{SIMU}$, and 48 ISOR to correct thermal ellipsoids in the same groups.

Structure 3 contains two crystallographically independent $\left[\operatorname{Sn}^{\mathrm{II}} \operatorname{Pc}(3-)\right]^{\bullet-}$ radical anions, cryptand $\left(\mathrm{Na}^{+}\right)$cations, and solvent $\mathrm{C}_{6} \mathrm{H}_{4} \mathrm{Cl}_{2}$ molecules. Among them, only one $\mathrm{C}_{6} \mathrm{H}_{4} \mathrm{Cl}_{2}$ molecule is disordered between two orientations with $0.864(8) / 0.136(8)$ occupancies. We used the following restraints: 54 SAME to fix the geometry of disordered solvent $\mathrm{C}_{6} \mathrm{H}_{4} \mathrm{Cl}_{2}$ molecule; 36 DELU, 24 SIMU, and 48 ISOR to correct thermal ellipsoids of atoms in this molecule. Refinement of the crystal structure was made using all experimental data excepting $16 \mathrm{hkl}$ reflections $\left(F(\mathrm{obs})^{2}-\right.$ $\left.F(\text { calc })^{2}\right) /$ esd $>6.0$, which were rejected using OMIT instructions.

The structure of 4 has one ordered $\left\{\mathrm{CpFe}(\mathrm{CO})_{2}\left[\mathrm{Sn}^{\mathrm{II}} \mathrm{Pc}(4-)\right]\right\}^{-}$anion, whereas the cryptand $\left(\mathrm{Na}^{+}\right)$ cation is disordered between two orientations with $0.707(4) / 0.293(4)$ occupancies. There are also three positions for the solvent $\mathrm{C}_{6} \mathrm{H}_{4} \mathrm{Cl}_{2}$ molecules with half occupancy. All of them are disordered between two orientations with $0.377(3) / 0.123(3), 0.344(3) / 0.156(3)$ and $0.275(3) / 0.225(3)$ occupancies. We used the following restraints: 270 SAME to fix geometry of disordered solvent $\mathrm{C}_{6} \mathrm{H}_{4} \mathrm{Cl}_{2}$ molecules; $387 \mathrm{DELU}$ was used for all atoms in the unit cell; $132 \mathrm{SIMU}$, and 348 ISOR to correct thermal ellipsoids of disordered cryptand $\left(\mathrm{Na}^{+}\right)$cation and solvent $\mathrm{C}_{6} \mathrm{H}_{4} \mathrm{Cl}_{2} \quad \mathrm{molecules}$ Refinement of the crystal structure was made using all experimental data excepting 12 hkl reflections $\left(F(\mathrm{obs})^{2}-F(\text { calc })^{2}\right) /$ esd $>5.0$, which were rejected using OMIT instructions. 
One of two independent cryptand $\left(\mathrm{Na}^{+}\right)$cations with 0.5 occupation is strongly disordered in 5 between three orientations with $0.267(3) / 0.156(2) / 0.077(2)$ occupancies, whereas the solvent $\mathrm{C}_{6} \mathrm{H}_{4} \mathrm{Cl}_{2}$ molecule with 0.5 occupancy is disordered between two orientations (0.39/0.11). We used the following restraints: 369 SAME to fix geometry of strongly disordered cryptand $\left(\mathrm{Na}^{+}\right)$cation; 966 SIMU, and 468 ISOR to correct thermal ellipsoids in disordered cryptand( $\left.\mathrm{Na}^{+}\right)$cation.

The cryptand $\left(\mathrm{Na}^{+}\right)$cation is disordered in 6 with $0.633(4) / 0.367(4)$ occupancies. There are four positions for the solvent $\mathrm{C}_{6} \mathrm{H}_{4} \mathrm{Cl}_{2}$ molecules in 6. In two positions with full occupancy, they are disordered between two orientations with $0.715(6) / 0.285(5)$ and $0.704(5) / 0.296(5)$ occupancies. Ordered $\mathrm{C}_{6} \mathrm{H}_{4} \mathrm{Cl}_{2}$ molecules occupy two positions with full and half occupancies. We used the following restraints: $381 \mathrm{SAME}$ to fix geometry of disordered cryptand $\left(\mathrm{Na}^{+}\right)$cation and solvent $\mathrm{C}_{6} \mathrm{H}_{4} \mathrm{Cl}_{2}$ molecules. 468 SIMU, and 180 ISOR to correct thermal ellipsoids of the $\mathrm{C}, \mathrm{N}, \mathrm{O}$ и $\mathrm{Cl}$ atoms for the disordered cryptand( $\left.\mathrm{Na}^{+}\right)$cation and solvent $\mathrm{C}_{6} \mathrm{H}_{4} \mathrm{Cl}_{2}$ molecules. 10 FLAT were used for additional correction of the geometry of the disordered $\mathrm{C}_{6} \mathrm{H}_{4} \mathrm{Cl}_{2}$ molecules.

We used the following restraints for the refinement of crystal structure of 7: 111 DELU, 144 and ISOR to correct thermal ellipsoids of the $\mathrm{C}, \mathrm{N}, \mathrm{O}$ atoms of cryptand $\left(\mathrm{Na}^{+}\right)$cation.

All components are ordered in the crystal structure of $\mathbf{8}$. No restraints are used for the refinement of this crystal structure.

\section{References.}

1. Bruker Analytical X-ray Systems, Madison, Wisconsin, U.S.A, 1999.

2. Sheldrick, G. M. Acta Cryst. Sect. C. 2015, 71, 3-8 
Table S1. Crystallographic data and some details of data collection and refinement for 1-4.

\begin{tabular}{|c|c|c|c|}
\hline Compound & $\mathbf{1}$ & $\mathbf{3}$ & $\mathbf{4}$ \\
Empirical formula & $\mathrm{C}_{47} \mathrm{H}_{33} \mathrm{BrCl} \mathrm{MoN}_{8} \mathrm{O}_{2}$ & $\mathrm{C}_{56} \mathrm{H}_{56} \mathrm{Cl}_{2} \mathrm{~N}_{10} \mathrm{NaO}_{6} \mathrm{Sn}$ & $\mathrm{C}_{66} \mathrm{H}_{63} \mathrm{Cl}_{3} \mathrm{FeN}_{10} \mathrm{NaO}_{8} \mathrm{Sn}$ \\
$\mathrm{M}_{\mathrm{r}}\left[\mathrm{g} \cdot \mathrm{mol}^{-1}\right]$ & 1071.80 & 1177.68 & 1428.14 \\
Crystal color and shape, & Black prism & Black parallelepiped & Black prism \\
Crystal system & Triclinic & Orthorhombic & Monoclinic \\
Space group & $P \overline{1}$ & $P 2_{1} 2_{1} 2_{1}$ & $P 2_{1} / \mathrm{n}$ \\
$a, \AA$ & $13.4963(2)$ & $11.3884(3)$ \\
$b, \AA$ & $12.5315(2)$ & $22.4928(2)$ & $22.9569(7)$ \\
$c, \AA$ & $13.2913(2)$ & $34.7416(5)$ & $23.6336(7)$ \\
$\alpha,{ }^{\circ}$ & $13.5195(2)$ & 90 & 90 \\
$\beta,{ }^{\circ}$ & $91.901(1)$ & 90 & $90.574(2)$ \\
$\gamma,{ }^{\circ}$ & $92.247(1)$ & 90 & 90 \\
$V, \AA^{3}$ & $112.733(1)$ & $10546.5(2)$ & $6178.5(3)$ \\
$Z$ & $2072.42(6)$ & 8 & 4 \\
$\rho_{\text {calc }}\left[\mathrm{g} / \mathrm{cm}^{3}\right]$ & 2 & 1.483 & 1.535 \\
$\mu\left[\mathrm{mm}^{-1}\right]$ & 1.718 & 0.656 & 0.842 \\
$F(000)$ & 1.985 & 4840 & 2924 \\
$T[\mathrm{~K}]$ & 1062 & $150(2)$ & $150(2)$ \\
$2 \Theta,{ }^{\circ}$ & $150(2)$ & 56.604 & 56.58 \\
Reflns measured & 58.220 & 114428 & 55582 \\
Unique reflns & 20043 & 25297 & 14627 \\
Params $/$ Restraints & 9997 & $1418 / 162$ & $1046 / 1137$ \\
Reflns $\left[F_{\mathrm{o}}>2 \sigma\left(F_{\mathrm{o}}\right)\right]$ & $607 / 108$ & 19692 & 10741 \\
$R_{1}\left[F_{\mathrm{o}}>2 \sigma\left(F_{\mathrm{o}}\right)\right] / \mathrm{w} R_{2}$ all $)^{\mathrm{a}}$ & 9055 & $0.0592 / 0.1502$ & $0.0472 / 0.1172$ \\
$\mathrm{G} . \mathrm{O} \cdot \mathrm{F}$ & $1.0343 / 0.1006$ & 1.043 & 1.021 \\
$\mathrm{CCDC}$ number & 1409661 & 1413374 & 1413375 \\
\hline
\end{tabular}

(a) $w=1 /\left[\sigma^{2}\left(\mathrm{~F}_{\mathrm{o}}^{2}\right)+(\mathrm{aP})^{2}+\mathrm{bP}\right], \mathrm{P}=\left[\mathrm{Max}\left(\mathrm{F}_{\mathrm{o}}^{2}, 0\right)+2 \mathrm{~F}_{\mathrm{c}}^{2}\right] / 3$ 
Table S2. Crystallographic data and some details of data collection and refinement for 5-8.

\begin{tabular}{|c|c|c|c|c|}
\hline $\begin{array}{c}\text { Compound } \\
\text { Empirical formula }\end{array}$ & $\begin{array}{c}\quad \mathbf{5} \\
\mathrm{C}_{168} \mathrm{H}_{160} \mathrm{Cl}_{2} \mathrm{Fe}_{3} \\
\mathrm{~N}_{30} \mathrm{Na}_{3} \mathrm{O}_{30} \mathrm{Sn}_{3}\end{array}$ & $\begin{array}{c}\mathbf{6} \\
\mathrm{C}_{110} \mathrm{H}_{87} \mathrm{Cl}_{7} \mathrm{Mo} \\
\mathrm{N}_{18} \mathrm{NaO}_{8} \mathrm{Sn} 2\end{array}$ & $\begin{array}{c}7 \\
\mathrm{C}_{66} \mathrm{H}_{71} \mathrm{Cl}_{4} \mathrm{~N}_{10} \mathrm{Na} \\
\mathrm{O}_{6} \mathrm{RhSn}\end{array}$ & $\begin{array}{c}\mathbf{8} \\
\mathrm{C}_{69} \mathrm{H}_{41} \mathrm{~N}_{8} \mathrm{O}_{2} \mathrm{RuSn}\end{array}$ \\
\hline $\mathrm{M}_{\mathrm{r}}\left[\mathrm{g} \cdot \mathrm{mol}^{-1}\right]$ & 3742.81 & 2393.43 & 1486.71 & 1233.86 \\
\hline Crystal color and shape, & Black block & Black block & Black plate & Black block \\
\hline Crystal system & Monoclinic & $\underset{P}{\operatorname{1}}$ Triclinic & Monoclinic & Triclinic \\
\hline $\begin{array}{c}\text { Space group } \\
a, \AA\end{array}$ & $\begin{array}{c}P 2_{1} / \mathrm{m} \\
13.3558(3)\end{array}$ & $\begin{array}{c}P 1 \\
17.0023(4)\end{array}$ & $\begin{array}{c}P 2_{1} \\
13.0896(1)\end{array}$ & $\begin{array}{c}P 1 \\
11.9653(4)\end{array}$ \\
\hline$b, \AA$ & $37.2399(6)$ & $17.4314(5)$ & $26.0217(3)$ & $12.4086(5)$ \\
\hline$c, \AA$ & $16.3799(3)$ & $17.7859(3)$ & $18.9023(2)$ & $19.4571(6)$ \\
\hline$\alpha,{ }^{\circ}$ & 90 & $85.695(2)$ & 90 & $75.005(3)$ \\
\hline$\beta,^{\circ}$ & $98.649(2)$ & $88.189(2)$ & $95.741(1)$ & $72.626(3)$ \\
\hline$\gamma,^{\circ}$ & 90 & $77.512(2)$ & 90 & $73.457(3)$ \\
\hline$V, \AA^{3}$ & $8054.2(3)$ & $5131.4(2)$ & $6406.09(11)$ & $2594.84(17)$ \\
\hline Z & 2 & 2 & 4 & 2 \\
\hline$\rho_{\text {calc }}\left[\mathrm{g} / \mathrm{cm}^{3}\right]$ & 1.543 & 1.549 & 1.542 & 1.579 \\
\hline$\mu\left[\mathrm{mm}^{-1}\right]$ & 0.847 & 0.858 & 0.882 & 0.832 \\
\hline$F(000)$ & 3826 & 2418 & 3036 & 1242 \\
\hline$T[\mathrm{~K}]$ & $150(2)$ & $150(2)$ & $180(2)$ & $150(2)$ \\
\hline $2 \Theta{ }^{\circ}$ & 58.062 & 58.096 & 58.742 & 58.206 \\
\hline Reflns measured & 65899 & 44402 & 57412 & 22242 \\
\hline Unique reflns & 19416 & 23517 & 28726 & 11953 \\
\hline Params/Restraints & $1526 / 1804$ & $1589 / 1039$ & $1579 / 256$ & $730 / 0$ \\
\hline Reflns $\left[F_{\mathrm{o}}>2 \sigma\left(F_{\mathrm{o}}\right)\right]$ & 14365 & 14971 & 23680 & 10019 \\
\hline$R_{1}\left[F_{\mathrm{o}}>2 \sigma\left(F_{\mathrm{o}}\right)\right] / \mathrm{w} R_{2}$ all $)^{\mathrm{a}}$ & $0.0587 / 0.1322$ & $0.0623 / 0.1779$ & $0.0477 / 0.0964$ & $0.0312 / 0.0775$ \\
\hline G.O.F & 1.000 & 1.028 & 1.031 & 1.057 \\
\hline $\mathrm{CCDC}$ number & 1409659 & 1409663 & 1409651 & 1409662 \\
\hline
\end{tabular}

(a) $w=1 /\left[\sigma^{2}\left(\mathrm{~F}_{\mathrm{o}}^{2}\right)+(\mathrm{aP})^{2}+\mathrm{bP}\right], \mathrm{P}=\left[\operatorname{Max}\left(\mathrm{F}_{\mathrm{o}}^{2}, 0\right)+2 \mathrm{~F}_{\mathrm{c}}{ }^{2}\right] / 3$ 
Table S3. IR spectra of starting compounds, salt $\mathbf{3}$ and coordination complex $\mathbf{1}$.

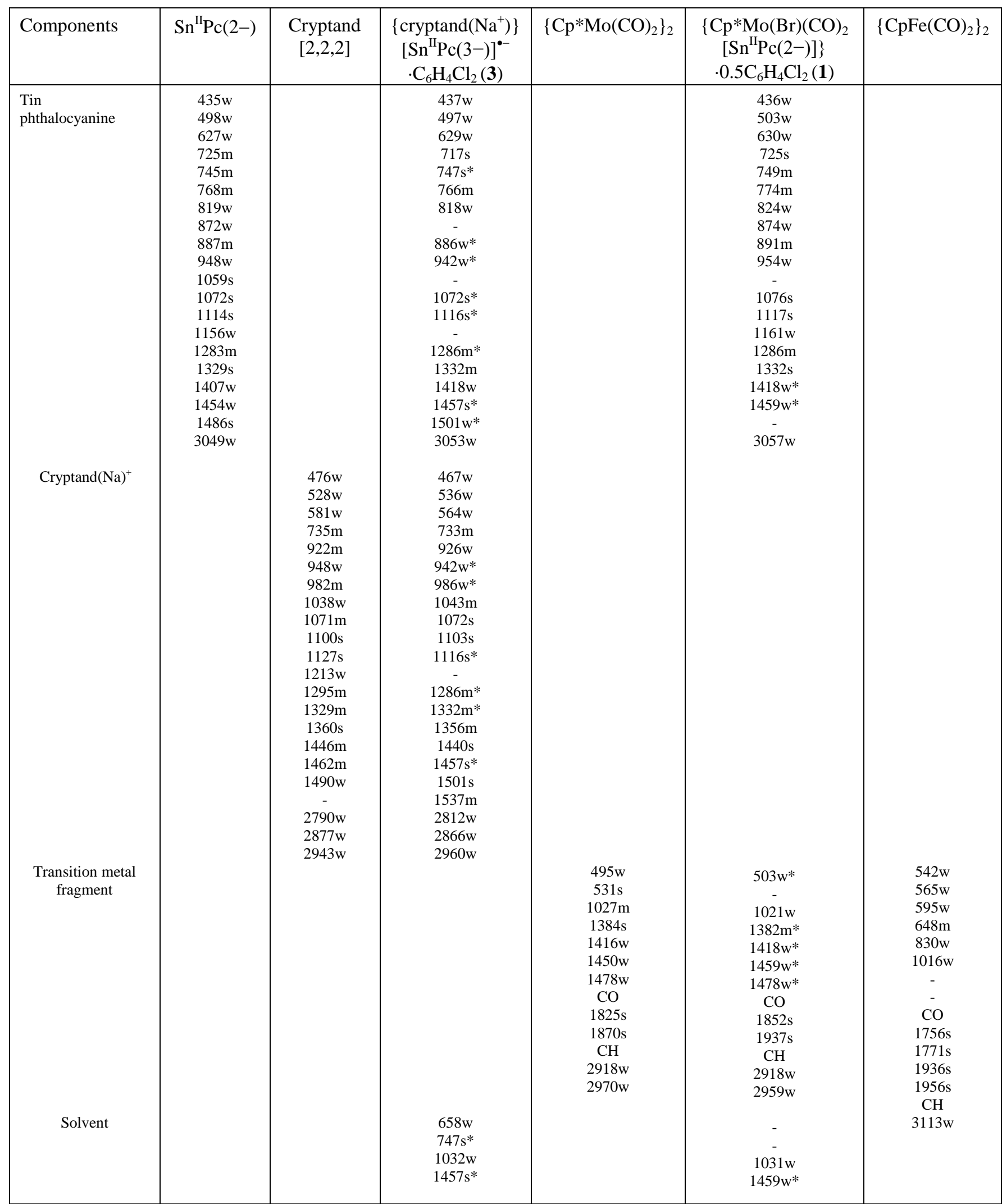

* - bands are coincided; $\mathrm{w}$ - weak intensity, $\mathrm{m}$-middle intensity, $\mathrm{s}$ - strong intensity 
Table S4. IR spectra of starting compounds and coordination complexes 3-6.

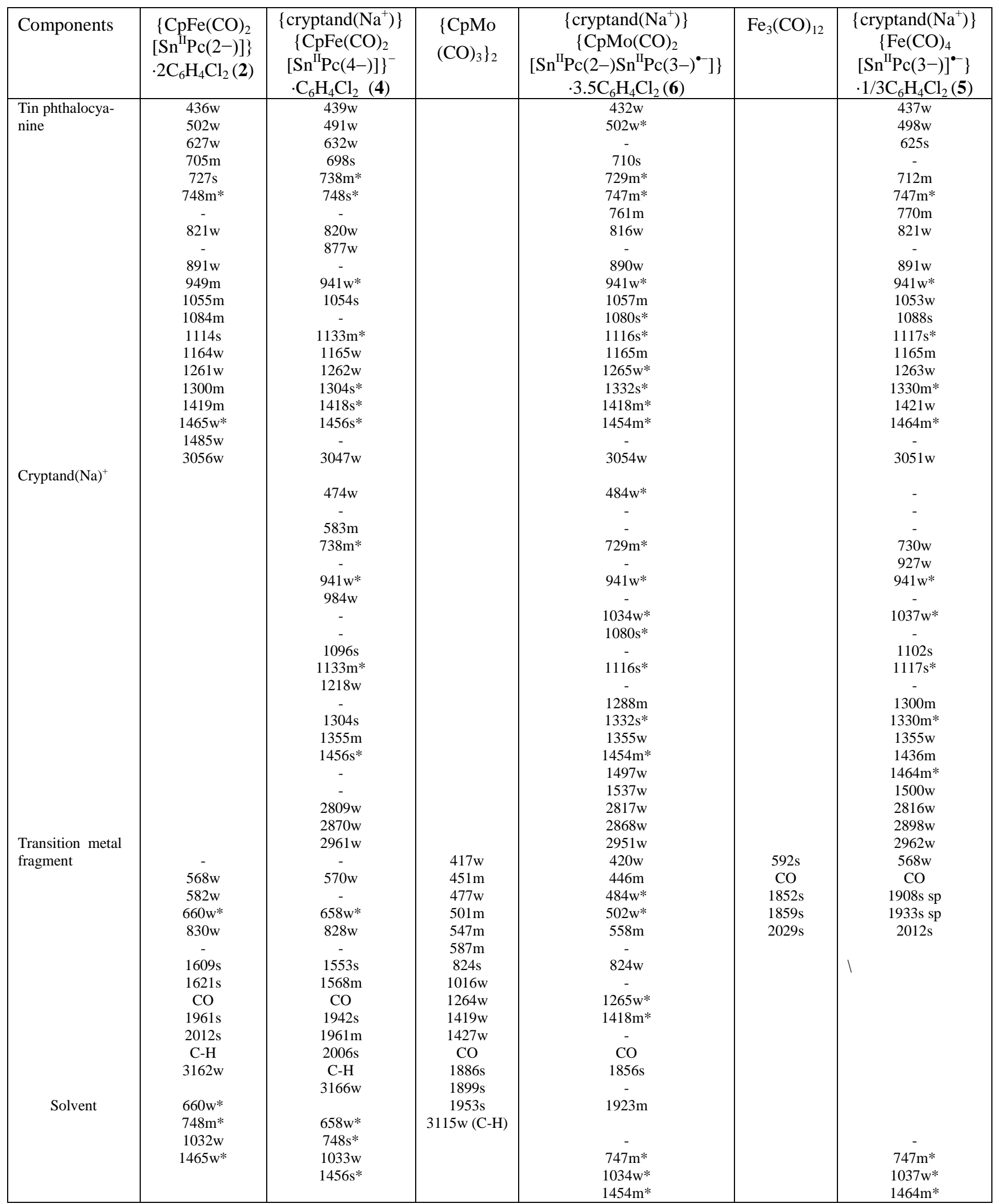

\footnotetext{
* - bands are coincided; sp - split band, w - weak intensity, $\mathrm{m}$-middle intensity, s - strong intensity
} 
Table S5. IR spectra of starting compounds and coordination complexes $\mathbf{7}$ and $\mathbf{8}$.

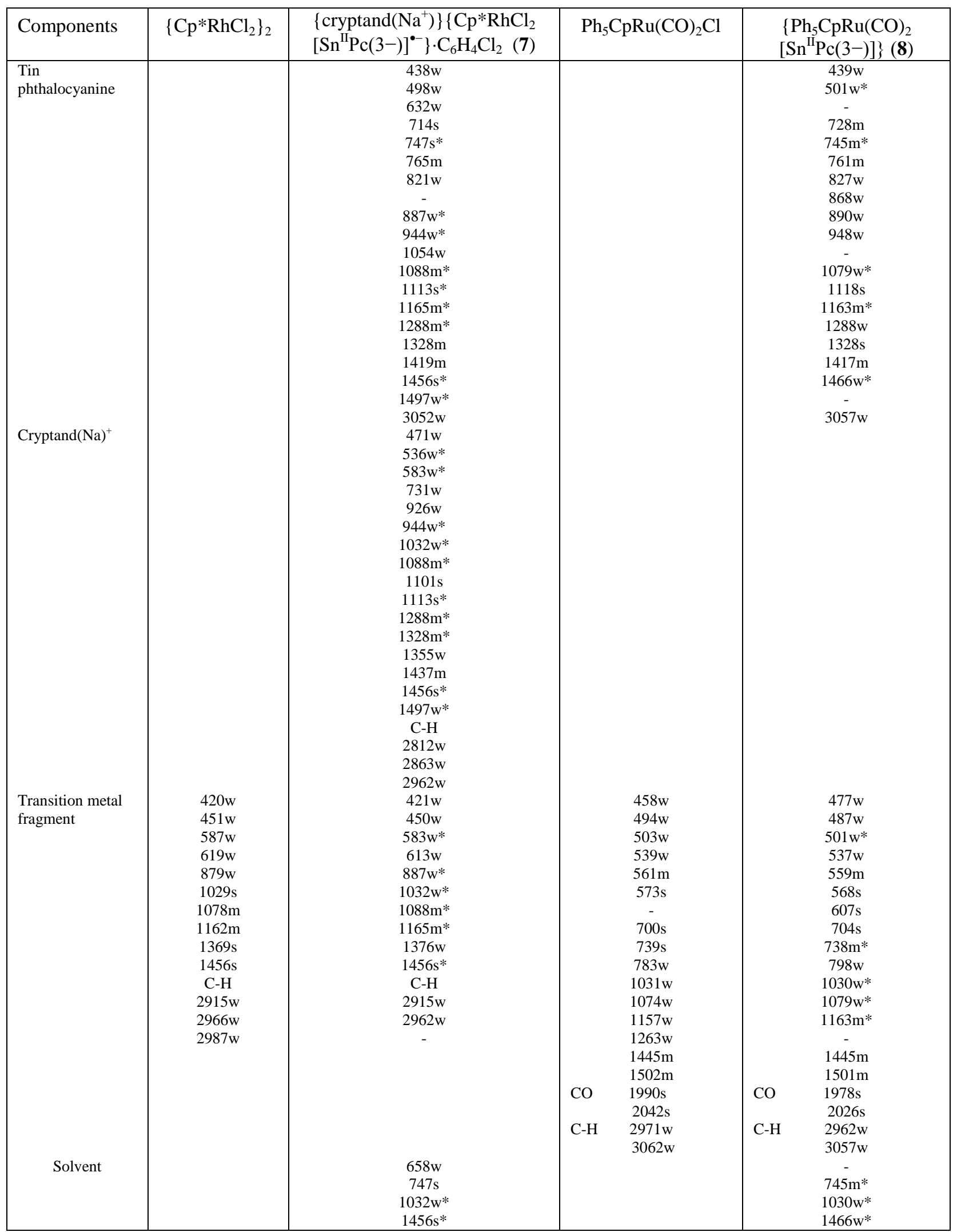

\footnotetext{
* - bands are coincided, $\mathrm{w}$ - weak, $\mathrm{m}$-middle, $\mathrm{s}$ - strong intensity
} 
IR spectra of starting metal phthalocyanines and their anion-radical salts.

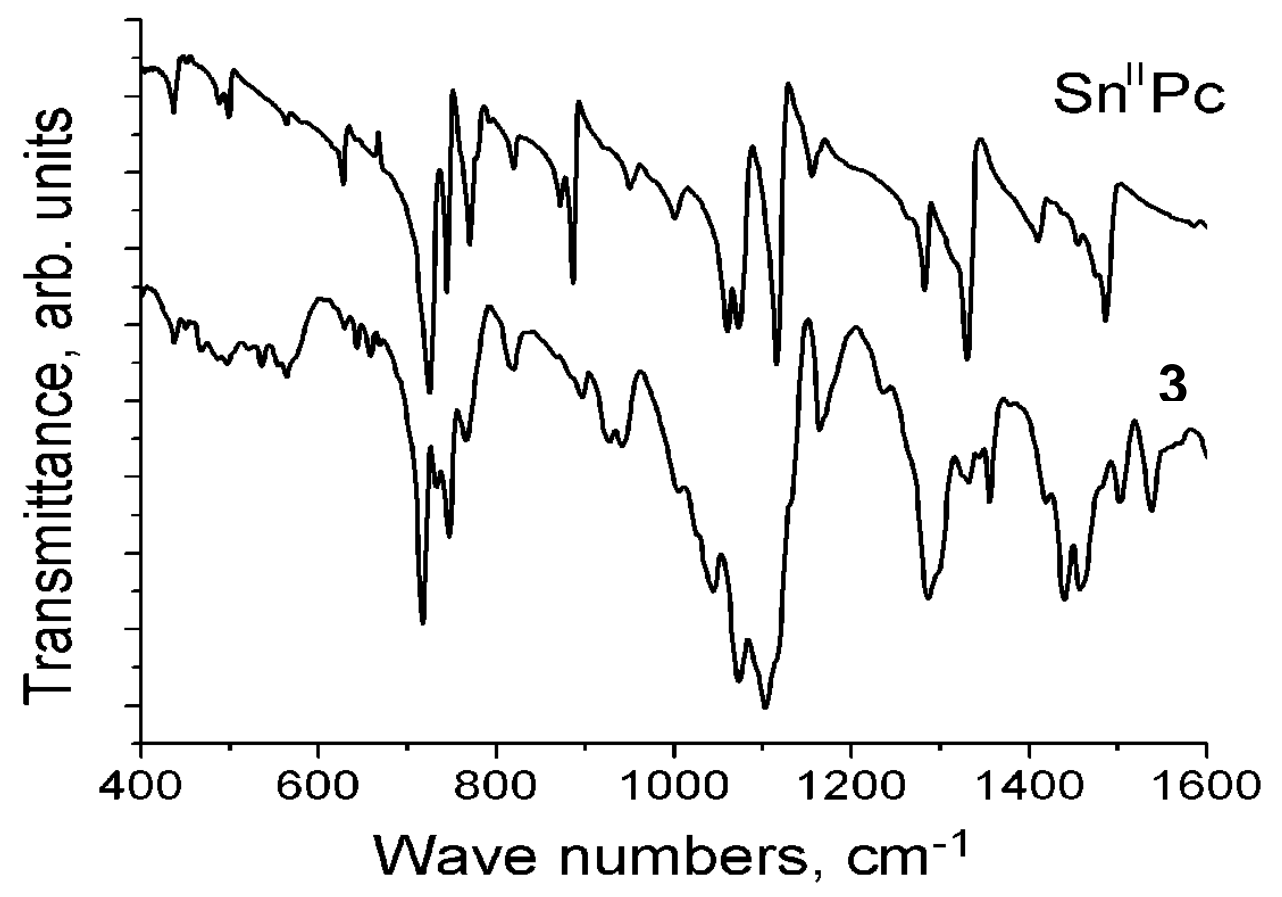

Figure S1. IR spectra of starting neutral tin(II) phthalocyanine $\left[\mathrm{Sn}^{\mathrm{II}} \mathrm{Pc}(2-)\right]^{0}$ and salt $\left\{\operatorname{cryptand}\left(\mathrm{Na}^{+}\right)\right\}\left[\mathrm{Sn}^{\mathrm{II}} \mathrm{Pc}\left(3^{-}\right)\right]^{\bullet-} \cdot \mathrm{C}_{6} \mathrm{H}_{4} \mathrm{Cl}_{2}(3)$ in $\mathrm{KBr}$ pellet prepared in anaerobic condition.

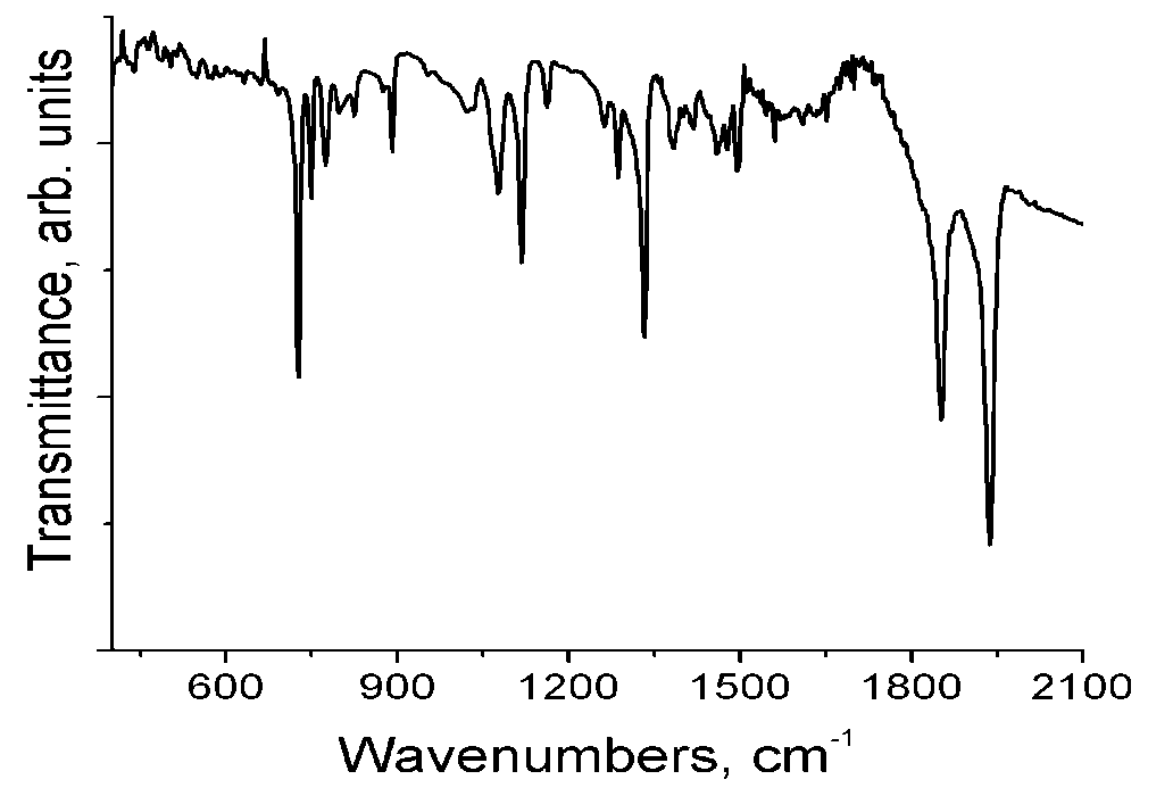

Figure S2. IR spectrum of neutral coordination complex $\left\{\mathrm{Cp} * \mathrm{Mo}(\mathrm{Br})(\mathrm{CO})_{2}\right.$ $\left.\left[\mathrm{Sn}^{\mathrm{II}} \mathrm{Pc}(2-)\right]\right\} \cdot 0.5 \mathrm{C}_{6} \mathrm{H}_{4} \mathrm{Cl}_{2}(\mathbf{1})$ in $\mathrm{KBr}$ pellet prepared in anaerobic condition. 


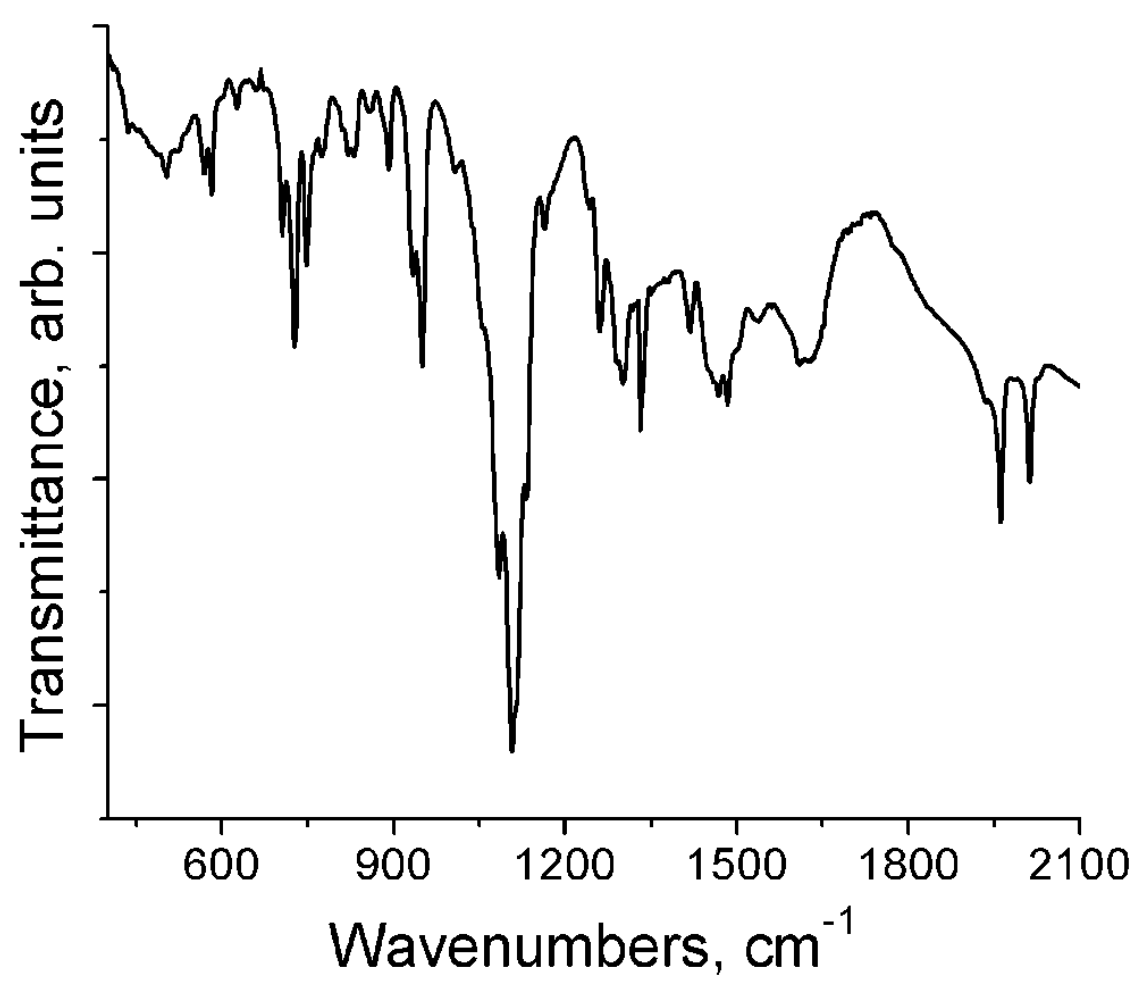

Figure S3. IR spectrum of neutral coordination complex $\left\{\mathrm{CpFe}(\mathrm{CO})_{2}\left[\mathrm{Sn}{ }^{\mathrm{II}} \mathrm{Pc}(2-)\right]\right\} \cdot 2 \mathrm{C}_{6} \mathrm{H}_{4} \mathrm{Cl}_{2}(2)$ in $\mathrm{KBr}$ pellet prepared in anaerobic condition.

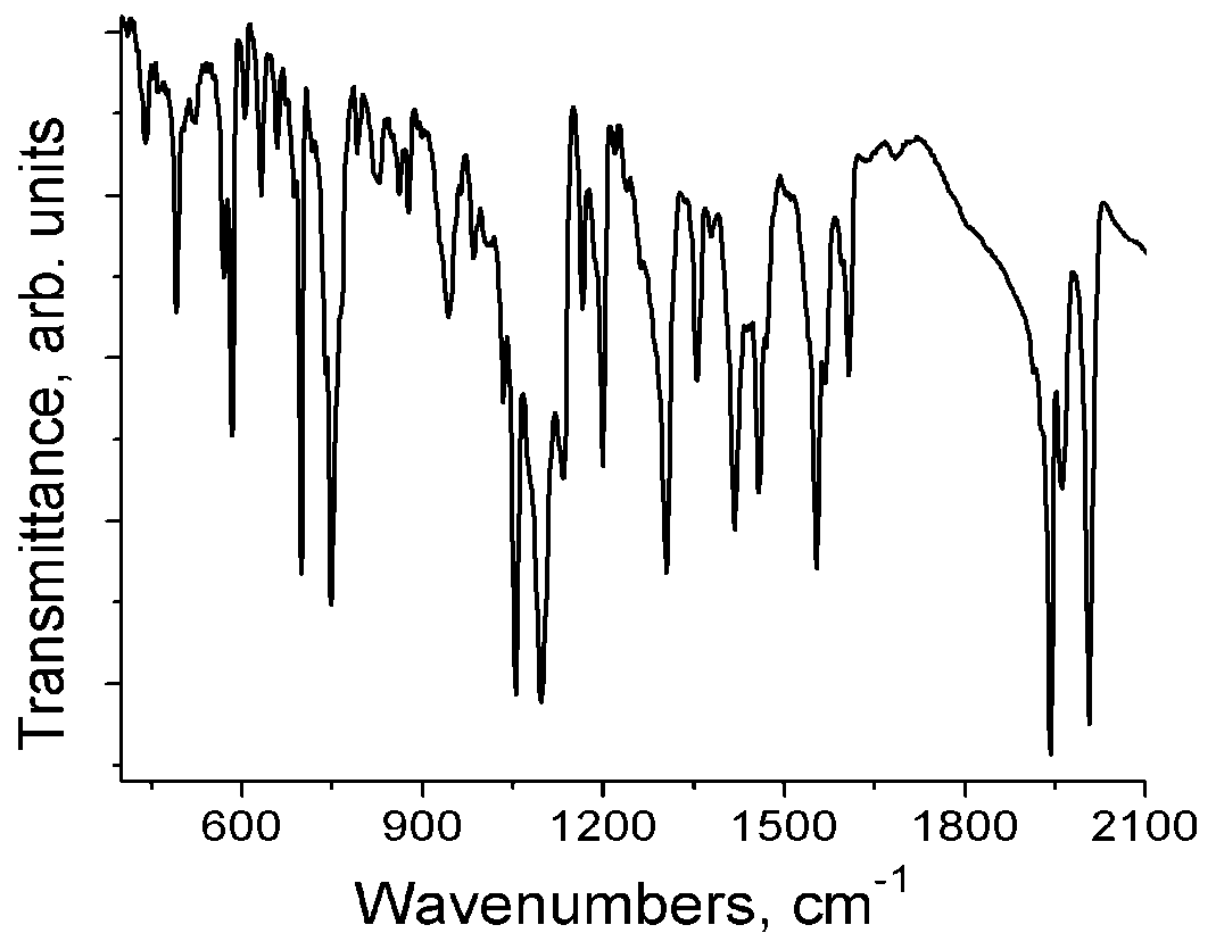

Figure S4. IR spectrum of $\left\{\operatorname{cryptand}\left(\mathrm{Na}^{+}\right)\right\}\left\{\mathrm{CpFe}(\mathrm{CO})_{2}\left[\mathrm{Sn}{ }^{\mathrm{II}} \mathrm{Pc}(4-)\right]\right\}^{-} \cdot \mathrm{C}_{6} \mathrm{H}_{4} \mathrm{Cl}_{2}$ (4) in $\mathrm{KBr}$ pellet prepared in anaerobic condition. 


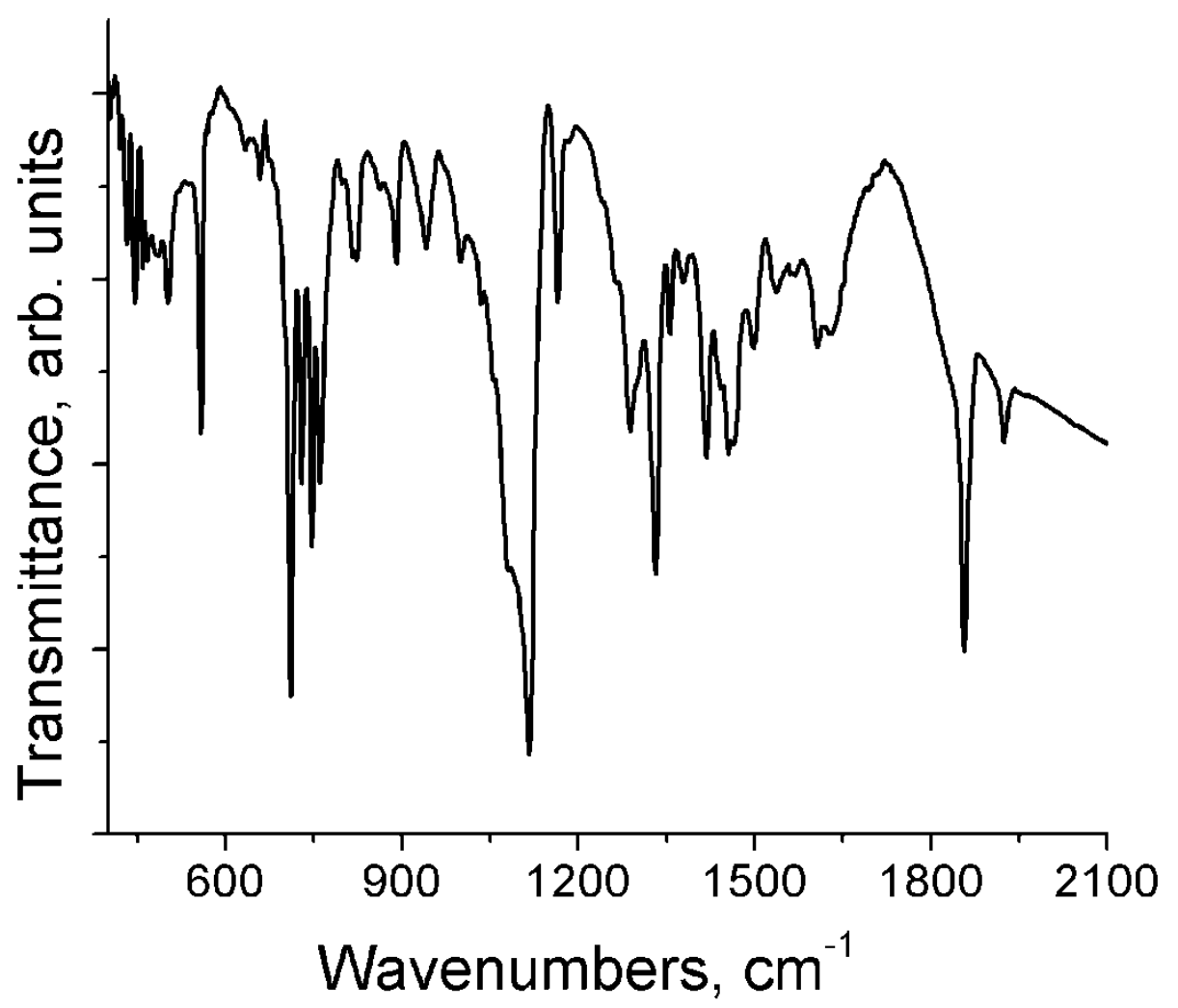

Figure S5. IR spectrum of $\left\{\operatorname{cryptand}\left(\mathrm{Na}^{+}\right)\right\}\left\{\mathrm{CpMo}(\mathrm{CO})_{2}\left[\mathrm{Sn}^{\mathrm{II}} \mathrm{Pc}(2-) \mathrm{Sn}^{\mathrm{II}} \mathrm{Pc}(3-)^{\bullet-}\right]\right\} \cdot 3.5 \mathrm{C}_{6} \mathrm{H}_{4} \mathrm{Cl}_{2}$ (6) in $\mathrm{KBr}$ pellet prepared in anaerobic condition.

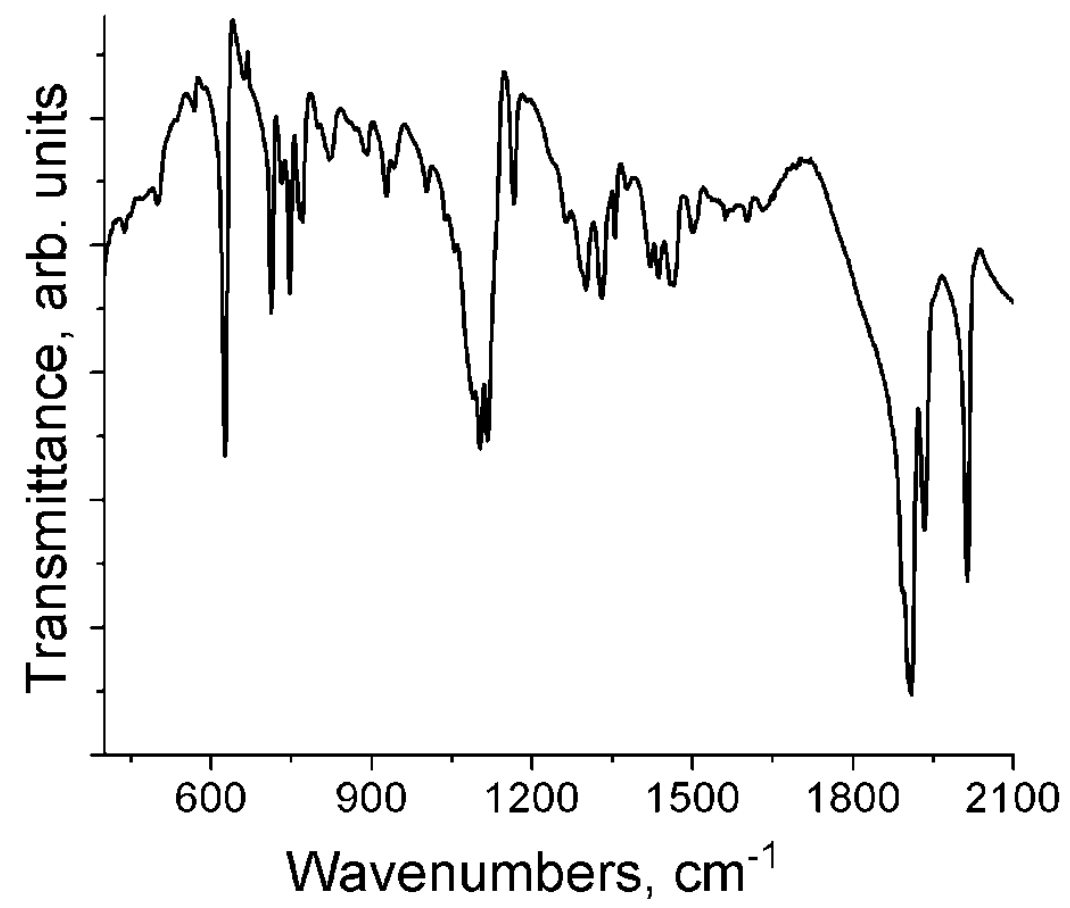

Figure S6. IR spectrum of $\left\{\right.$ cryptand $\left.\left(\mathrm{Na}^{+}\right)\right\}\left\{\mathrm{Fe}(\mathrm{CO})_{4}\left[\mathrm{Sn}{ }^{\mathrm{II}} \mathrm{Pc}\left(3^{-}\right)\right]^{\bullet-}\right\} \cdot 1 / 3 \mathrm{C}_{6} \mathrm{H}_{4} \mathrm{Cl}_{2}(\mathbf{5})$ in $\mathrm{KBr}$ pellet prepared in anaerobic condition. 


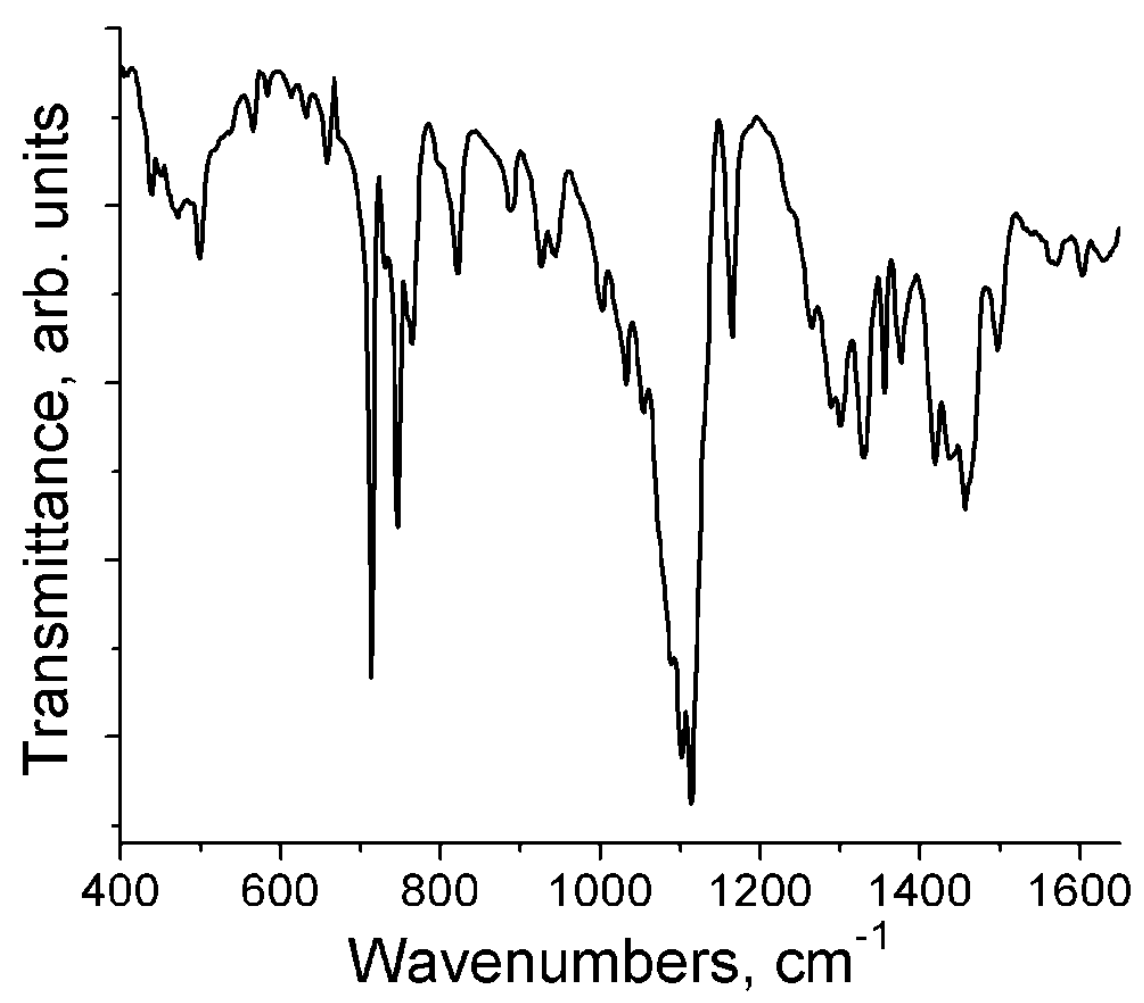

Figure S7. IR spectrum of anionic coordination complex $\left\{\right.$ cryptand $\left.\left(\mathrm{Na}^{+}\right)\right\}\left\{\mathrm{Cp}^{*} \mathrm{RhCl}_{2}\right.$ $\left.\left[\mathrm{Sn}{ }^{\mathrm{II}} \mathrm{Pc}\left(3^{-}\right)\right]^{\bullet-}\right\} \cdot \mathrm{C}_{6} \mathrm{H}_{4} \mathrm{Cl}_{2}$ (7) in $\mathrm{KBr}$ pellet prepared in anaerobic condition.

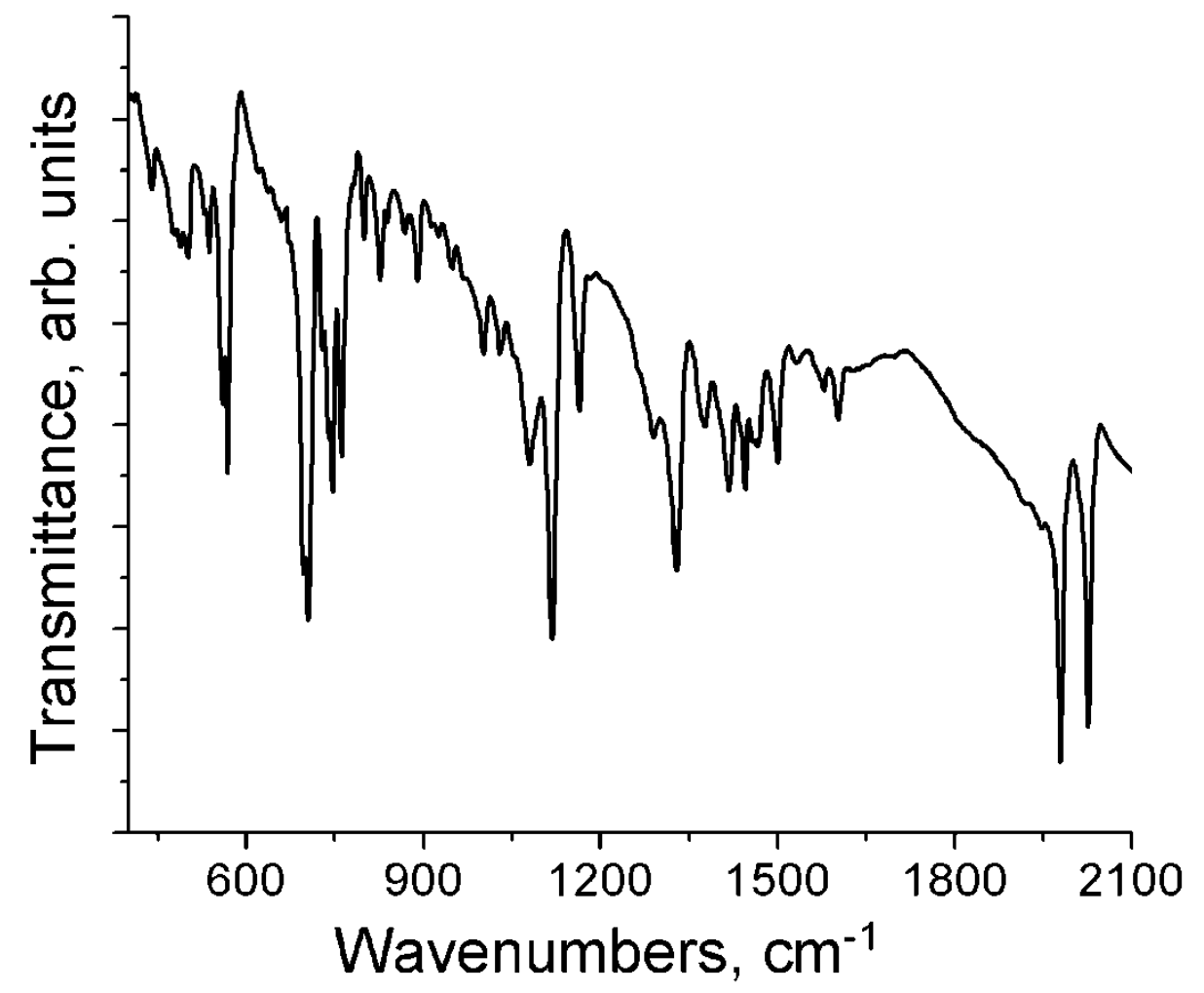

Figure S8. IR spectrum of $\left\{\mathrm{Ph}_{5} \mathrm{CpRu}{ }^{\mathrm{II}}(\mathrm{CO})_{2}\left[\mathrm{Sn}^{\mathrm{II}} \mathrm{Pc}\left(3^{-}\right)\right]\right\}(\mathbf{8})$ in $\mathrm{KBr}$ pellet prepared in anaerobic ${ }^{13}$ condition. 


\section{Crystal structures of the salts.}

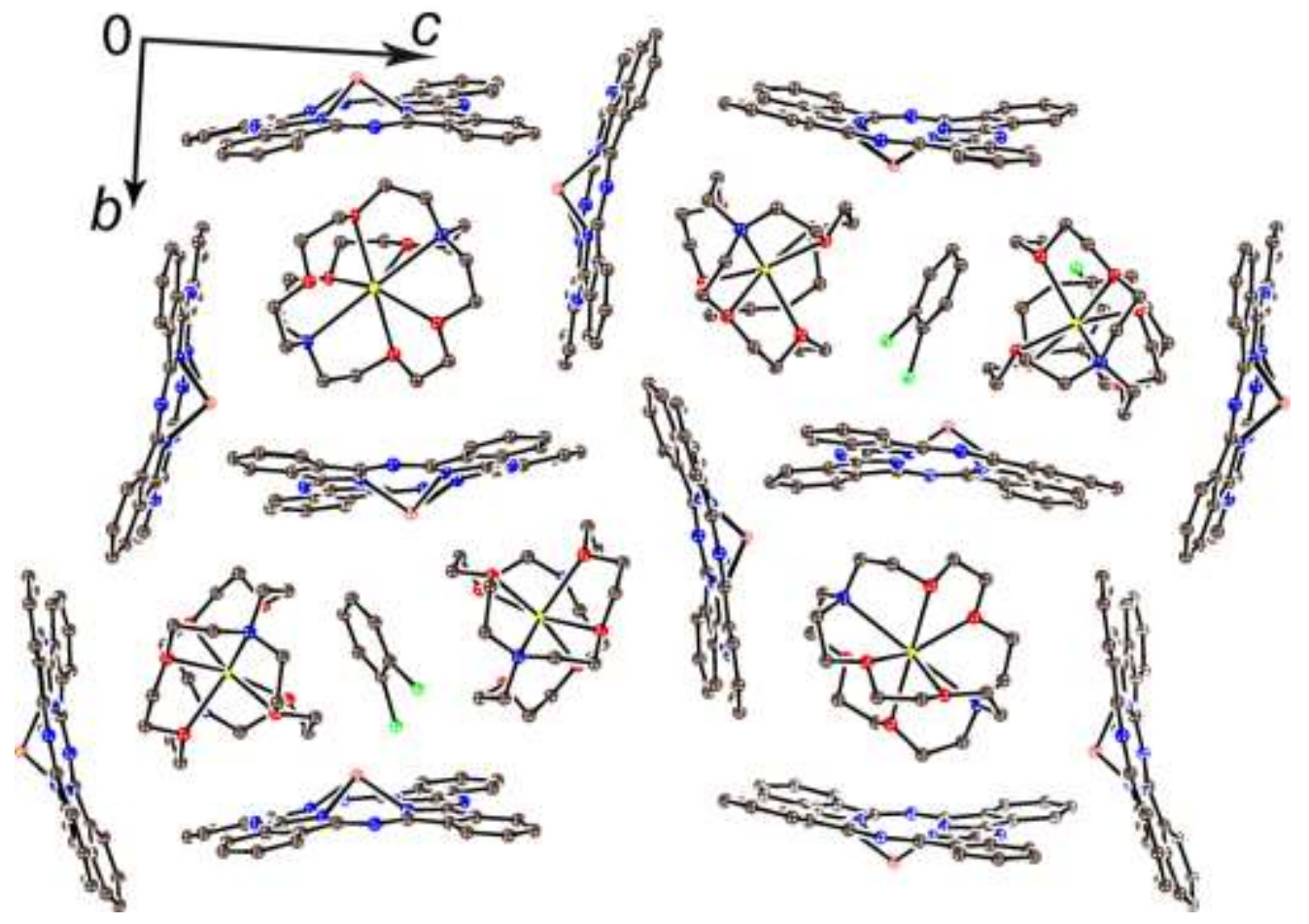

Figure S9. View along the $a$-axis on two types of channels formed by the $\left[\operatorname{Sn}^{\mathrm{II}} \mathrm{Pc}(3-)\right]^{{ }^{--}}$planes in $\left\{\right.$ cryptand $\left.\left(\mathrm{Na}^{+}\right)\right\}\left[\mathrm{Sn}^{\mathrm{II}} \mathrm{Pc}\left(3^{-}\right)\right]^{\bullet-} \cdot \mathrm{C}_{6} \mathrm{H}_{4} \mathrm{Cl}_{2}$ (3). The two type of channels occupied by the cryptand $\left(\mathrm{Na}^{+}\right)$cations or by the cryptand $\left(\mathrm{Na}^{+}\right)$cations and solvent $\mathrm{C}_{6} \mathrm{H}_{4} \mathrm{Cl}_{2}$ molecules.

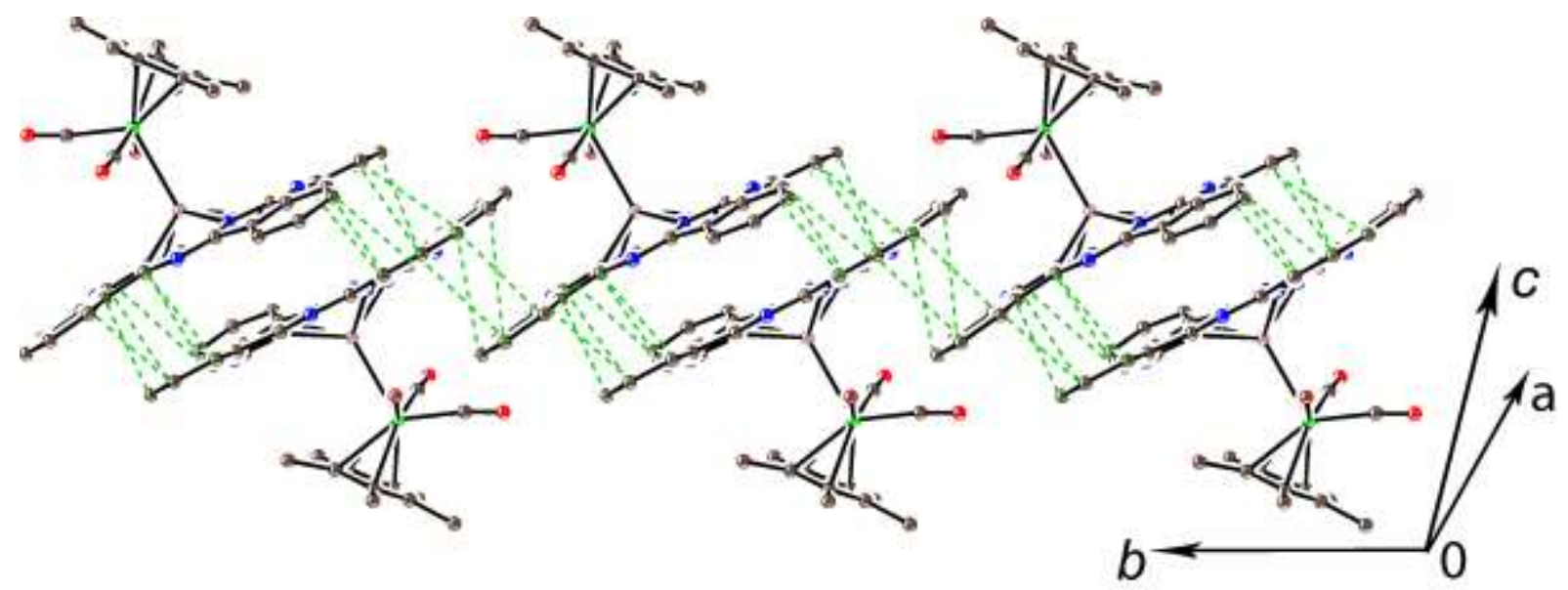

Figure S10. Crystal structure of $\mathrm{Cp} * \mathrm{Mo}(\mathrm{Br})(\mathrm{CO})_{2}\left[\mathrm{Sn}^{\mathrm{II}} \mathrm{Pc}(2-)\right] \cdot 0.5 \mathrm{C}_{6} \mathrm{H}_{4} \mathrm{Cl}_{2}$ (1), view on the chain from the $\pi$-stacking dimers formed by two coordination units. Van der Waals C,N...C,N contacts between Pc planes are shown by green dashed lines. 


\section{Data of magnetic measurement by SQUID and EPR .}

\section{$\left\{\right.$ Cryptand $\left.\left(\mathrm{Na}^{+}\right)\right\}\left[\mathrm{Sn}^{\mathrm{II}} \mathrm{Pc}\left(3^{-}\right)\right]^{\bullet-} \cdot \mathrm{C}_{6} \mathrm{H}_{4} \mathrm{Cl}_{2}(3)$}
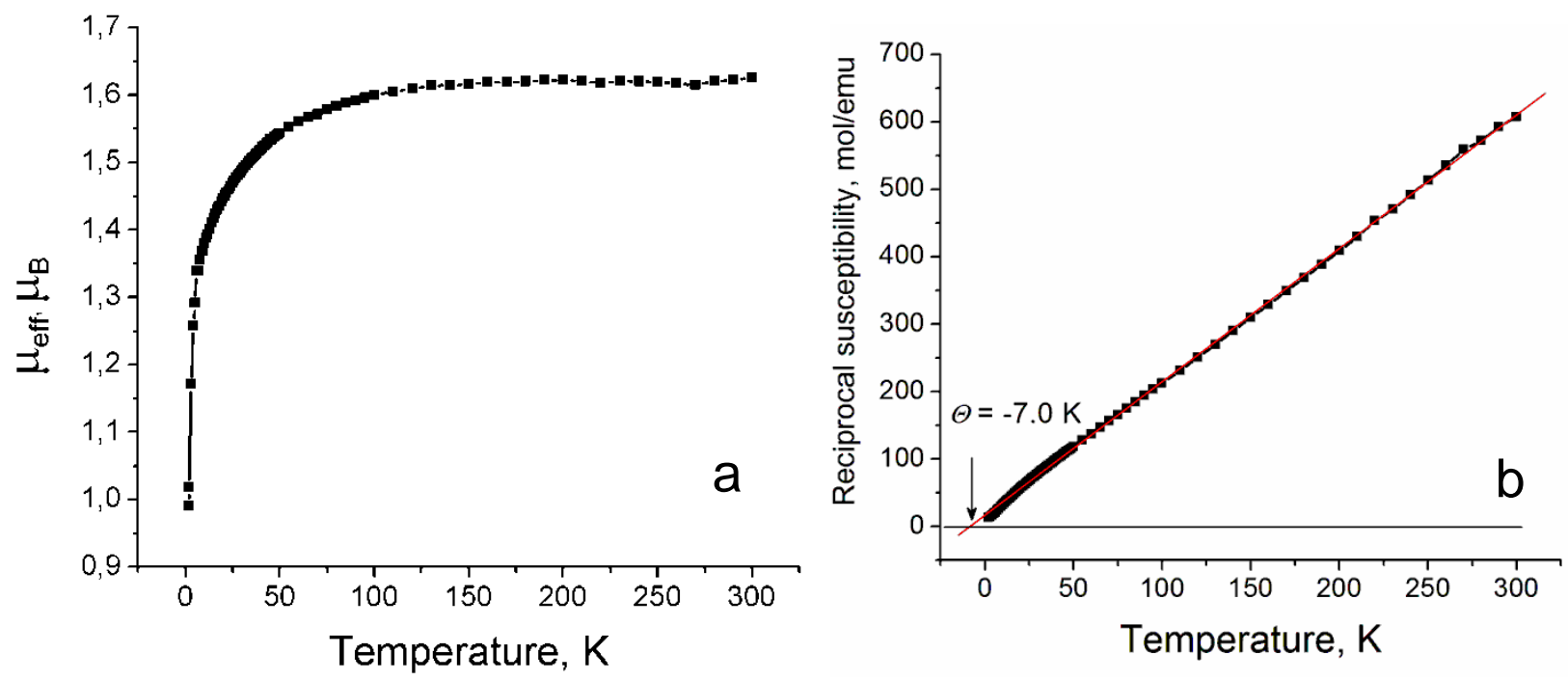

Figure S11. Temperature dependence of effective magnetic moment (a) and reciprocal molar magnetic susceptibility (b) for polycrystalline salt $\mathbf{3}$.
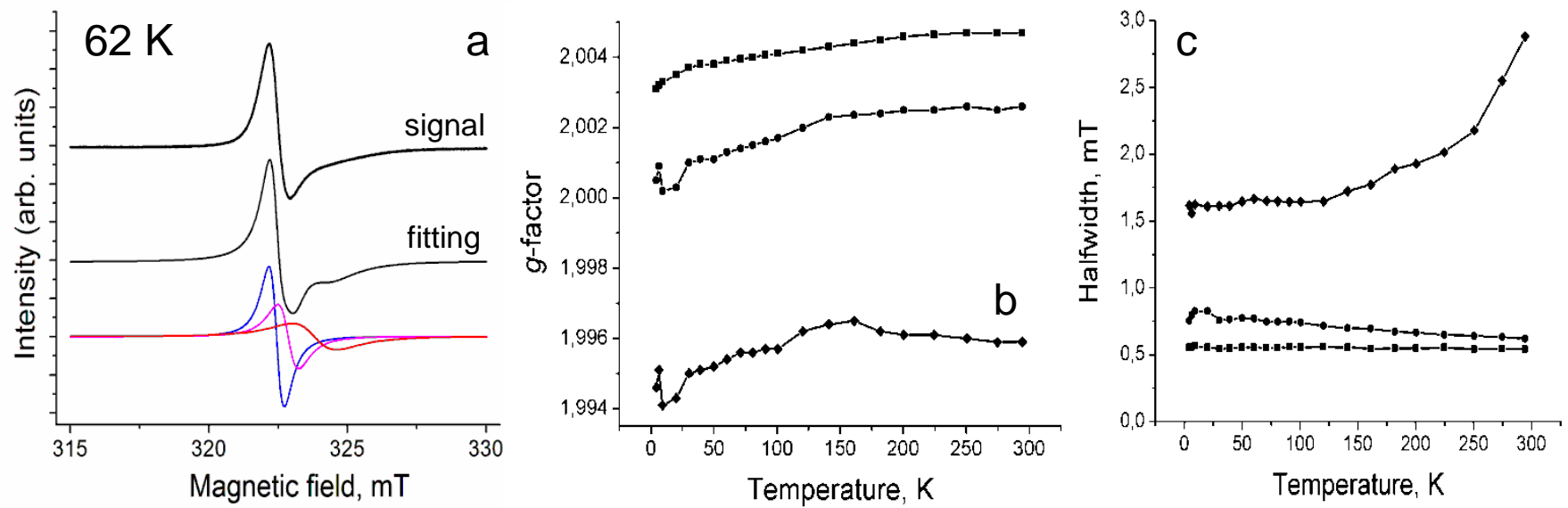

Figure S12. (a) EPR spectrum of polycrystalline 3 at $62 \mathrm{~K}$. The fitting of the signal by three Lorentzian lines is shown below. Temperature dependencies of three components of EPR signal in 3: $g$-factor (b) and linewidth (c). 


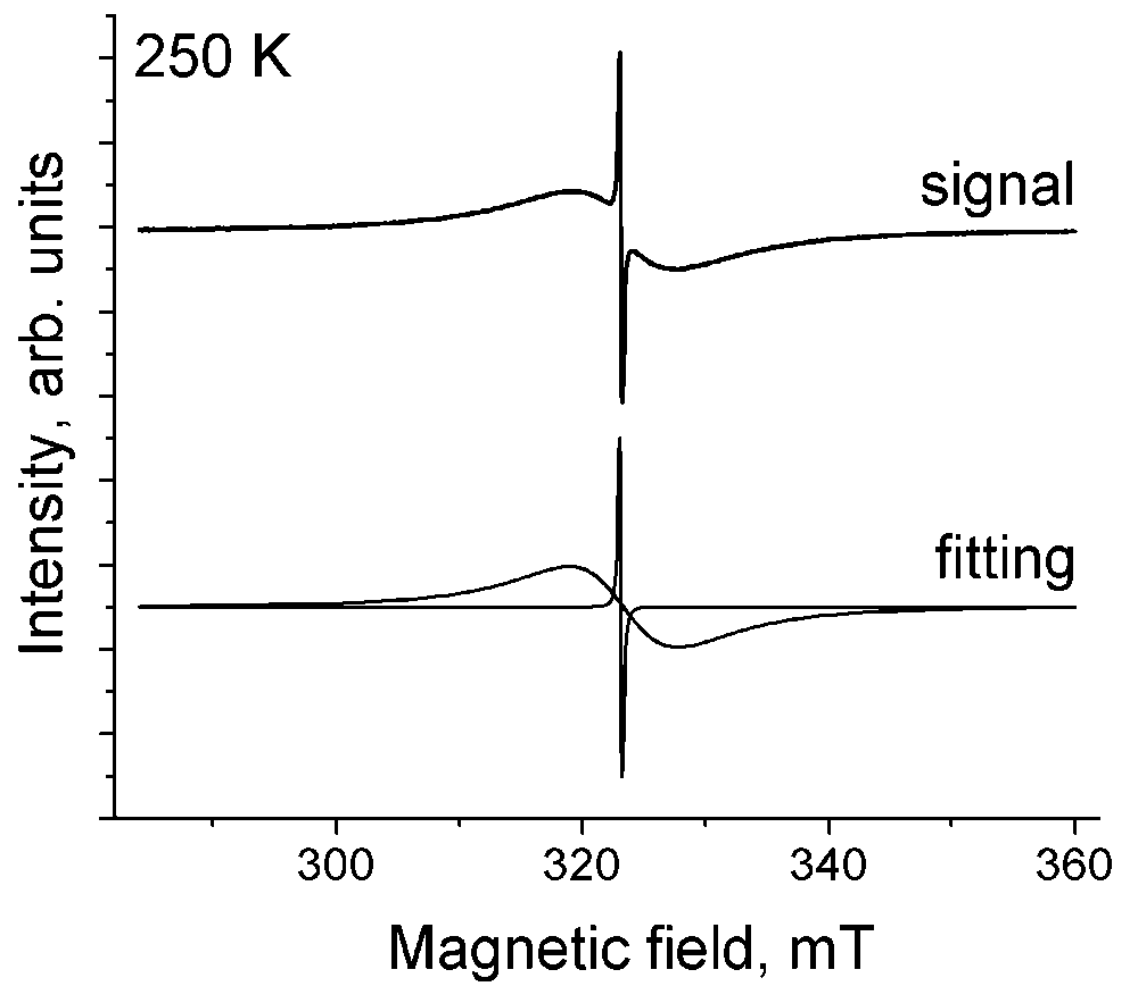

Figure S13. EPR signal from polycrystalline 1 at $250 \mathrm{~K}$.

\section{$\left\{\right.$ Cryptand $\left.\left(\mathrm{Na}^{+}\right)\right\}\left\{\mathrm{CpFe}(\mathrm{CO})_{2}\left[\mathrm{Sn}{ }^{\mathrm{II}} \mathrm{Pc}(4-)\right]\right\}^{-} \cdot \mathrm{C}_{6} \mathrm{H}_{4} \mathrm{Cl}_{2}$ (4)}
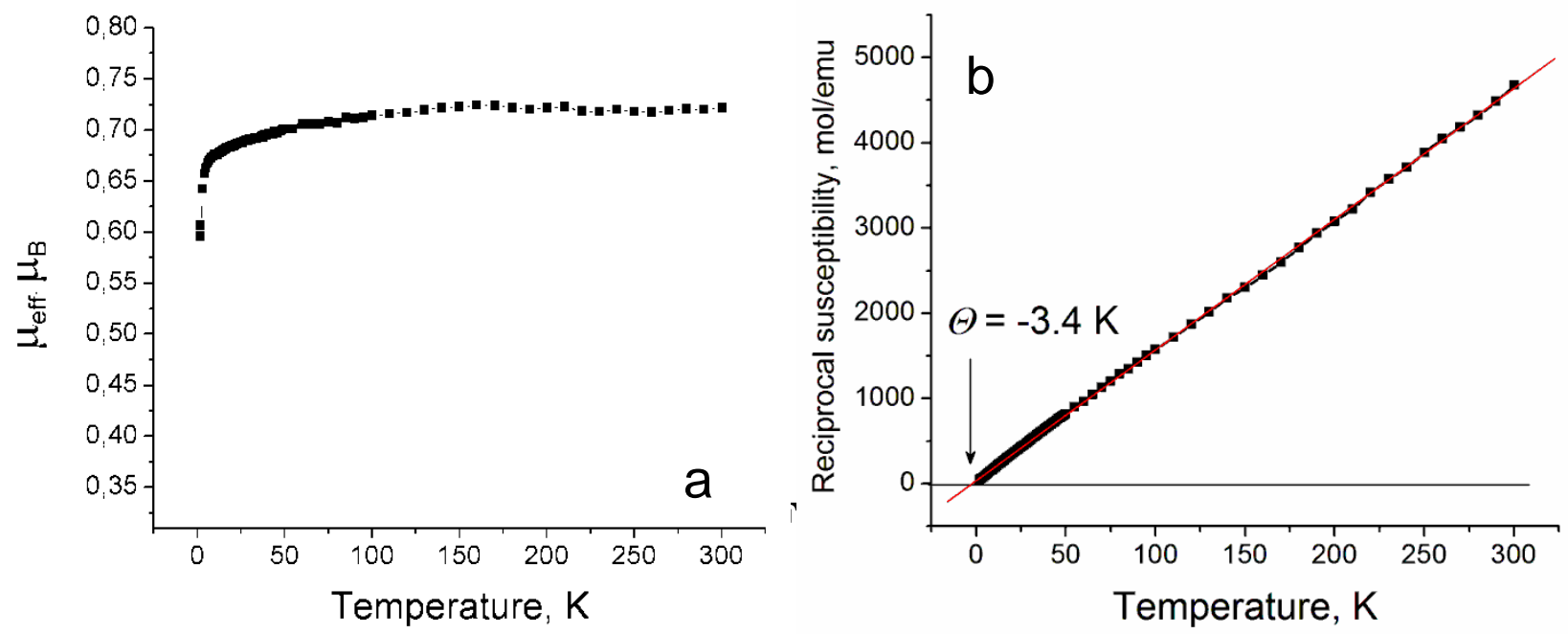

Figure S14. Temperature dependence of effective magnetic moment (a) and reciprocal molar magnetic susceptibility (b) for polycrystalline salt 4 . 


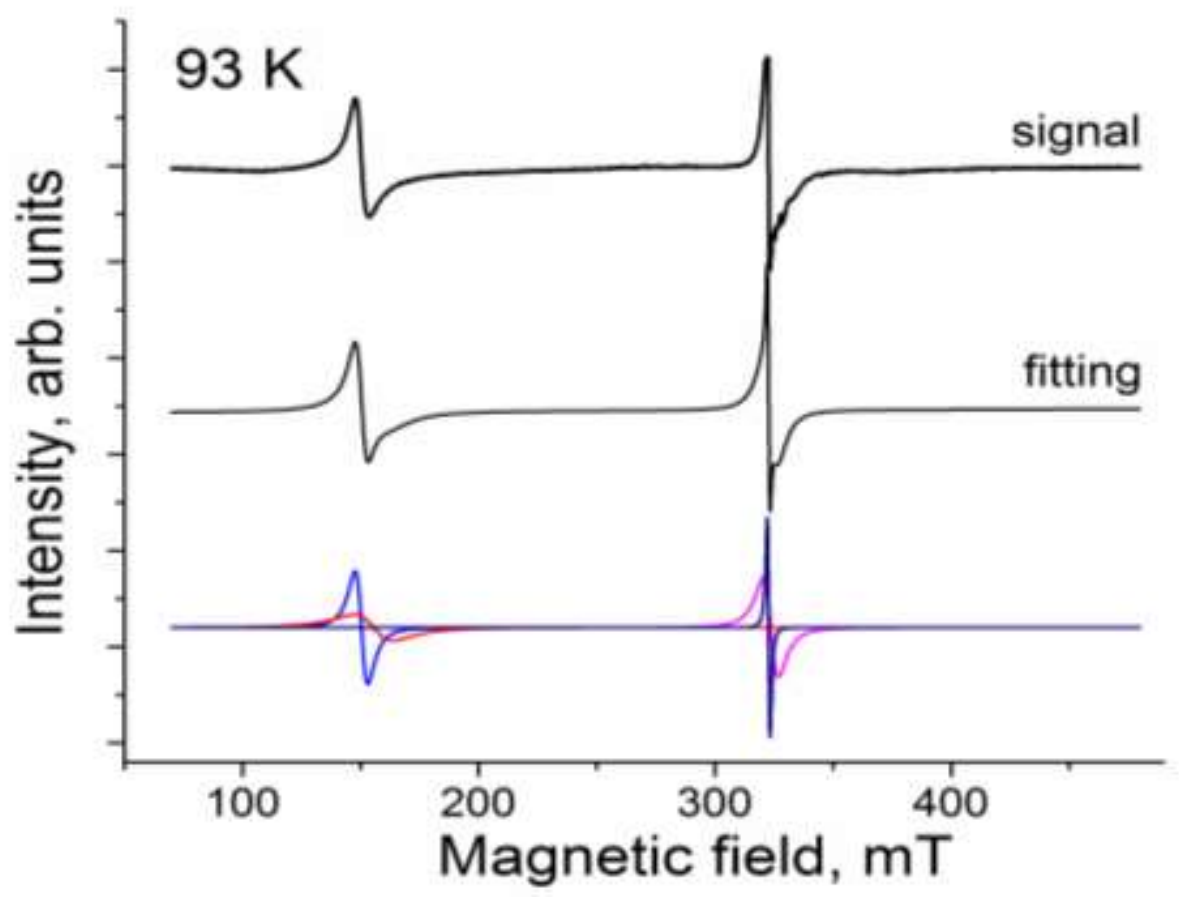

Figure S15. Weak EPR signal observed polycrystalline 4 at $93 \mathrm{~K}$. The fitting of two components by two Lorentzian lines is shown below.

\section{$\left\{\right.$ Cryptand $\left.\left(\mathrm{Na}^{+}\right)\right\}\left\{\mathrm{Fe}(\mathrm{CO})_{4}\left[\mathrm{Sn}^{\mathrm{II}} \mathrm{Pc}\left(3^{-}\right)\right]^{\bullet-}\right\} \cdot 1 / 3 \mathrm{C}_{6} \mathrm{H}_{4} \mathrm{Cl}_{2}$}

(5)
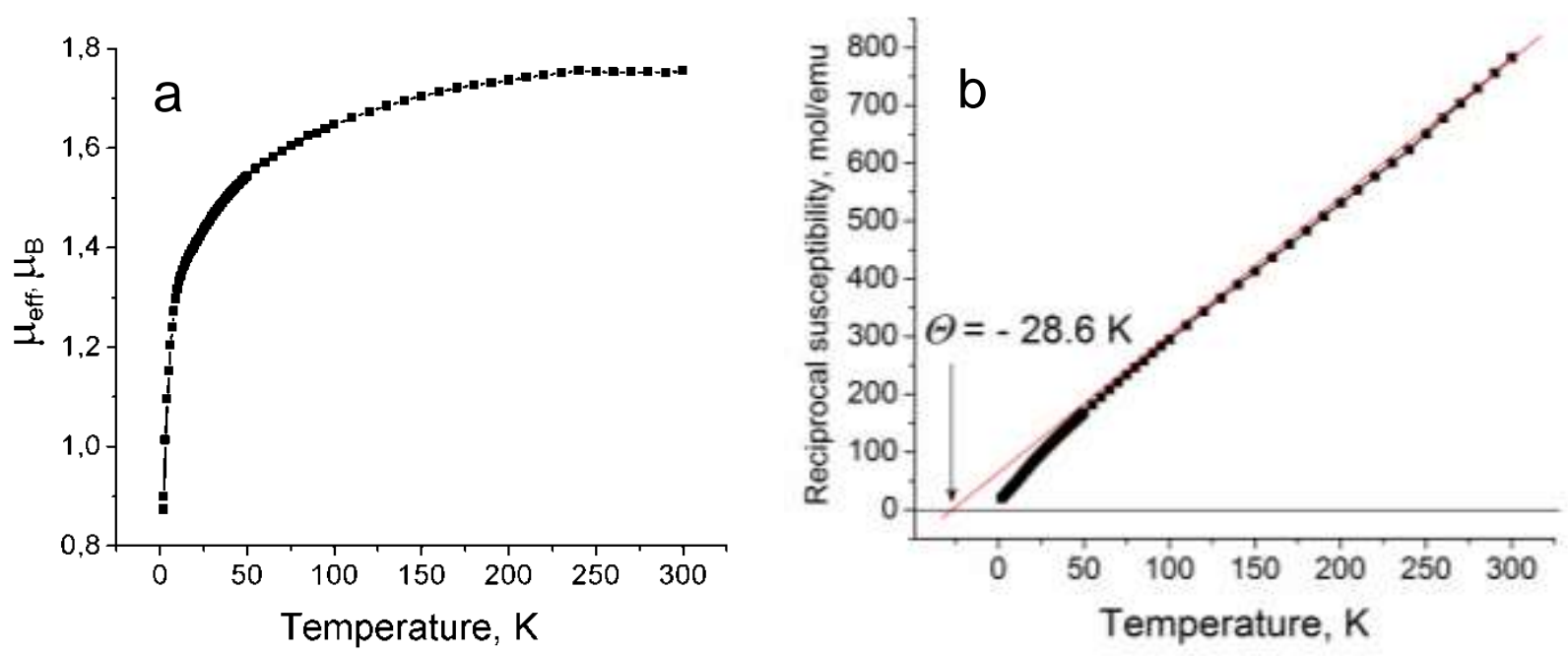

Figure S16. Temperature dependence of effective magnetic moment (a) and reciprocal molar magnetic susceptibility (b) for polycrystalline complex 5. 

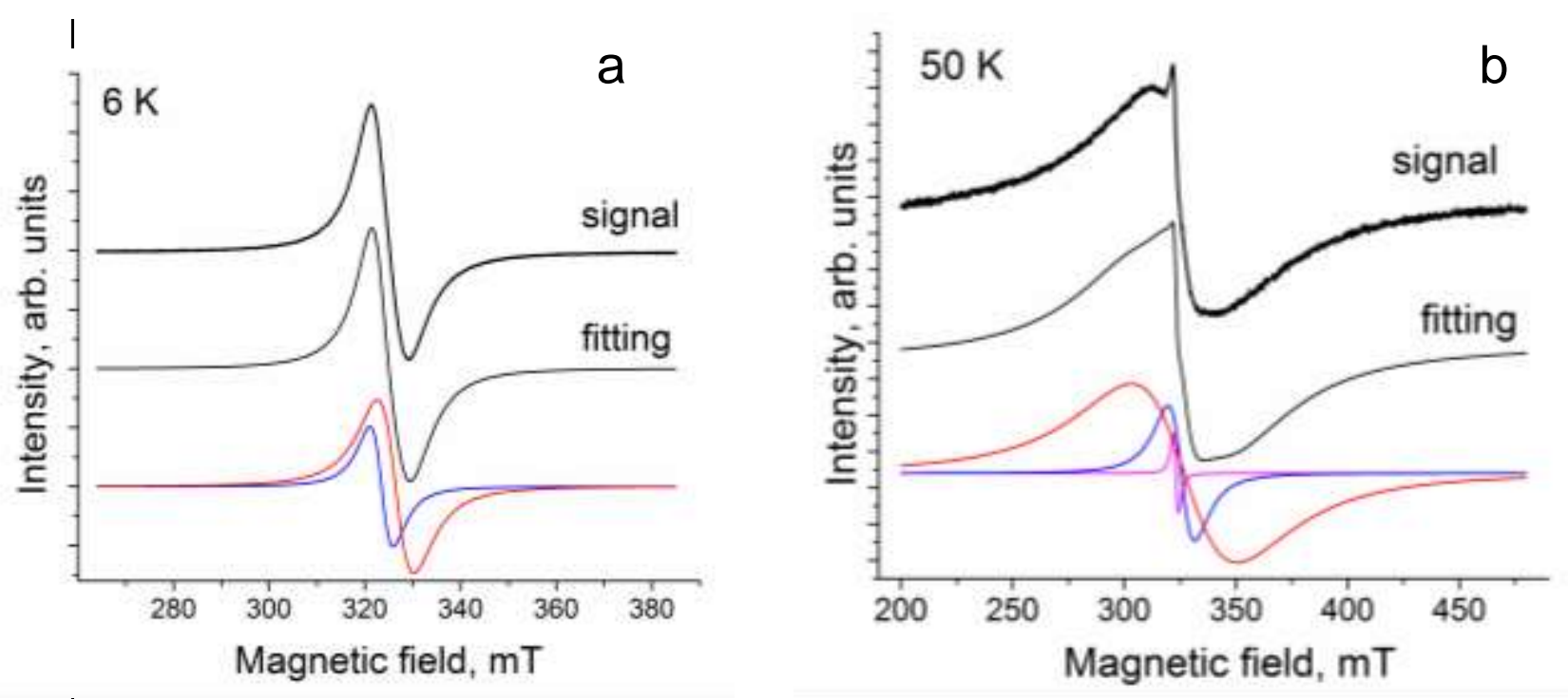

Figure S17. EPR signal from polycrystalline 5 at 6 (a) and $50 \mathrm{~K}$ (b). The fitting of the signals by two and three Lorentzian lines, respectively is shown below.
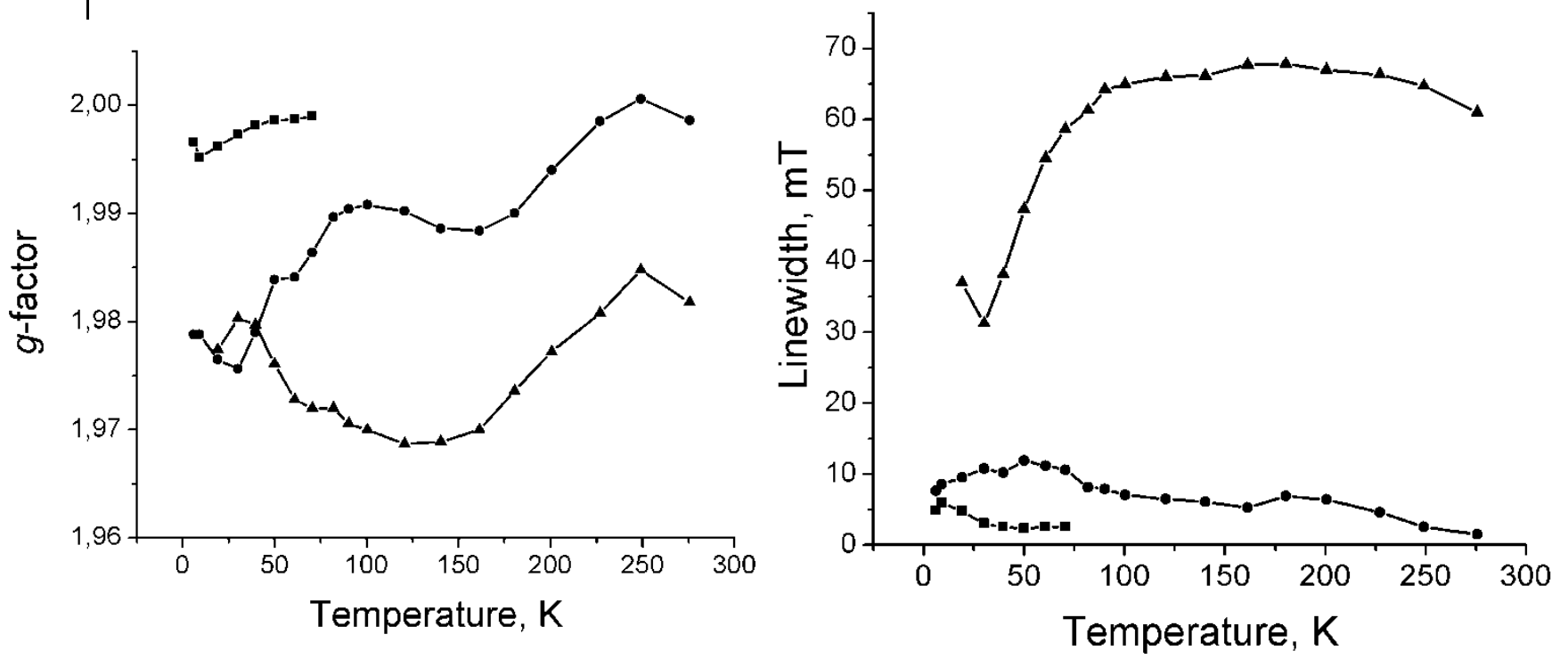

Figure S18. Temperature dependence of $g$-factors and linewidths of three components of EPR signal in 5. 


\section{$\left\{\mathrm{Cryptand}\left(\mathrm{Na}^{+}\right)\right\}\left\{\mathrm{CpMo}(\mathrm{CO})_{2}\left[\mathrm{Sn}{ }^{\mathrm{II}} \mathrm{Pc}(2-) \mathrm{Sn}^{\mathrm{II}} \mathrm{Pc}(3-)^{\bullet-}\right]\right\} \cdot 3.5 \mathrm{C}_{6} \mathrm{H}_{4} \mathrm{Cl}_{2}(6)$}
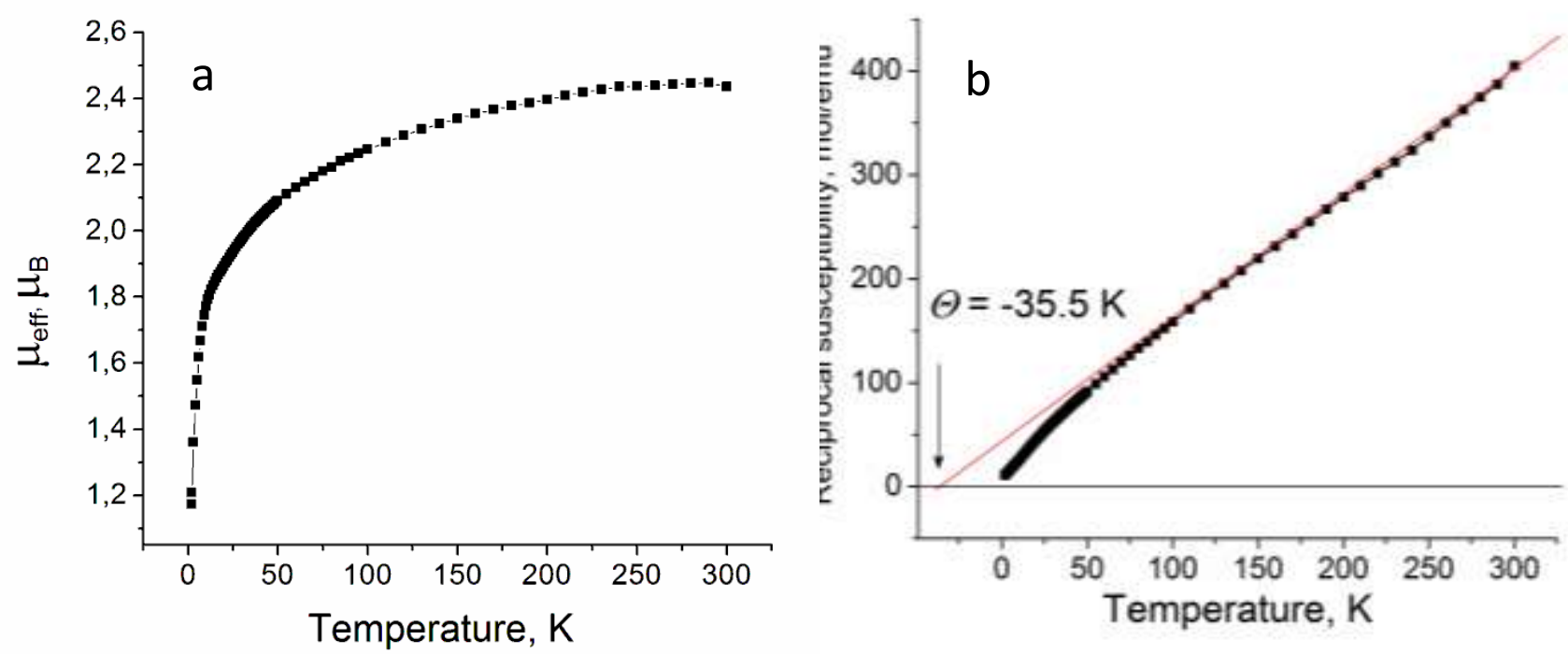

Figure S19. Temperature dependence of effective magnetic moment (a) and reciprocal molar magnetic susceptibility (b) for polycrystalline 6.

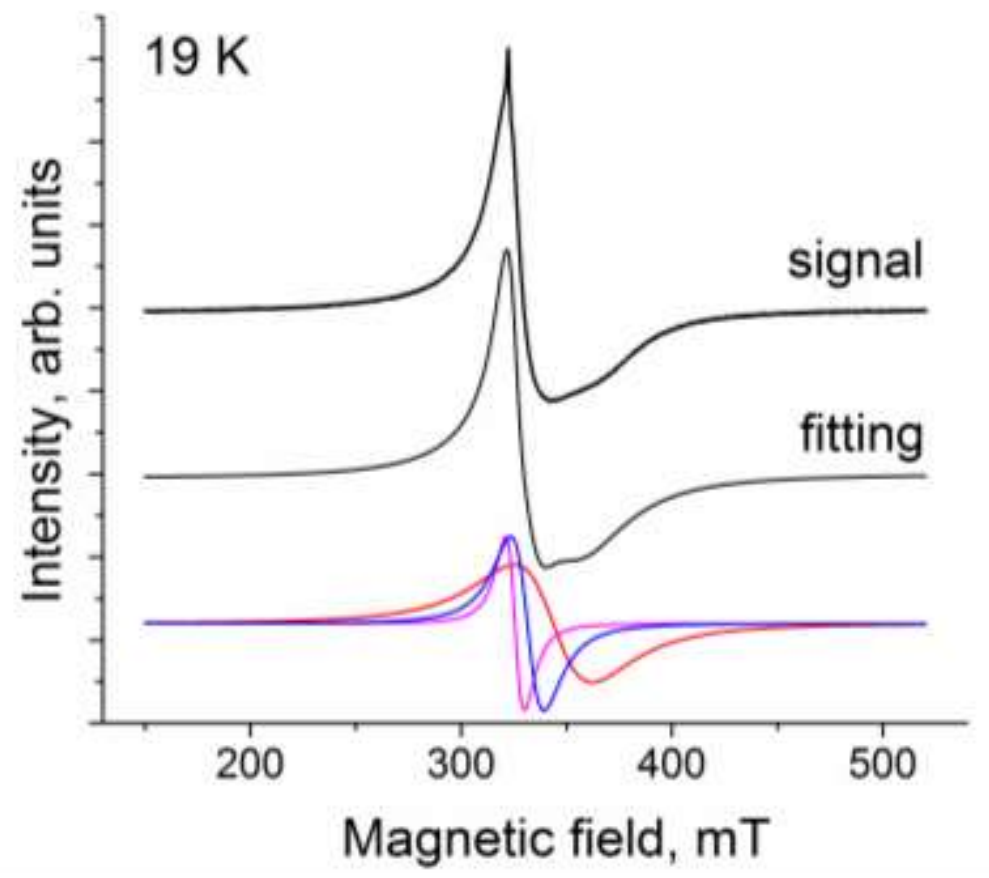

Figure S20. EPR signal from polycrystalline 6 at 19 K. The fitting of the signal by three Lorentzian lines is shown below. 

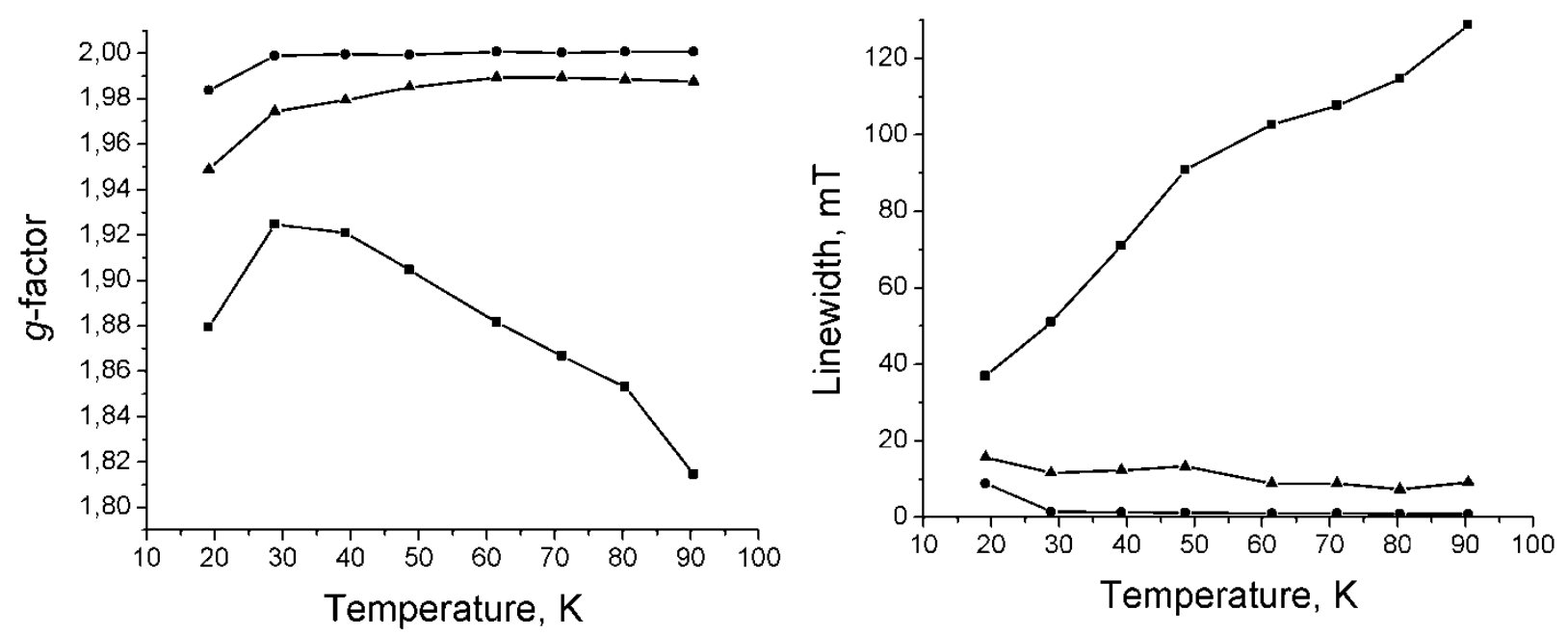

Figure S21. Temperature dependence of $g$-factors and linewidths of three components of EPR signal in 6.

\section{$\left\{\right.$ Cryptand $\left.\left(\mathrm{Na}^{+}\right)\right\}\left\{\mathrm{Cp}^{*} \mathrm{RhCl}_{2}\left[\mathrm{Sn}{ }^{\mathrm{II}} \mathrm{Pc}\left(3^{-}\right)\right]^{--}\right\} \cdot \mathrm{C}_{6} \mathrm{H}_{4} \mathrm{Cl}_{2}$}
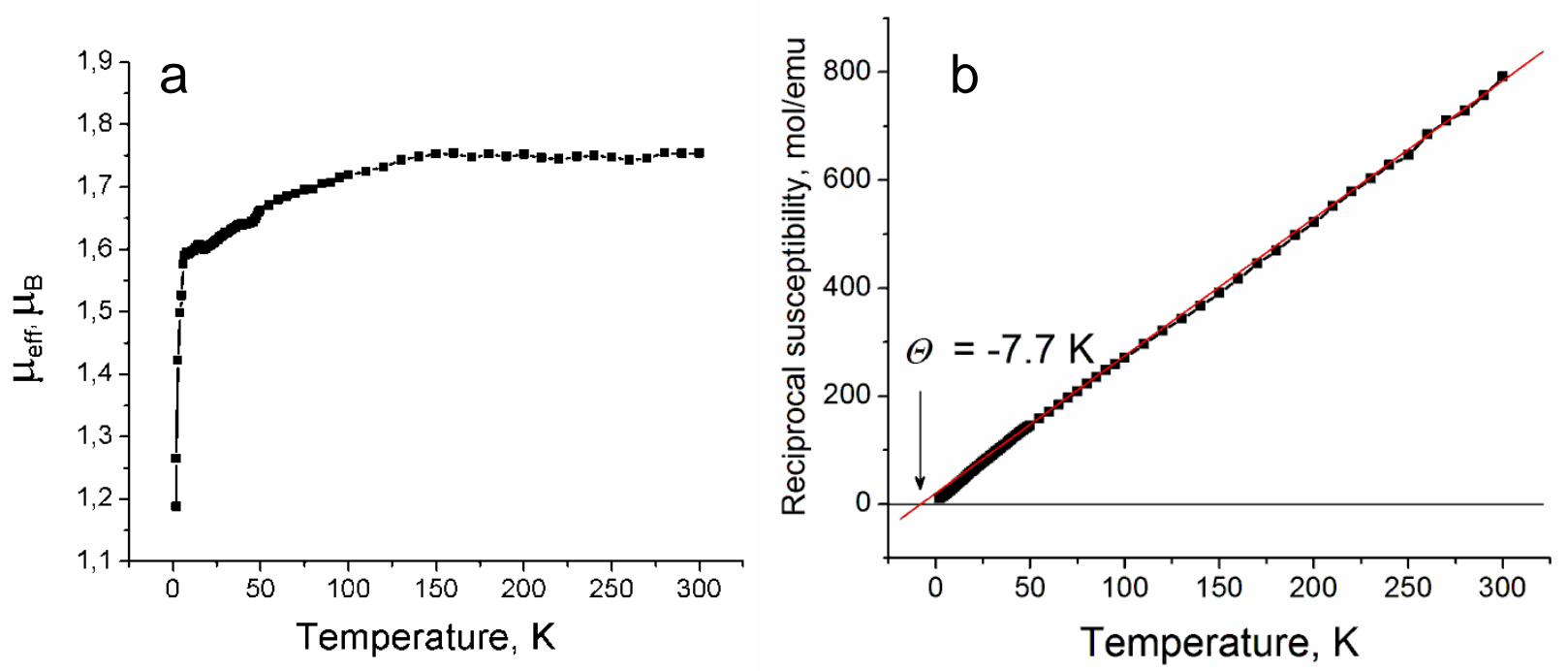

Figure S22. Temperature dependence of effective magnetic moment (a) and reciprocal molar magnetic susceptibility (b) for polycrystalline salt 7. 

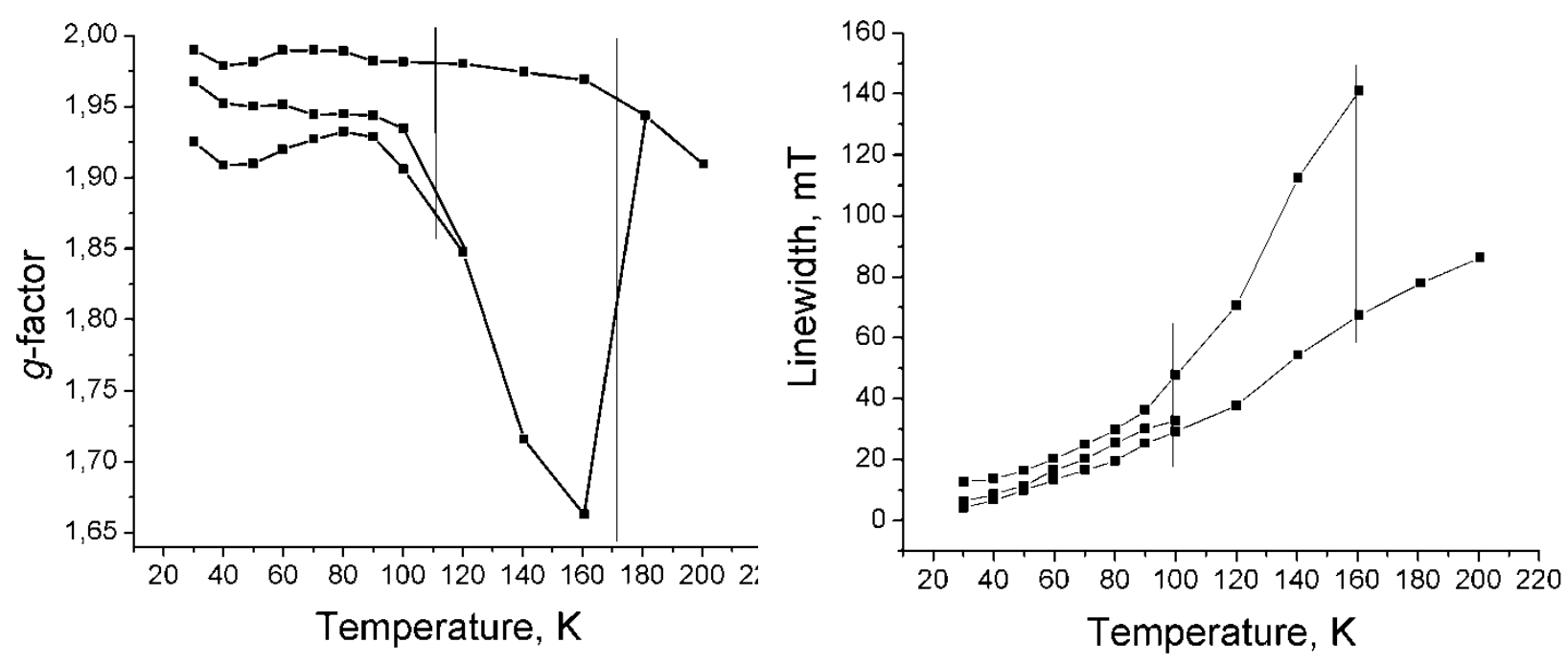

Figure S23. Temperature dependence of $g$-factors and linewidths of three components of EPR signal in 7.

\section{$\left\{\mathrm{Ph}_{5} \mathrm{CpRu}(\mathrm{CO})_{2}\left[\operatorname{Sn}^{\mathrm{II}} \mathrm{Pc}\left(3^{-}\right)\right]\right\}(8)$.}

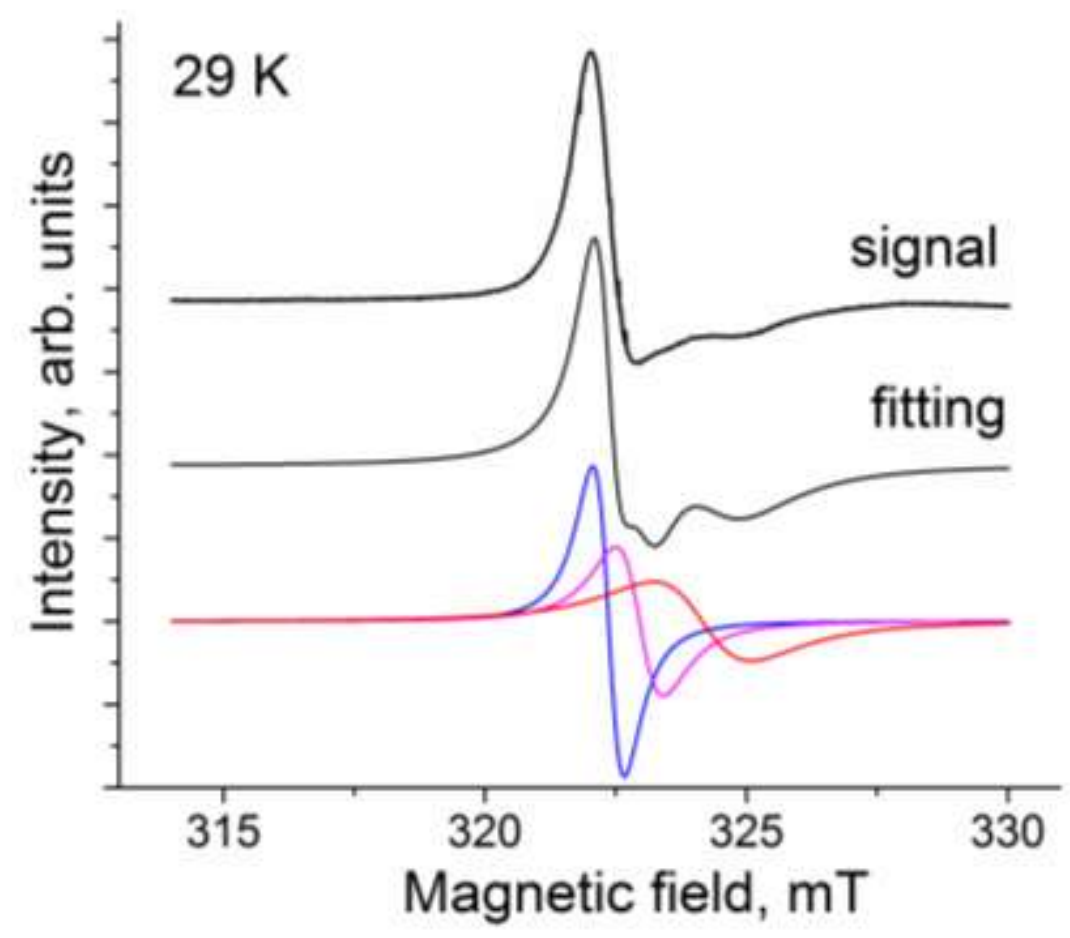

Figure S24. EPR signal from polycrystalline 8 at $29 \mathrm{~K}$. The fitting of the signal by three Lorentzian lines is shown below. 


\section{Theoretical calculations.}

Table S6.

Calculation method, point group (PG), state, total and relative energy ( $E$ and $E_{\text {rel }}$ ), and $\left\langle S^{2}\right\rangle$ value of $\left[\mathrm{CpFe}(\mathrm{CO})_{2}(\mathrm{SnPc})\right]^{-}, \mathrm{Ph}_{5} \mathrm{CpRu}(\mathrm{CO})_{2}(\mathrm{SnPc})$, and $\left[\mathrm{Ph}_{5} \mathrm{CpRu}(\mathrm{CO})_{2}(\mathrm{SnPc})\right]_{2}$ calculated at the M11/ccpVTZ(-PP)/cc-pVDZ level of theory.

\begin{tabular}{|c|c|c|c|c|c|}
\hline Method $^{a}$ & $P G$ & State & $E /$ hartree & $E_{\mathrm{rel}} / \mathrm{K}$ & $\left\langle S^{2}\right\rangle$ \\
\hline \multicolumn{6}{|l|}{$\left[\mathrm{CpFe}(\mathrm{CO})_{2}(\mathrm{SnPc})\right]^{-}$} \\
\hline $\mathrm{RM} 11 / / \mathrm{RM} 11^{a}$ & $C_{1}$ & ${ }^{1} A$ & -3564.28356 & -3687 & 0 \\
\hline $\mathrm{RM} 11 / / \mathrm{RM}_{1}{ }^{b}$ & $C_{1}$ & ${ }^{1} A$ & -3564.27188 & 0 & 0 \\
\hline UM11//UM11 ${ }^{b}$ & $C_{1}$ & ${ }^{3} A$ & -3564.23822 & 10630 & 2.019 \\
\hline $\mathrm{UM} 11 / / \mathrm{UM} 11^{b}$ & $C_{1}$ & ${ }^{5} A$ & -3564.15503 & 36899 & 6.035 \\
\hline \multicolumn{6}{|l|}{$\mathrm{Ph}_{5} \mathrm{CpRu}(\mathrm{CO})_{2}(\mathrm{SnPc})$} \\
\hline $\mathrm{UM} 11 / / \mathrm{UM} 11^{b}$ & $C_{1}$ & ${ }^{2} A$ & -3549.72165 & 0 & 0.824 \\
\hline $\mathrm{UM} 11 / / \mathrm{UM} 11^{b}$ & $C_{1}$ & ${ }^{4} A$ & -3549.68701 & 10939 & 3.785 \\
\hline \multicolumn{6}{|l|}{$\left[\mathrm{Ph}_{5} \mathrm{CpRu}(\mathrm{CO})_{2}(\mathrm{SnPc})\right]_{2}$} \\
\hline $\mathrm{UM} 11 / / \mathrm{UM} 11^{b}$ & $C_{\mathrm{i}}$ & $\mathrm{BS}^{\mathrm{B} \text { singlet }}{ }^{c}$ & -7099.48911 & 0 & 1.194 \\
\hline $\mathrm{UM} 11 / / \mathrm{UM} 11^{b}$ & $C_{\mathrm{i}}$ & ${ }^{3} A_{\mathrm{u}}$ & -7099.48816 & 299 & 2.219 \\
\hline
\end{tabular}

${ }^{a}$ Full geometry optimization was done. ${ }^{b}$ Only the coordinates of hydrogen atoms were optimized.

${ }^{c}$ Broken-symmetry singlet. 
Table S7.

Charge and spin densities of the ${ }^{1} A$ state in $\left[\mathrm{CpFe}(\mathrm{CO})_{2}(\mathrm{SnPc})\right]^{-}$, the ${ }^{2} A$ state in $\mathrm{Ph}_{5} \mathrm{CpRu}(\mathrm{CO})_{2}(\mathrm{SnPc})$, and the broken-symmetry singlet state in $\left[\mathrm{Ph}_{5} \mathrm{CpRu}(\mathrm{CO})_{2}(\mathrm{SnPc})\right]_{2}$ by Mulliken and natural population analysis at the M11/cc-pVTZ(-PP)/cc-pVDZ level of theory.

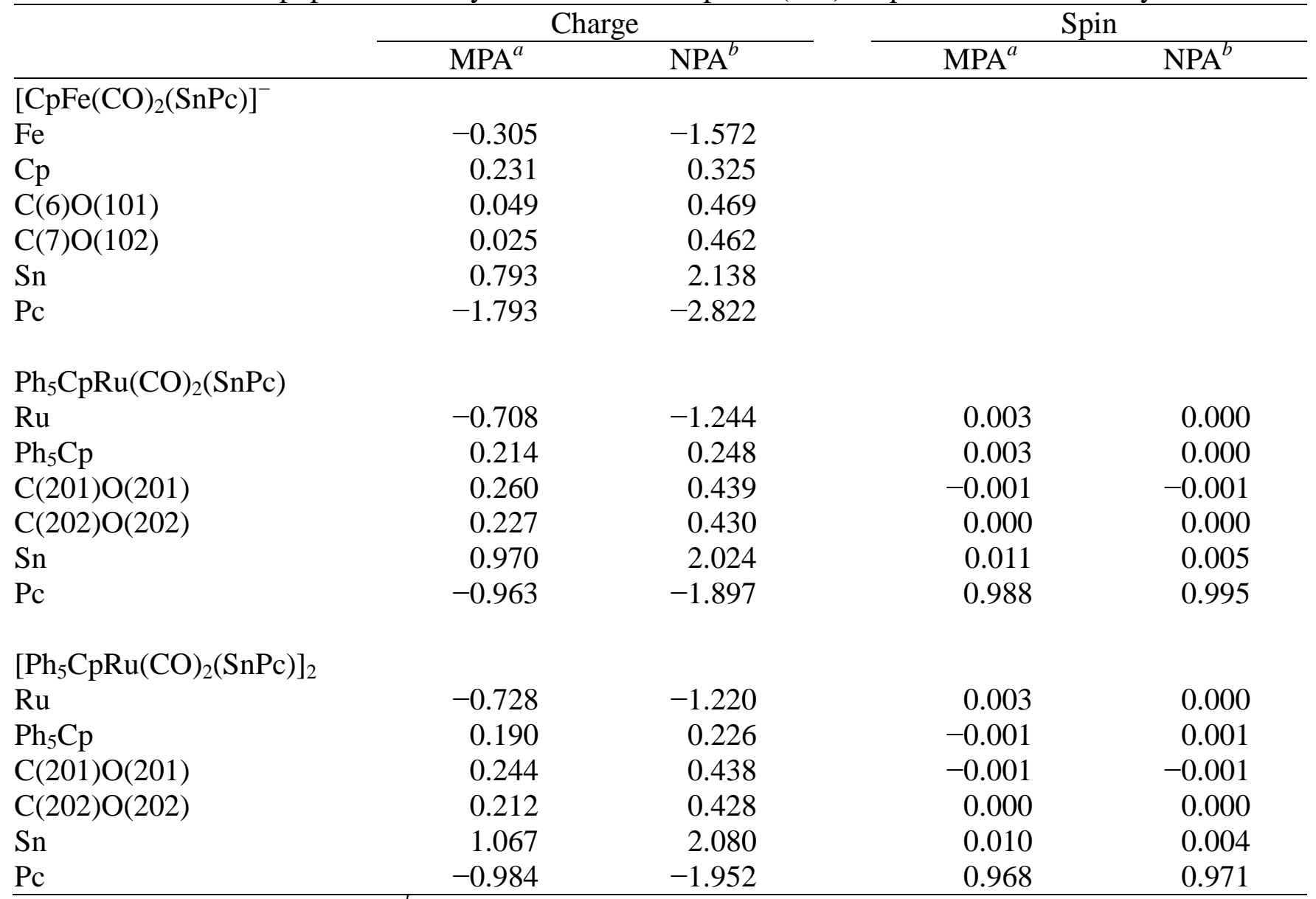

${ }^{a}$ Mulliken population analysis. ${ }^{b}$ Natural population analysis.

Table S8

Wiberg bond indices calculated at the M11/cc-pVTZ(-PP)/cc-pVDZ level of theory.

\begin{tabular}{lccccc}
\hline & {$\left[\mathrm{CpFe}(\mathrm{CO})_{2}(\mathrm{SnPc})\right]^{-}$} & $\mathrm{Ph}_{5} \mathrm{CpRu}(\mathrm{CO})_{2}(\mathrm{SnPc})$ & {$\left[\mathrm{Ph}_{5} \mathrm{CpRu}(\mathrm{CO})_{2}(\mathrm{SnPc})\right]_{2}$} \\
\hline $\mathrm{Fe}-\mathrm{Sn}$ & 0.641 & $\mathrm{Ru}-\mathrm{Sn}$ & 0.724 & $\mathrm{Ru}-\mathrm{Sn}$ & 0.716 \\
& & & & & \\
Total$(\mathrm{Fe})$ & 5.038 & Total$(\mathrm{Ru})$ & 5.074 & $\operatorname{Total}(\mathrm{Ru})$ & 5.029 \\
Total$(\mathrm{Sn})$ & 2.687 & Total $(\mathrm{Sn})$ & 2.670 & Total $(\mathrm{Sn})$ & 2.606 \\
\hline
\end{tabular}


Table S9.

Selected bond lengths $(\AA)$ of the ${ }^{1} A$ state in fully-geometry-optimized $\left[\mathrm{CpFe}(\mathrm{CO})_{2}(\mathrm{SnPc})\right]^{-}$at the RM11/cc-pVTZ(-PP)/cc-pVDZ level of theory.

\begin{tabular}{lll}
\hline & Calc. & Exp. \\
\hline Fe-Sn & 2.495 & $2.5087(5)$ \\
Fe-C(carbonyl) & 1.778 & $1.758(3)$ \\
& 1.785 & $1.767(3)$ \\
$\mathrm{CO}$ & 1.143 & $1.148(4)$ \\
$\mathrm{Fe}-\mathrm{C}(\mathrm{Cp})$ & 1.141 & $1.143(4)$ \\
& 2.120 & $2.095(3)$ \\
& 2.114 & $2.094(3)$ \\
& 2.103 & $2.097(3)$ \\
& 2.097 & $2.104(3)$ \\
\hline
\end{tabular}



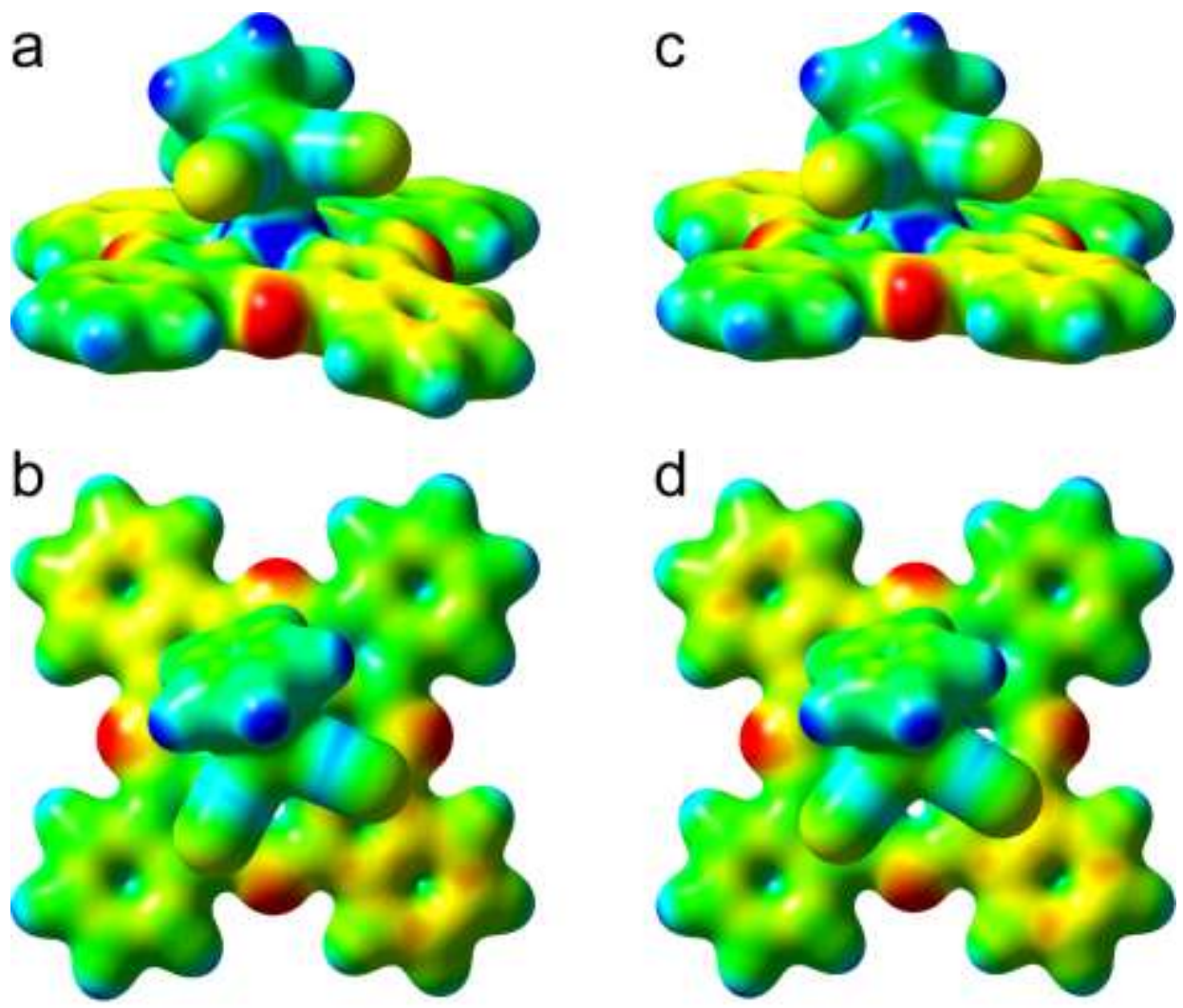

Figure S25. Electrostatic potential maps for $(\mathrm{a}, \mathrm{c})$ side and $(\mathrm{b}, \mathrm{d})$ top views on the $0.02 \mathrm{electron} / \mathrm{au}^{3}$ of electron density surface for the ${ }^{1} A$ state in (a,b) partially- and (c,d) fully-optimized $\left[\mathrm{CpFe}(\mathrm{CO})_{2}(\mathrm{SnPc})\right]^{-}$anion calculated at the RM11/cc-pVTZ(-PP)/cc-pVDZ level of theory. 


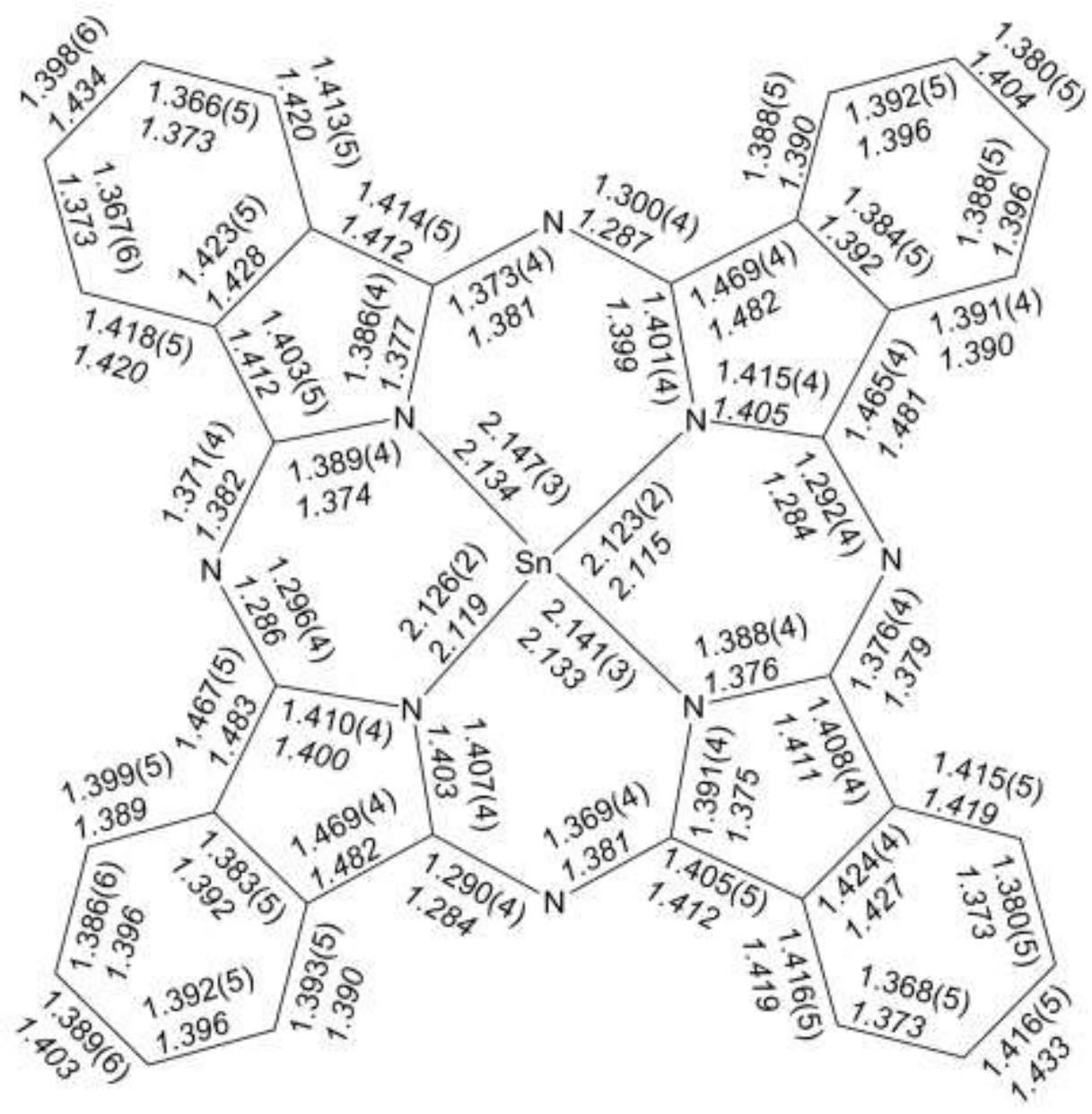

Figure S26. Experimental and calculated bond lengths $(\AA)$ of SnPc moiety in $\left[\mathrm{CpFe}(\mathrm{CO})_{2}(\mathrm{SnPc})\right]^{-}$ anion. Calculated bond lengths are in italics. Full geometry optimization on $\left[\mathrm{CpFe}(\mathrm{CO})_{2}(\mathrm{SnPc})\right]^{-}$ anion was carried out at the RM11/cc-pVTZ(-PP)/cc-pVDZ level of theory.

a)

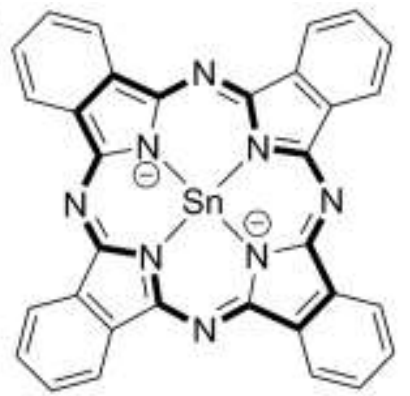

b)

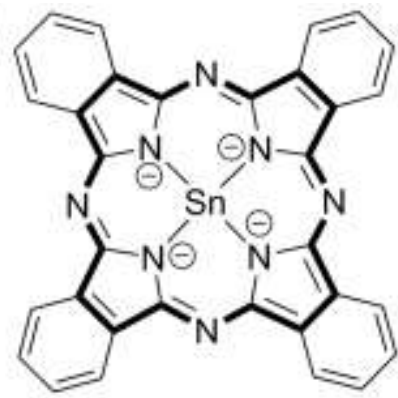

Figure S27. (a) $[\mathrm{SnPc}]^{0}$ and (b) $[\mathrm{SnPc}]^{2-}$ with 18 and $20 \pi$-electronic phthalocyanine moieties, respectively. 


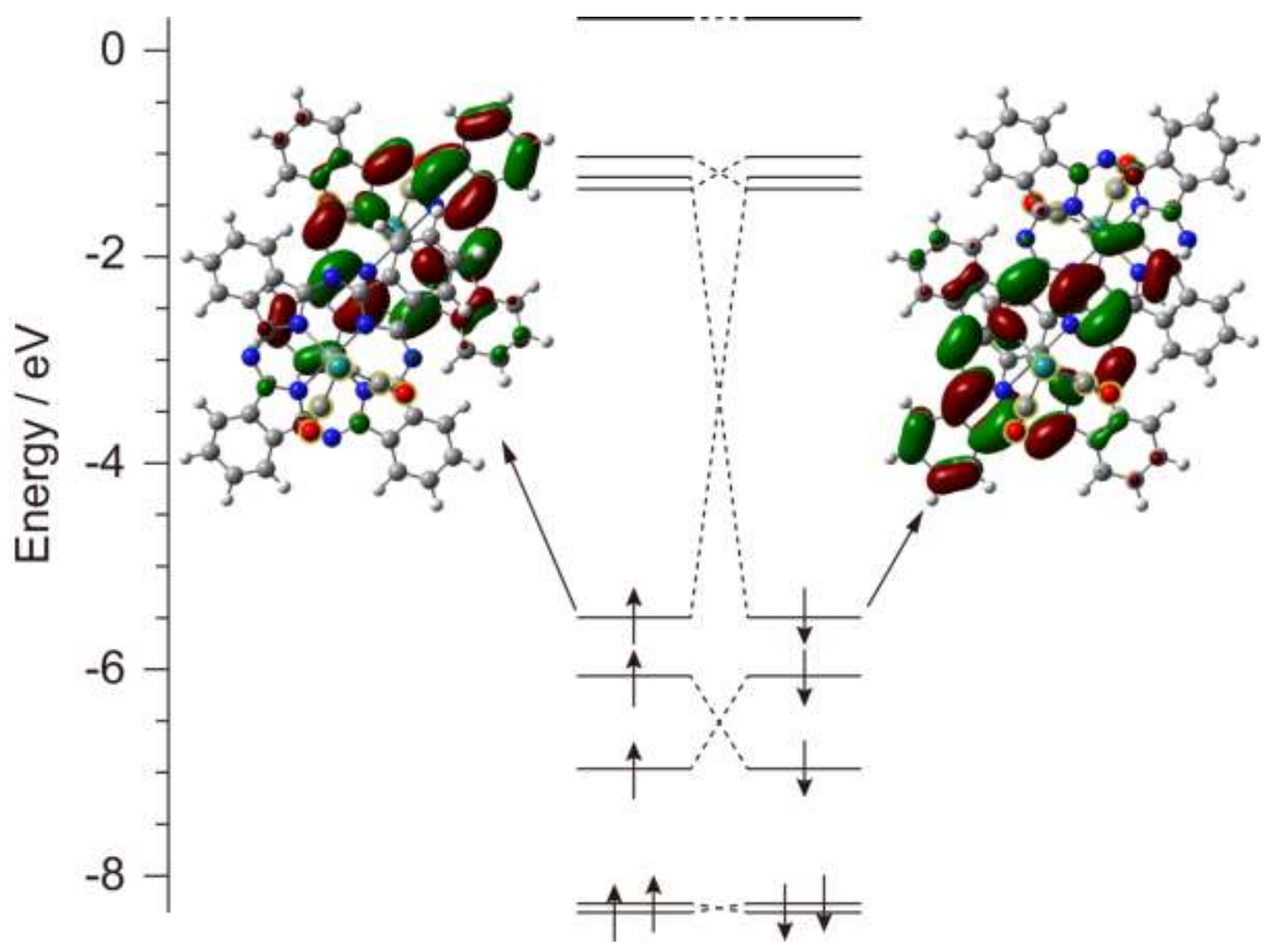

Figure S28. Energy diagram for the frontier Kohn-Sham orbitals of $\left[\mathrm{Ph}_{5} \mathrm{CpRu}(\mathrm{CO})_{2}(\mathrm{SnPc})\right]_{2}$ dimer in the broken-symmetry singlet state calculated at the UM11/cc-pVTZ-PP/cc-pVDZ level of theory. For clarity, the pentaphenylcyclopentadienyl ligand is omitted, and $\mathrm{Ru}(\mathrm{CO})_{2}$ moieties are highlighted in $\alpha$ - and $\beta$-HO orbitals. 

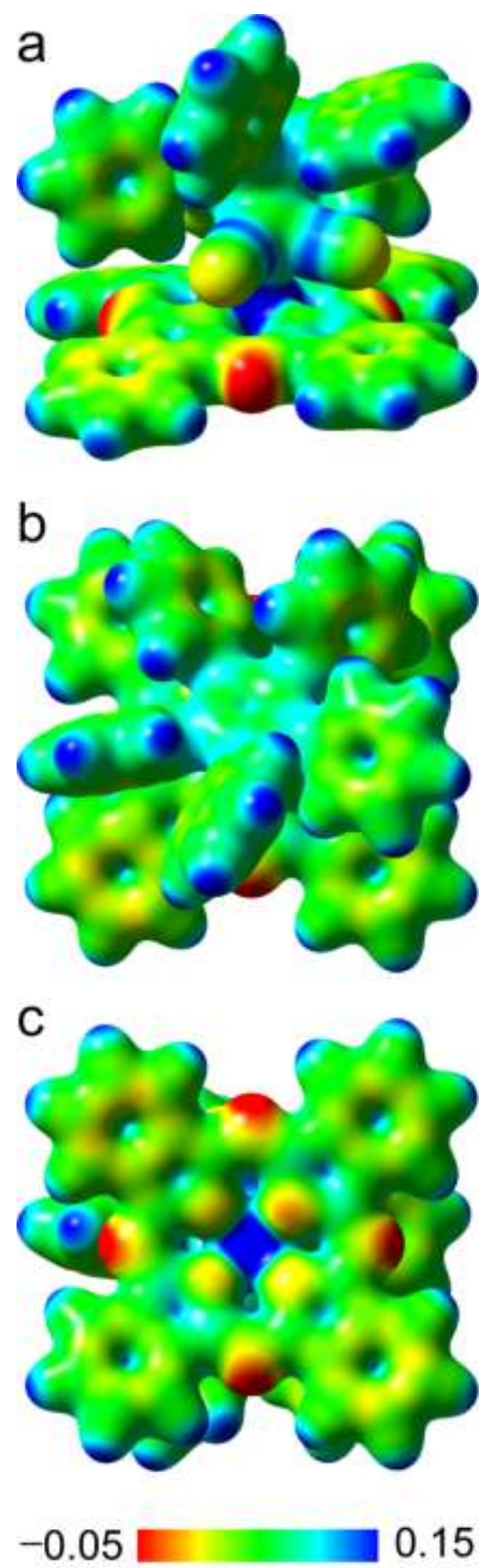

Figure S29. Electrostatic potential maps for (a) side, (b) top, and (c) bottom views on the 0.02 electron $/ \mathrm{au}^{3}$ of electron density surface for the ${ }^{2} A$ state in $\mathrm{Ph}_{5} \mathrm{CpRu}(\mathrm{CO})_{2}(\mathrm{SnPc})$ monomer calculated at the UM11/cc-pVTZ(-PP)/cc-pVDZ level of theory. 


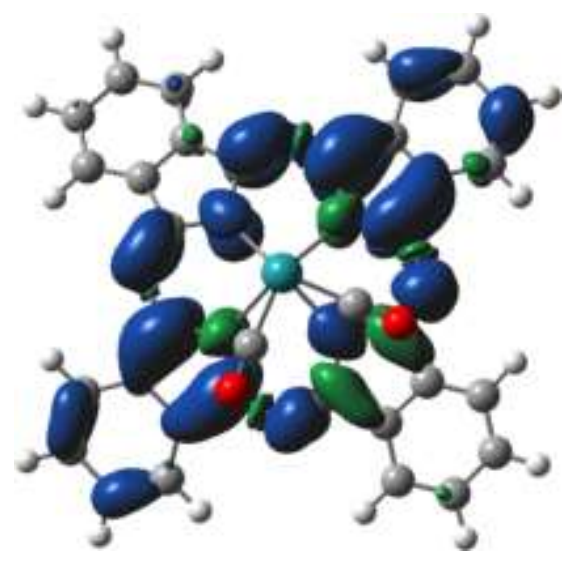

Figure S30. Isosurface plot on spin density distribution of the ${ }^{2} A$ state in $\mathrm{Ph}_{5} \mathrm{CpRu}(\mathrm{CO})_{2}(\mathrm{SnPc})$ monomer calculated at the UM11/cc-pVTZ-PP/cc-pVDZ level of theory. The isosurface value is 0.0009 electron $/ \mathrm{au}^{3}$, and the isosurfaces in blue and green denote the positive and negative spin density, respectively. For clarity, pentaphenylcyclopentadienyl ligand is omitted.

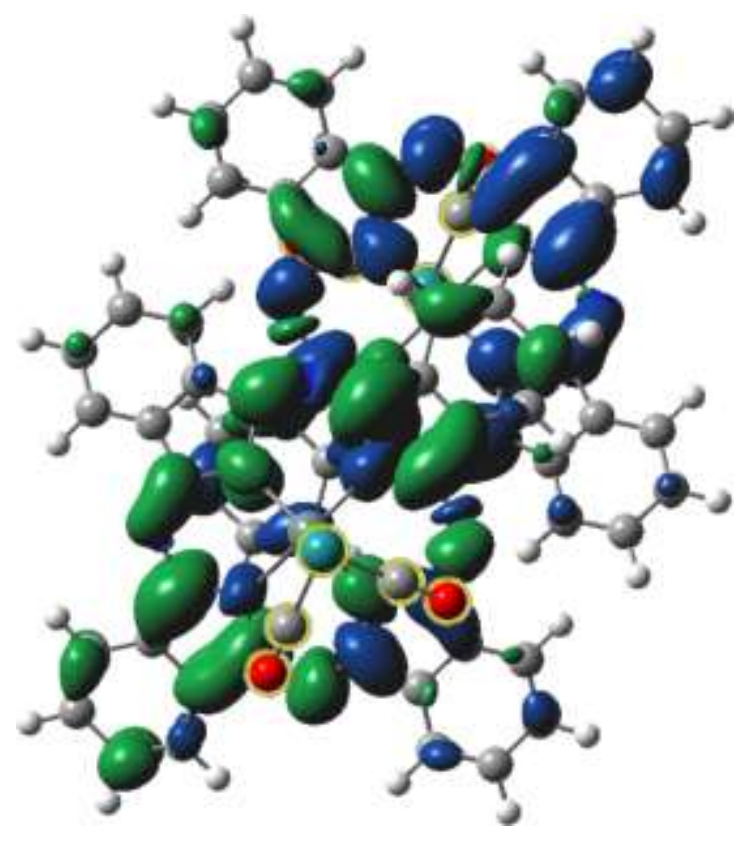

Figure S31. Isosurface plot on spin density distribution of the broken-symmetry singlet state in $\left[\mathrm{Ph}_{5} \mathrm{CpRu}(\mathrm{CO})_{2}(\mathrm{SnPc})\right]_{2}$ dimer calculated at the UM11/cc-pVTZ-PP/cc-pVDZ level of theory. The isosurface value is 0.0009 electron $/ \mathrm{au}^{3}$, and the isosurfaces in blue and green denote the positive and negative spin density, respectively. For clarity, pentaphenylcyclopentadienyl ligand is omitted, and $\mathrm{Ru}(\mathrm{CO})_{2}$ moieties are highlighted. 